UNIVERSIDADE ESTADUAL PAULISTA “JÚLIO DE MESQUITA FILHO” FACULDADE DE CIÊNCIAS AGRONÔMICAS CAMPUS DE BOTUCATU

\title{
DETERMINAÇÃO DO RENDIMENTO NA BARRA DE TRAÇÃO DE TRATORES AGRÍCOLAS COM TRAÇÃO DIANTEIRA AUXILIAR (4X2 TDA)
}

\section{FABRÍCIO CAMPOS MASIERO}

Dissertação apresentada à Faculdade de Ciências Agronômicas da Unesp Campus de Botucatu, para obtenção do título de Mestre em Agronomia (Energia na Agricultura).

BOTUCATU - SP

Fevereiro - 2010 
UNIVERSIDADE ESTADUAL PAULISTA “JÚLIO DE MESQUITA FILHO” FACULDADE DE CIÊNCIAS AGRONÔMICAS

CAMPUS DE BOTUCATU

\section{DETERMINAÇÃO DO RENDIMENTO NA BARRA DE TRAÇÃO DE TRATORES AGRÍCOLAS COM TRAÇÃO DIANTEIRA AUXILIAR (4X2 TDA)}

\section{FABRÍCIO CAMPOS MASIERO}

Orientador: Professor Doutor Kléber Pereira Lanças

Dissertação apresentada à Faculdade de Ciências Agronômicas da Unesp Campus de Botucatu, para obtenção do título de Mestre em Agronomia (Energia na Agricultura).

BOTUCATU - SP

Fevereiro - 2010 
FICHA CATALOGRÁpICA JLABORADA PALA SAÇÃo TÉCNICA DE AQUISIÇÃo I TRATaMJNTO DA INPORMAÇÃO - SERVIÇO TÍCMICO DI BIBLIOTBCA E DOCUIINTAÇẤO - UNJSP - FCA - LAgEAdO - BotucatU (SP)

Masiero, Fabrício Campos, 1982-

M397d Determinação do rendimento na barra de tração de tratores agrícolas com tração dianteira auxiliar (4x2 TDA) / Fabrício Campos Masiero. - Botucatu : [s.n.], 2010. xii, $79 \mathrm{f}$. : tabs., gráfs., fots. color.

Dissertação (Mestrado) - Universidade Estadual Paulista, Faculdade de Ciências Agronômicas, Botucatu, 2010 Orientador: Kléber Pereira Lanças Inclui bibliografia.

1. Ensaio de máquinas. 2. Condição de superfície. 3. Consumo específico de combustível. 4. Patinagen. 5. Tratores agrícolas. I. Lanças, Kléber Pereira. II. Universidade Estadual Paulista "Júlio de Mesquita Filho" (Campus de Botucatu). Faculdade de Ciências Agronômicas. III. Título. 
UNIVERSIDADE ESTADUAL PAULISTA “JúLIO DE MESQUITA FILHO" FACULDADE DE CIÊNCIAS AGRONÔMICAS

CAMPUS DE BOTUCATU

\section{CERTIFICADO DE APROVAÇĀO}

TÍTULO: "DETERMINAÇĀO DO RENDIMENTO NA BARRA DE TRAÇĀO DE TRATORES AGRICOLAS COM TRAÇĀO DIANTEIRA AUXILIAR (4X2 TDA)"

ALUNO: FABRICIO CAMPOS MASIERO

ORIENTADOR: PROF. DR. KLEBER PEREIRA LANÇAS

Aprovado pela Comissão Examinadora

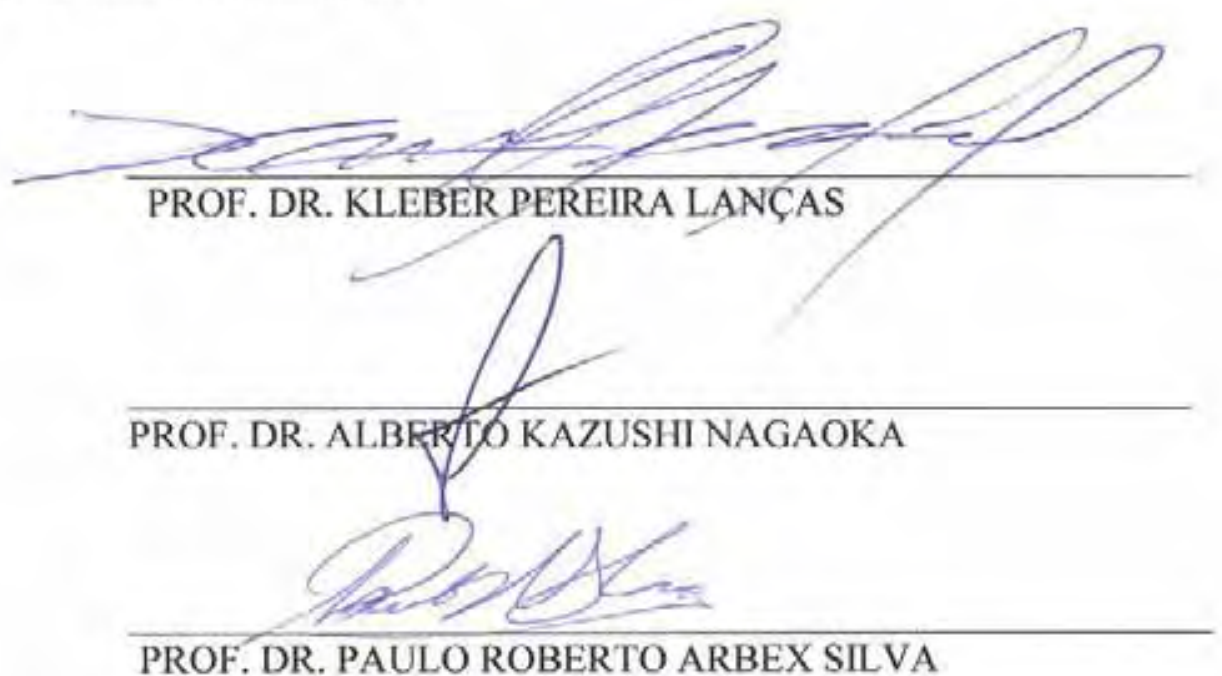

Data da Realização: 05 de fevereiro de 2010. 


\section{AGRADEÇO}

\section{à DEUS}

pela vida, sabedoria e oportunidades

Aos meus queridos pais, Lorival e Célia

e minha noiva Débora

pelo constante incentivo apoio, carinho, compreensão e, sobretudo, exemplo de vida, que me possibilitaram realizar esse trabalho

\section{DEDICO}

Para meus irmãos Fernando e Felipe 


\section{AGRADECIMENTOS}

À Faculdade de Ciências Agronômicas (FCA-UNESP), campus de Botucatu e a Coordenadoria do Programa de Pós-Graduação em Agronomia, área de concentração em Energia na Agricultura, pela vaga concedida, apoio e atenção durante o curso de Mestrado.

Ao Professor Doutor Kléber Pereira Lanças, do Departamento de Engenharia Rural da FCA-UNESP, pela orientação segura, atenção, dedicação, compreensão, sinceridade, amizade em todas as fases do curso. Sem dúvida um estímulo para ver na Academia um caminho para a vida.

A CAPES, pela disponibilidade de bolsa de auxílio financeiro durante o curso de mestrado;

Aos Professores Doutores: Paulo Roberto Arbex Silva e Saulo Philipe Sebastião Guerra, pela amizade, sugestões, críticas e apoio técnico.

Ao colega e Mestre Leonardo de Almeida Monteiro, pela consideração, amizade e ajuda decisiva nos ensaios.

Ao Professor Doutor Alberto Kazushi Nagaoka pela amizade, consideração e incentivo na minha carreira profissional.

Aos amigos do curso de Pós Graduação de Energia na Agricultura: André Satoshi Seki, Éder Aparecido Garcia, Fernando Henrique Campos, Gabriel Lyra, Guilherme Oguri, Gustavo Montanha, Neilor Bugonni, Indiamara Marasca e Samir Paulo Jasper pela convivência, ajuda, amizade e obrigado por terem crescido comigo.

Aos amigos e companheiros de república: Alexandre, Emerson, Evandro, Gregório, Hélio e Rodolfo pela convivência e amizade.

A todos os funcionários do Departamento de Engenharia Rural pela atenção, amizade e serviços prestados.

Às secretárias da Seção de Pós-graduação da FCA-UNESP, Câmpus de Botucatu pela atenção e atendimento.

A todas as pessoas e instituições que de forma direta ou indireta contribuíram para a realização deste trabalho. 


\section{SUMÁRIO}

Página

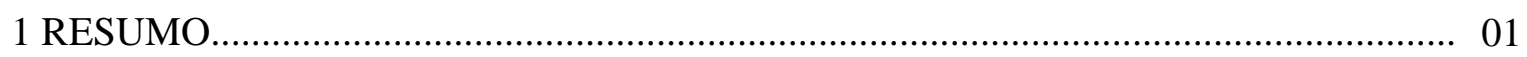

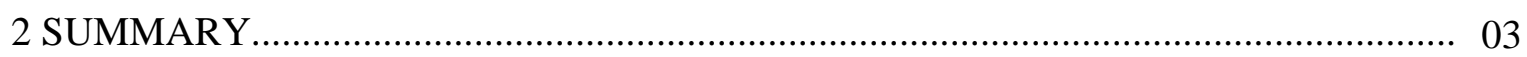

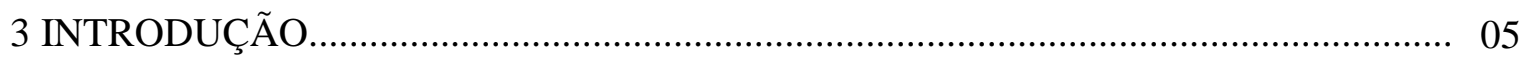

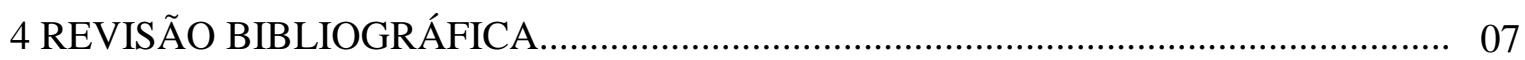

4.1 Trator com tração dianteira auxiliar (4X2 TDA) ….............................................. 08

4.2 Relação entre peso e potência do trator.................................................................. 10

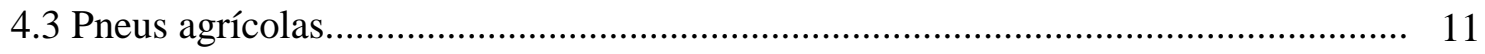

4.4 Superfície de tração...................................................................................... 14

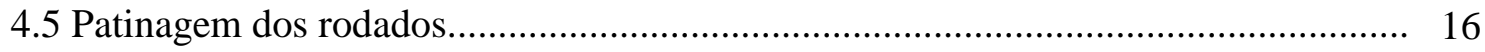

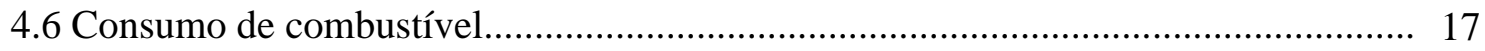

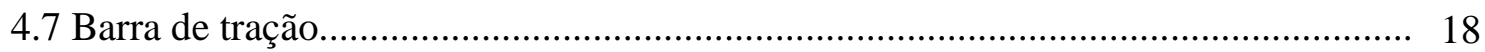

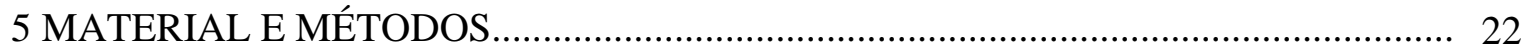

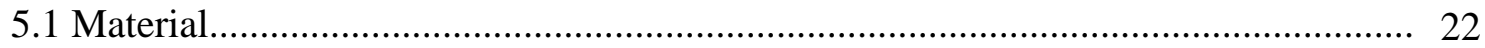

5.1.1 Localização da área experimental................................................................. 22

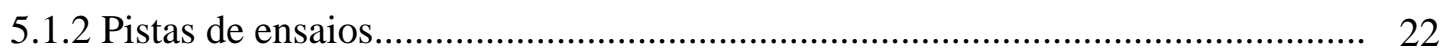

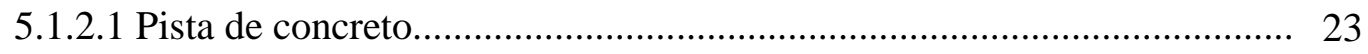

5.1.2.2 Pista de solo firme .... .................................................................... 23

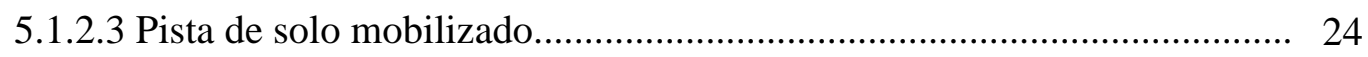

5.1.2.4 Pistas de solo com cobertura vegetal............................................... 25

5.1.3 Carro dinamométrico ou de frenagem - UMEB........................................... 26

5.1.4 Tratores e conjuntos de pneus..................................................................... 26

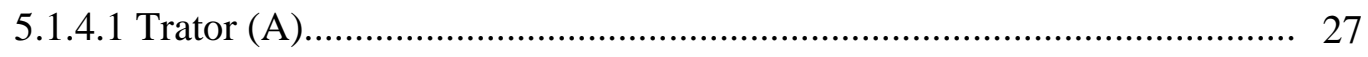

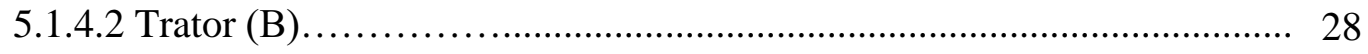

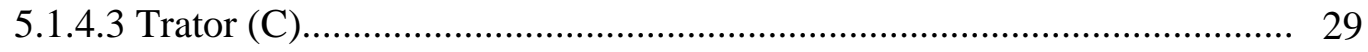

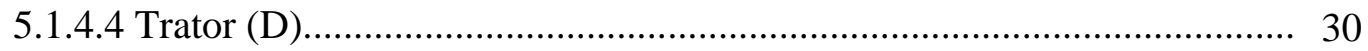

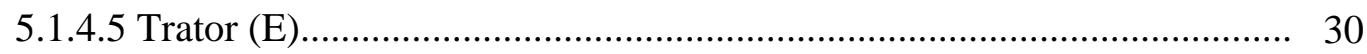

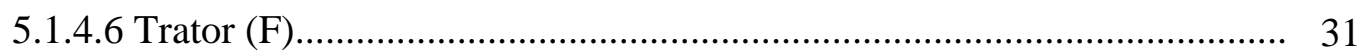




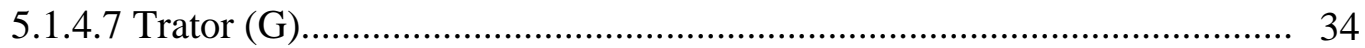

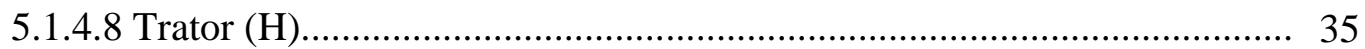

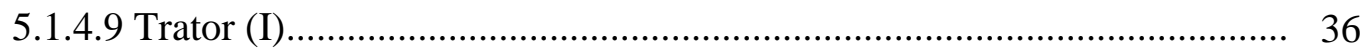

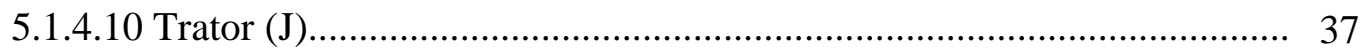

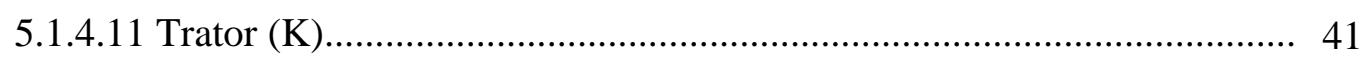

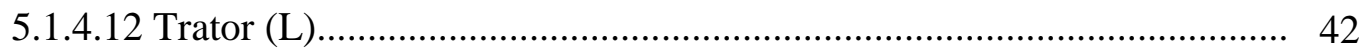

5.1.5 Sistema de aquisição de dados... .................................................................. 44

5.1.5.1 Força na barra de tração do trator........................................................... 45

5.1.5.2 Patinagem dos rodados do trator......................................................... 46

5.1.5.3 Consumo de combustível do trator....................................................... 46

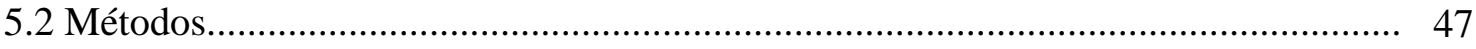

5.2.1 Condução do experimento............................................................................. 47

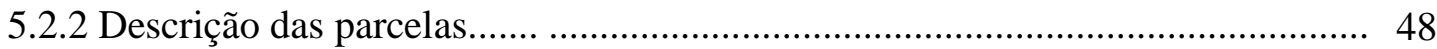

5.2.3 Força na barra de tração do trator....................................................................... 48

5.2.4 Velocidade de deslocamento do conjunto.......................................................... 49

5.2.5 Patinagem dos rodados do trator..................................................................... 49

5.2.6 Potência disponível na barra de tração do trator.................................................. 50

5.2.7 Rendimento na barra de tração do trator........................................................ 50

5.2.8 Consumo horário de combustível....................................................................... 50

5.2.9 Consumo específico de combustível............................................................... 51

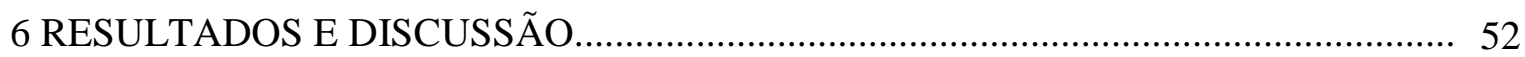

6.1 Resultados obtidos por tipo e modelo de trator................................................... 52

6.2 Resultados obtidos nas diferentes superfícies trativas............................................ 67

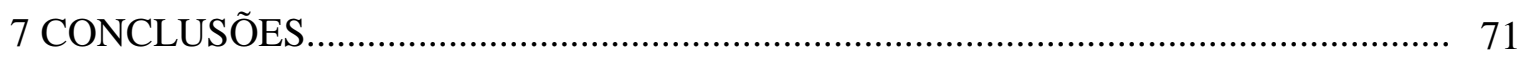

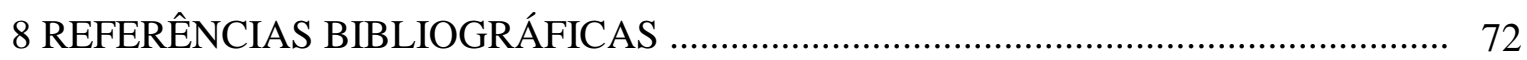

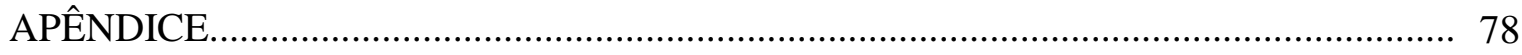




\section{LISTA DE TABELAS}

\section{Tabela}

Página

1 - Rendimento na barra de tração para tratores de rodas pneumáticas e diversas condições de solo baseado no fator " 0,86 " de Wendel Bowers.

2 - Rendimento na Barra de Tração (\%) de diversos tipos de tratores em diversas condições de superfície baseado na Norma ASAE D497.4 (1999).

3 - Conjuntos e pressões de inflação dos pneus utilizados no trator (A).

4 - Denominação das parcelas de acordo com o pneu utilizado, relação entre peso e potência, velocidade teórica adotada e superfície trativa.

5 - Conjuntos e pressões de inflação dos pneus utilizados no trator (B).

6 - Denominação das parcelas de acordo com o pneu utilizado, relação entre peso e potência, velocidade teórica adotada e superfície trativa.

7 - Conjuntos e pressões de inflação dos pneus utilizados no trator (C).

8 - Denominação das parcelas de acordo com o pneu utilizado, relação entre peso e potência, velocidade teórica adotada e superfície trativa.

9 - Conjunto e pressão de inflação dos pneus utilizado no trator (D).

10 - Denominação das parcelas de acordo com o pneu utilizado, relação entre peso e potência, velocidade teórica adotada e superfície trativa.

11 - Conjunto e pressões de inflação dos pneus utilizado no trator (E)

12 - Denominação das parcelas de acordo com o pneu utilizado, relação entre peso e potência, velocidade teórica adotada em superfície trativa de solo firme

13 - Conjuntos e pressões de inflação dos pneus utilizados no trator (F).

14 - Denominação das parcelas de acordo com o pneu utilizado, relação entre peso e potência e velocidade teórica adotada em pista de solo firme.

15 - Denominação das parcelas de acordo com o pneu utilizado, relação entre peso e potência e velocidade teórica adotada em pista de solo com cobertura vegetal.

16 - Denominação das parcelas de acordo com o pneu utilizado, relação entre peso e potência e velocidade teórica adotada em pista de solo mobilizado 
17 - Conjunto e pressões de inflação dos pneus utilizado no trator $(\mathrm{G})$

18 - Denominação das parcelas de acordo com o pneu utilizado, relação entre peso e potência, velocidade teórica adotada e superfície trativa.

19 - Conjunto e pressão de inflação dos pneus utilizado no trator $(\mathrm{H})$

20 - Denominação das parcelas de acordo com o pneu utilizado, relação entre peso e potência, velocidade teórica adotada em superfície de solo firme

21 - Conjunto e pressão de inflação dos pneus utilizado no trator (I)

22 - Denominação das parcelas de acordo com o pneu utilizado, relação entre peso e potência, velocidade teórica adotada e superfície trativa.

23 - Conjuntos e pressões de inflação dos pneus utilizado no trator (J)

24 - Denominação das parcelas de acordo com o pneu utilizado, relação entre peso e potência, velocidade teórica adotada em superfície de concreto

25 - Denominação das parcelas de acordo com o pneu utilizado, relação entre peso e potência, velocidade teórica adotada em superfície trativa de solo firme

26 - Denominação das parcelas de acordo com o pneu utilizado, relação entre peso e potência, velocidade teórica adotada em superfície de solo com cobertura vegetal....... 40

27 - Conjuntos e pressões de inflação dos pneus utilizados no trator (K)

28 - Denominação das parcelas de acordo com o pneu utilizado, relação entre peso e potência, velocidade teórica adotada e superfície trativa.

29 - Conjuntos e pressões de inflação dos pneus utilizados no trator (L).

30 - Denominação das parcelas de acordo com o pneu utilizado, relação entre peso e potência, velocidade teórica adotada e superfície trativa.

31 - Valores de rendimento máximo na barra de tração, patinagem dos rodados e consumo específico de combustível para as condições do ensaio do trator (A)....

32 - Valores de rendimento máximo na barra de tração, patinagem dos rodados e consumo específico de combustível para as condições do ensaio do trator (B).

33 - Valores de rendimento máximo na barra de tração, patinagem dos rodados e consumo específico de combustível para as condições do ensaio do trator $(\mathrm{C})$...... 
34 - Valores de rendimento máximo na barra de tração, patinagem dos rodados e consumo específico de combustível para as condições do ensaio do trator (D)...

35 - Valores de rendimento máximo na barra de tração, patinagem dos rodados e consumo específico de combustível para as condições do ensaio do trator (E)

36 - Valores de rendimento máximo na barra de tração, patinagem dos rodados e consumo específico de combustível para as condições do ensaio do trator (F).

37 - Valores de rendimento máximo na barra de tração, patinagem dos rodados e consumo específico de combustível para as condições do ensaio do trator $(\mathrm{G})$.

38 - Valores de rendimento máximo na barra de tração, patinagem dos rodados e consumo específico de combustível para as condições do ensaio do trator $(\mathrm{H})$.

39 - Valores de rendimento máximo na barra de tração, patinagem dos rodados e consumo específico de combustível para as condições do ensaio do trator (I)

40 - Valores de rendimento máximo na barra de tração, patinagem dos rodados e consumo específico de combustível para as condições do ensaio do trator $(\mathbf{J})$

41 - Valores de rendimento máximo na barra de tração, patinagem dos rodados e consumo específico de combustível para as condições do ensaio do trator (K).

42 - Valores de rendimento máximo na barra de tração, patinagem dos rodados e consumo específico de combustível para as condições do ensaio do trator (L).

43 - Média dos valores de rendimento máximo na barra de tração, patinagem dos rodados e consumo específico de combustível para os tratores avaliados e respectivas condições de superfície trativa

44 - Média dos valores de rendimento máximo na barra de tração, patinagem dos rodados e consumo específico de combustível para as condições de superfície trativa.

45 - Valores de rendimento na barra de tração de tratores 4x2 TDA, valores da bibliografia e valores dinâmicos obtidos neste trabalho. 


\section{LISTA DE FIGURAS}

Figura

Página

1 - Partes constituintes do pneu agrícola.

2 - Pneu diagonal (A), radial (B) e BPAF (C)......

3 - Diagrama de estimativa de perda de potência nos diferentes setores do trator e em diversos tipos de tratores e condições de piso, adaptado: ASAE D497.4 (1999).

4 - Pista de concreto

5 - Pista de solo firme

6 - Pista de solo mobilizado.

7 - Pista de solo com cobertura vegetal: braquiária (a), restos da cultura do milho (b) e retos da cultura de cana-de-açúcar (c).

8 - Unidade Móvel de Ensaio na Barra de Tração (UMEB)..

9 - Painel com indicadores eletrônicos (a) e bancada de instrumentação com o CLP e um microcomputador portátil (b).

10 - Célula de carga marca SODMEX, modelo N400.......

11 - Geradores de pulsos instalados no trator para determinar a patinagem nos rodados. 46

12 - Fluxômetros volumétricos.

13 - Resultados obtidos em pista de concreto, valor médio, desvio padrão superior e inferior e valores da bibliografia de rendimento máximo na barra de tração.

14 - Resultados obtidos em pista de solo firme, valor médio, desvio padrão superior e inferior e valores da bibliografia de rendimento máximo na barra de tração.

15 - Resultados obtidos em pista de solo com cobertura vegetal, valor médio, desvio padrão superior e inferior.

16 - Resultados obtidos em pista de solo mobilizado, valor médio, desvio padrão superior e inferior e valores da bibliografia de rendimento máximo na barra de tração. 


\section{RESUMO}

O trator agrícola é a principal fonte de potência utilizada na agricultura e a maioria dos novos modelos disponíveis no mercado apresenta tração dianteira auxiliar (TDA). A preferência pelos tratores com tração dianteira auxiliar é devido à sua maior capacidade de tração, principalmente em condições trativas adversas e, sobretudo pela relação benefício e custo ser positiva e maior que os outros modelos.

Esse trabalho foi realizado com o objetivo de avaliar o rendimento dinâmico na barra de tração de tratores agrícolas com tração dianteira auxiliar (4x2 TDA) em diferentes condições de superfície trativa comparando-os com os valores teóricos e práticos da bibliografia ("Fator 0,86" de Wendel Bowers e norma D497.4 ASAE, 1999) e determinar o rendimento dinâmico na barra para a superfície de solo com cobertura vegetal, pois existe pouca bibliografia e é uma realidade no Brasil com o plantio direto na palha.

Avaliaram-se onze tratores agrícolas em diversas condições de ensaio de campo e condições de superfície, variando-se o tipo construtivo e modelos de conjunto de pneus, pressões de inflação dos pneus, relações entre o peso e potência do motor e velocidade teórica de deslocamento. Os dados de rendimento máximo na barra de tração do trator obtidos nos ensaios foram arranjados em grupos, obtendo-se o rendimento dinâmico médio na barra de tração e desvio padrão para cada condição de superfície.

Foram coletados os dados para o cálculo do rendimento na barra de tração do trator, velocidade de deslocamento, patinagem das rodas dianteiras e traseiras do trator, consumo de combustível, força de tração e potência disponível na barra de tração. Para 
a realização do experimento, utilizou-se a Unidade Móvel de Ensaio na Barra de Tração UMEB, pertencente ao Núcleo de Ensaios de Máquinas e Pneus Agroflorestais - NEMPA, do Departamento de Engenharia Rural da Faculdade de Ciências Agronômicas - FCA - UNESP, Botucatu - SP, como carro dinamométrico (de frenagem), estando equipado com os sistemas de aquisição e armazenamento de dados.

Os resultados mostraram que o consumo específico de combustível e a patinagem dos rodados do trator comportaram-se de forma semelhante, apresentando valores menores em pista de concreto e solo firme e maiores nas pistas de solo com cobertura vegetal e solo mobilizado.

Em pista de concreto os resultados mostraram que o valor médio de rendimento máximo na barra de tração obtido $(63,2 \%)$ foi inferior aos valores teóricos da bibliografia. Em pista de solo firme utilizável o valor obtido (56,5\%) confirmou os valores da bibliografia. Em pista de solo mobilizado o valor obtido (44\%) confirmou o valor proposto por Wendel Bowers $(42,8 \%)$ e foi inferior ao determinado pela ASABE $(53,9 \%)$. Em pistas de solo com cobertura vegetal o valor médio de rendimento máximo na barra de tração obtido foi de $49,7 \%$. 
DRAWBAR PERFORMANCE OF AGRICULTURAL TRACTORS WITH AUXILIARY FRONT DRIVE (4 WD). Botucatu, 2010. 79f.

Dissertação (Mestrado em Agronomia/Energia na Agricultura) - Faculdade de Ciências Agronômicas, Universidade Estadual Paulista.

Author: FABRÍCIO CAMPOS MASIERO

Adviser: KLÉBER PEREIRA LANÇAS

\section{SUMMARY}

The agricultural tractor is the main power source used in the agriculture and the most of available new tractor models in the marketing present auxiliary front drive (4WD). The preference for the 4WD tractors is due to biggest traction capacity, mainly in adverse tractive conditions and, mainly for the relationship benefit and cost to be positive and larger than the other models.

This research was accomplished with the objective to evaluate the dynamic drawbar performance of several agricultural tractors 4WD in different surface condition (concrete, firm soil and tilled soil) comparing them with the theoretical and practical values of the bibliography (Wendel Bowers "0.86 Factor" and D497.4 ASAE standard, 1999) and to determine the dynamic drawbar performance for the soil surface with vegetable covering, that doesn't exist in the bibliography and it is a reality in Brazil with the minimum cultivate.

Eleven agricultural tractors were evaluated all 4WD in several field test conditions and surface conditions, being varied the tire constructive type and models, tire inflation pressures, relationships between the weight and engine power and forward speed. The maximum tractor drawbar performance obtained in the tests was arranged in groups, being obtained the medium dynamic drawbar performance and standard deviation for each surface condition.

The data were collected for calculation of tractor yield drawbar performance, forward speed, front and back wheel tractor slippage, fuel consumption, traction 
force and available drawbar power. For the accomplishment of the experiment the UMEB Mobile Unit for Drawbar Test, belonging to the NEMPA - Nucleus of Agricultural and Forestry Machines and Tires and Test, belonging to the Agricultural Engineering Department, College of Agronomic Sciences, São Paulo State University - FCA/UNESP, Botucatu-SP, as a dynamometric car, equipped with an acquisition and storage data system.

The results showed that the specific fuel consumption and the tractor wheel slippage behaved in a similar way, presenting results being smallest in the concrete tracks and firm and largest in the soil covered with vegetable straw and mobilized soil, respectively.

In concrete track the results showed that the medium obtained value of maximum drawbar performance $(63.2 \%)$ was inferior to the proposed by Wendel Bowers $(79.2 \%)$ and for the ASABE value (72.2\%). In the usable firm soil the obtained value (56.5\%) confirmed the values of the bibliography. In mobilized soil tracks the obtained value (44\%) confirmed the value proposed for Wendel Bowers' (42.8\%) and it was inferior to the certain value for ASAE (53.9\%). In vegetable covering soil surface the medium value obtained of maximum drawbar performance was of $49.7 \%$.

Keywords: tractor test, surface condition, specific fuel consumption. 


\section{INTRODUÇÃO}

Para se racionalizar as operações agrícolas mecanizadas, é necessária a caracterização das operações, a maneira de executá-las, a ordenação cronológica em função das condições climáticas e das fases de desenvolvimento das plantas e a seleção de tratores e equipamentos para que as executem da melhor maneira, na área disponível e no tempo estabelecido.

Com base nessas características, a análise operacional procura desenvolver técnicas de previsão, planejamento, controle e coordenação das atividades, visando obter o máximo de rendimento útil de todos os recursos disponíveis, com o mínimo de dispêndio.

Portanto, torna-se necessário conhecer a força e, conseqüentemente, a potência disponível na barra de tração dos tratores agrícolas, uma vez que, a partir do conhecimento desta potência, podem-se dimensionar equipamentos adequados à capacidade do trator.

Qualquer melhoria que puder ser feita com relação à transformação da potência do motor em potência de tração da forma mais eficiente possível, contribuirá diretamente na eficiência da produção agrícola e para a conservação e uso racional de energia.

A preferência pelos tratores com tração dianteira auxiliar é devido a maior capacidade de tração desses tratores, principalmente em condições trativas adversas.

Alguns trabalhos têm sido realizados para se determinar a potência disponível na barra de tração, considerando-se vários tipos e condições de solo, tais como a 
regra sugerida por Wendel Bowers ,conhecida como "Fator 0,86" e a norma ASAE D497, porém poucos são os estudos em pistas com cobertura vegetal.

O objetivo deste trabalho foi avaliar o rendimento dinâmico na barra de tração de tratores agrícolas com tração dianteira auxiliar (4x2 TDA) em diferentes condições de superfície trativa (concreto, solo firme utilizável e solo mobilizado) e diversas configurações de ensaio de campo, comparando os valores obtidos com valores teóricos da bibliografia e determinar o rendimento dinâmico na barra de tração para a condição de superfície de solo com cobertura vegetal, que hoje, é muito importante no Brasil em função da grande aceitação e adoção do plantio direto na palha. 


\section{REVISÃO BIBLIOGRÁFICA}

O ensaio de máquinas agrícolas vem sendo realizado há várias décadas e direcionado para o levantamento de dados que possibilitem avaliar características de desempenho. Esta atividade é realizada em três ambientes principais: em laboratórios, em dispositivos de simulação e no campo. Nos ensaios de campo, ao contrário dos demais, a máquina toda é submetida a condições reais de operação. Neste caso, a perfeita caracterização das condições sob as quais as mensurações são realizadas, sendo válidos os dados referentes ao desempenho para tais condições de campo. O ensaio de trator em solo agrícola é uma das maneiras de obter informações, principalmente no que diz respeito ao seu desenvolvimento de tração. Esses ensaios visam à obtenção de informações sobre o desempenho dos rodados, relacionados com as características da interação com o solo (MIALHE, 1996).

A instrumentação de máquinas agrícolas para a realização de ensaios de campo tem por finalidade a geração de informações, através de sensores instalados nestas e nos implementos, proporcionando o conhecimento de parâmetros que possibilitem dimensionar e racionalizar o uso desses conjuntos (SILVA et al., 2001).

As avaliações diretas do desempenho de tratores em condições de campo são obtidas através da instrumentação e monitoramento dos mesmos, permitindo assim a determinação de fatores diretamente relacionada com a eficiência de trabalho do trator (CORDEIRO, 2000). O autor realizou um estudo de desempenho de um trator agrícola em função do pneu, da lastragem e da velocidade de deslocamento e concluiu que estes fatores alteraram significativamente a conversão energética, a patinagem e a força de tração do trator. 
Silva e Benez (1997) construíram um sistema eletrônico de aquisição de dados e instrumentos indicadores digitais para medir, exibir e gravar os dados necessários à avaliação do desempenho energético de máquinas e implementos agrícolas em trabalhos de campo. Os autores concluíram que, a grande vantagem do sistema eletrônico de aquisição de dados é a variação na taxa de amostragem e a grande quantidade de dados coletados durante a realização dos ensaios, possibilitando o estudo da grandeza monitorada de modo detalhado.

Segundo Silva et al. (1997), o objetivo da avaliação do desempenho de tratores agrícola, em ensaios de campo, tem sido gerar informações que possibilitem dimensionar e racionalizar o uso de conjuntos motomecanizados na agricultura.

De acordo com Zoz (1997) os estudos da teoria de tração têm apresentado progressos consideráveis, sendo desenvolvidos critérios para avaliar o desempenho do trator com base nos resultados de ensaios realizados em pista de concreto. Entretanto para as condições de campo, são necessários mais pesquisas para fornecer as informações necessárias e estimar o desempenho de tratores.

O desempenho na barra de tração de um trator depende, primariamente, da potência do motor, da distribuição de peso sobre os rodados, altura e posição dos engates da barra e da superfície do solo (ASAE D497. 4, 1999).

Conhecer o rendimento útil dos tratores é uma ferramenta exigida para racionalizar as operações com conjunto ou sistema de máquinas de forma técnica e economicamente organizada, na execução das tarefas exigidas pela produção agrícola, visando obter o máximo de rendimento com o mínimo de dispêndio de energia, tempo e dinheiro (MIALHE, 1974).

\subsection{Trator com tração dianteira auxiliar (4x2 TDA)}

Os tratores agrícolas com tração dianteira auxiliar (4x2 TDA) possuem uma ligação rígida entre os eixos dianteiros e traseiros, sendo funcional quando acionada. Com o sistema conectado, o eixo dianteiro gira com uma rotação superior ao eixo traseiro, denominada avanço cinemático. Esse avanço varia conforme o modelo do trator de acordo com critérios do fabricante e tem a função de corrigir as diferenças de diâmetros entre as rodas do eixo dianteiro e traseiro. Como as velocidades periféricas das duas rodas devem ser 
aproximadamente iguais, os fabricantes recomendam pares compatíveis de pneus, deixando essas velocidades aproximadamente iguais (LINARES, 1996; RACKHAM e BLIGHT, 1985).

A relação cinemática entre eixos do trator depende de dois fatores, primeiro da relação de velocidade entre os eixos e segundo dos raios das rodas dianteira e traseira do trator. O primeiro fator é fixo e depende do projeto do fabricante que o estabelece por meio das relações de transmissão entre os dois diferenciais. Geralmente esta relação de velocidade é maior que 1 , a favor do eixo dianteiro, que gira mais rápido que o traseiro. $\mathrm{O}$ segundo fator é o próprio raio das rodas, que pode ser alterado pelo usuário, por meio da troca dos pneus ou pela variação da pressão interna dos mesmos. Os raios estáticos sob carga aumentam nos eixos, dianteiro e traseiro, quando se diminui o peso do trator ou à medida que se utiliza uma pressão interna maior nos pneus. Quanto maior a relação de avanço cinemático ocorre uma diminuição da eficiência trativa da máquina (SCHLOSSER et al., 2004).

Campos et al. (2008) avaliaram o desempenho operacional de um trator agrícola com três diferentes valores de avanço cinemático (3\%, 6\% e 12\%) em função da carga na barra de tração em uma superfície rígida (asfalto). O avanço cinemático de 3\% resultou em maior potência na barra de tração, menor patinagem e menor consumo de combustível.

Fontana et al. (1986), em operação de campo com escarificador, compararam o desempenho de tratores com e sem tração dianteira auxiliar, com e sem o uso de lastro dianteiro. Verificaram que houve aumento da velocidade de deslocamento com o uso da tração auxiliar, proporcionando um aumento médio de 5,76\% na capacidade operacional. Observaram também, um aumento de 5,82\% em média, no consumo horário de combustível com o uso da TDA.

Schlosser e Dallmeyer (1988) compararam o desempenho de um trator no campo, utilizando duas técnicas de aração, com e sem o uso da tração dianteira auxiliar. Observaram, com o uso da TDA, um aumento de $17 \%$ na capacidade operacional efetiva e diminuição da patinagem.

Yanai et al. (1988), com base em dados levantados em ensaios de tratores em pista de concreto, analisaram o desempenho de cinco tratores agrícolas com tração dianteira auxiliar, quando comparado com sua versão de tração simples: concluíram que o uso 
da tração dianteira causou um aumento de $33,3 \%$, em média, na força de tração e de $13,9 \%$ no consumo horário de combustível.

Yanai et al. (1999) avaliaram a eficiência do uso da tração dianteira auxiliar em pista de solo com cobertura vegetal, e observaram que a mesma influenciou significativa e positivamente a velocidade de deslocamento e a potência na barra de tração reduzindo a patinagem nos rodados.

\subsection{Relação entre peso e potência do trator}

A relação peso/potência do trator influi diretamente no seu desempenho em trabalho de campo (MÁRQUEZ, 1990).

A relação peso/potência dos tratores agrícolas fabricados e comercializados no Brasil varia, basicamente, em função da marca e modelo do trator e da

potência do motor. É importante salientar que estes dados são parâmetros que auxiliam na seleção dos tratores e na otimização do uso dos mesmos, visando à redução dos custos agregados nas máquinas agrícolas (SCHLOSSER et al., 2005).

Monteiro et al. (2009b), em estudos realizados, constataram que a adição de peso ao trator obedecendo a critérios de relação entre peso e potência, acarreta em melhorias em termos de rendimento operacional, aumento da força trativa, redução da patinagem, do consumo horário e específico de combustível.

Monteiro et al. (2009a) avaliaram o desempenho de um trator agrícola equipado com pneus radiais e diagonais, respectivamente, em três condições de lastragem líquida, com $0 \%, 37,5 \%$ e $75 \%$ de água, em três condições de deslocamento cujas velocidades teóricas foram respectivamente 4,5 e $7 \mathrm{~km} \cdot \mathrm{h}^{-1}$, em uma superfície de solo com cobertura vegetal e observaram que o pneu radial com 37,5\% de água obteve os menores valores de patinagem e consumo horário de combustível e o trator equipado com pneus diagonais obteve os melhores resultados com o lastro líquido de $75 \%$. 


\subsection{Pneus agrícolas}

O rodado pneumático apresenta estrutura em forma de tubo circular, de maneira que, ao se inflar com uma determinada pressão, resiste, dentro dos limites normais de trabalho, as cargas nele aplicadas e as solicitações dinâmicas e estáticas que agem sobre o mesmo. O pneu é composto basicamente por borracha vulcanizada e camadas de cordonéis, também chamadas de lonas (malhas de fibras de algodão, de aço, nylon, poliéster, etc), que se estendem ao longo de sua estrutura (MIALHE, 1980).

Wittcott e Reuben (1980) relataram que um pneu é constituído de quatro componentes principais conforme mostra a Figura 1:

- banda de rodagem: parte que está em contato com a superfície de rolamento;

- flancos: paredes laterais;

- talão: parte responsável pelo assento do pneu no aro;

- carcaça: corresponde ao conjunto de camadas ou lonas.

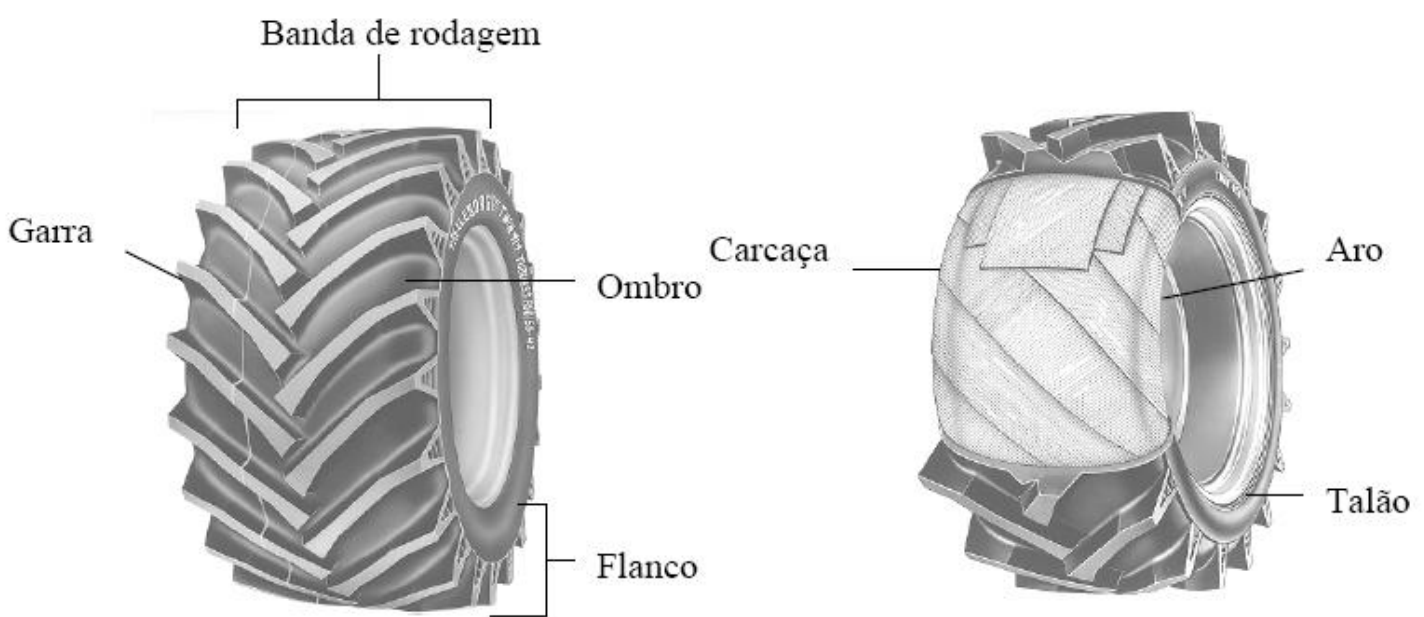

Figura 1. Partes constituintes do pneu agrícola. Fonte: adaptado de Trelleborg do Brasil, $2002^{1}$

Segundo a Associação Brasileira de Pneus e Aros (1994), existem três tipos distintos de configuração estrutural de pneus agrícolas de tração: diagonal, radial e baixa pressão e alta flutuação (BPAF). O pneu diagonal apresenta os cordonéis das lonas dispostos

\footnotetext{
1 A citação de marca ou modelo não implica na recomendação do autor.
} 
de talão a talão em ângulos menores que $90^{\circ}$ (aproximadamente $30^{\circ}$ a $40^{\circ}$ ). Os pneus diagonais são de fabricação nacional e admitem recauchutagem, refletindo em menor custo de aquisição. O pneu radial apresenta os cordonéis dispostos de talão a talão em ângulo de $90^{\circ}$, em relação à linha de centro da banda de rodagem, o que lhe confere maior flexibilidade. A banda de rodagem apresenta cintas que lhe proporciona uma característica plana da mesma. Os pneus radiais não admitem recauchutagem, implicando em maiores custos de aquisição e não são fabricados no país. O pneu baixa pressão e alta flutuação (BPAF) apresenta lonas com os cordonéis dispostos diagonalmente em relação à linha de tração do pneu e a banda de rodagem apresenta cintas que lhe proporciona uma característica plana, podendo-se dizer que esse tipo de pneu apresenta banda de rodagem radial e flanco diagonal, permitindo assim, maior flexibilidade e resistência ao mesmo tempo. Os pneus BPAF são mais largos que os outros tipos de pneus, não são fabricados no Brasil e não admitem recauchutagem, sendo assim, de maior custo de aquisição. A Figura 2 mostra as diferentes carcaças dos pneus diagonais, radiais e BPAF.

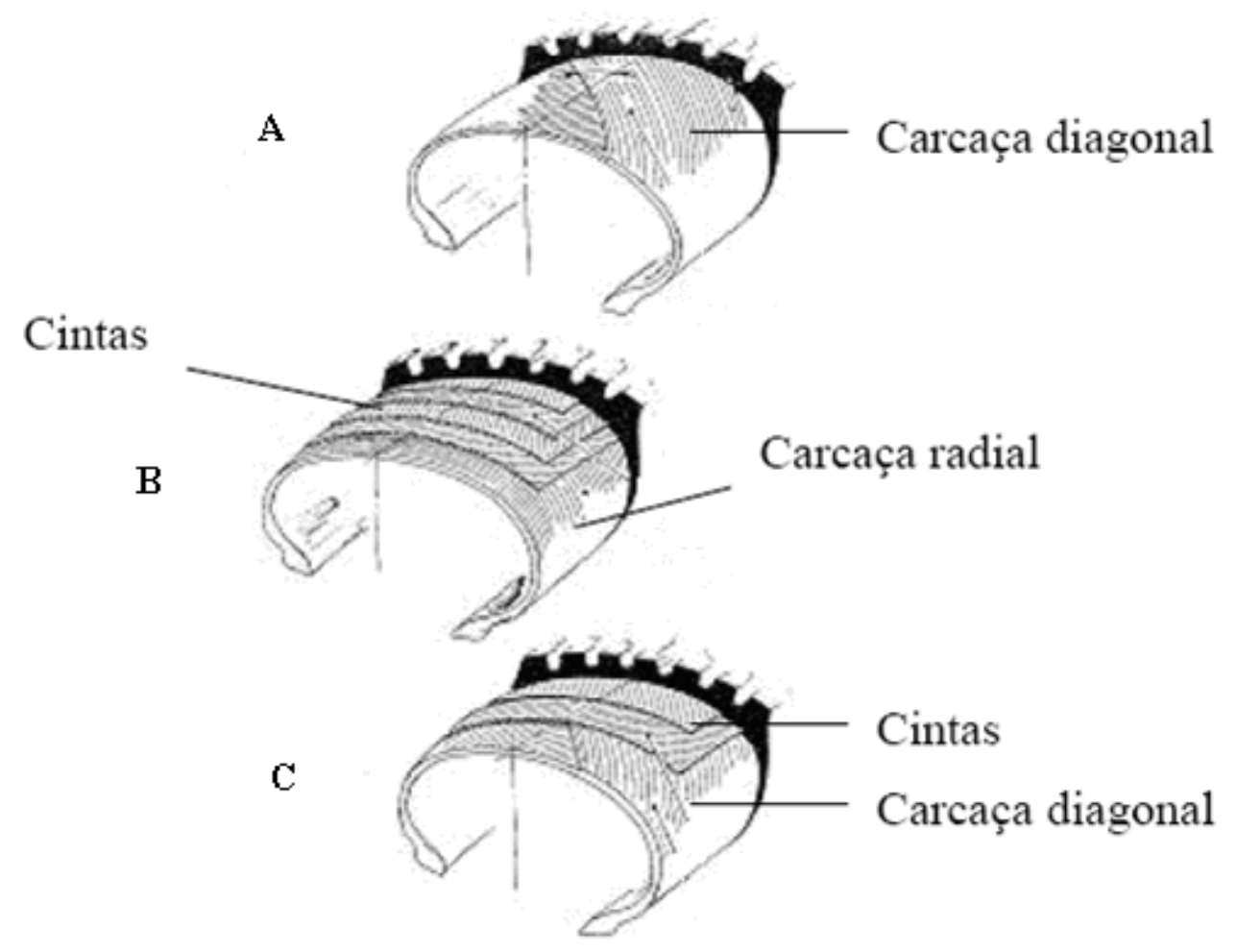

Figura 2. Pneu diagonal (A), radial (B) e BPAF (C). Fonte: adaptado de Trelleborg do Brasil, 2002 
A capacidade de tração e fornecimento de potência suficiente para desempenhar a maioria das operações necessárias na agricultura depende, em parte, do tipo de dispositivo de tração. Nos casos em que esses dispositivos são pneumáticos, o tamanho, a pressão de inflação, a carga aplicada sobre o eixo motriz, a transferência de peso, entre outros, interferem na capacidade de tração do trator (NAGAOKA et al., 2002; ZOZ e GRISSO, 2003).

Os pneus utilizados em tratores e máquinas agrícolas devem suportar, com segurança, o peso do trator ou da máquina em condição estática e dinâmica, agir como um sistema de amortecimento dos impactos provocados pelas irregularidades do solo, além de garantir, com eficiência, a transmissão das forças motrizes e frenantes do trator ao solo e viceversa (MIALHE, 1980).

Segundo Yanai et al. (1999), dentre as características dos pneus que afetam o desempenho operacional do trator, estão o tipo de construção, a configuração da banda de rodagem, a largura e o diâmetro dos rodados e a carga normal sobre as rodas motrizes.

Correa (1999a) destaca que o rodado é a última parte de ligação do motor do trator com o solo e seu estudo é de fundamental importância para o desempenho do trator, havendo, portanto, a necessidade de conhecê-lo melhor, utilizando a pressão de inflação indicada pelo fabricante e tomando os devidos cuidados com a sua manutenção.

Segundo Lopes et al. (2005), a pressão de inflação é um fator determinante para o desempenho dos tratores agrícolas. Em estudo realizado por esse autor, a pressão de inflação influenciou significativamente a velocidade de deslocamento, patinagem e potência na barra de tração, sem, no entanto, apresentar uma tendência de comportamento. A interação entre pressão de inflação e carga sobre os rodados mostrou que determinadas combinações desses dois fatores são mais favoráveis para o desenvolvimento de maior velocidade de deslocamento e menor patinagem.

A pressão de inflação ("baixa/correta") para pneus radiais apresentaram melhores resultados nos coeficientes de tração líquida e bruta e na eficiência trativa em função da carga no rodado (LANÇAS, 1996; LANÇAS et al., 2009).

Os conjuntos pneumáticos do trator constituem um de seus mais importantes componentes, pois tem a função de obter equilíbrio, deslocamento, 
direcionamento e esforço tratório. Em estudos comparativos do desempenho operacional de um trator agrícola, equipado alternadamente com pneu radial e diagonal, os autores concluíram que os pneus radiais apresentaram diferenças significativas favoráveis quando comparados com pneus diagonais para os parâmetros força de tração, potência na barra e consumo específico de combustível. (CORDEIRO, 2000; BARBOSA et al., 2005).

Masiero et al. (2009), avaliando o desempenho de um trator agrícola em função da variação da pressão de inflação dos pneus e da força na barra de tração, observaram que pressões abaixo do recomendado pelo fabricante resultaram em maior potência e rendimento na barra de tração com força de $30 \mathrm{kN}$ devido a maior área de contato dos pneus com o solo, fornecendo ao trator maior capacidade tratória. As pressões recomendadas pelos fabricantes forneceram menor consumo de combustível em mais ampla faixa de força na barra de tração.

A utilização de elevadas pressões de inflação dos pneus conduz a pequenas diminuições (da ordem de 3 a 5\%) na capacidade de trabalho e a um aumento significativo do consumo de combustível por hectare (entre 10 e 25\%), mesmo em boas condições de aderência dos pneus, refletidas no intervalo de valores médios de patinagem entre 7 e 15\%, dados obtidos avaliando-se o efeito da pressão de inflação dos pneus no desempenho de um conjunto trator e grade de discos (SERRANO, 2008).

\subsection{Superfície de tração}

Entre os fatores que interferem na tração, a condição da superfície do solo é um fator determinante, todavia nos modelos propostos para determinar a eficiência de um trator em desenvolver tração em condições de campo, não se contempla o tipo de cobertura vegetal presente sobre o solo. Destaca-se a importância de conhecer o desempenho sobre cobertura vegetal devido aos grandes avanços em termos de área dos sistemas conservacionistas, entre eles o sistema de plantio direto (GABRIEL FILHO et al., 2004; YANAI et al., 1999).

A cobertura do solo interfere na capacidade do trator em desenvolver esforço para tracionar máquinas e implementos enquanto o tipo de cobertura pode causar mudanças de patinagem e na eficiência tratória (GABRIEL FILHO et al., 2004). 
O solo atua de forma a diminuir a força de tração do trator ao oferecer uma resistência para o avanço da roda (resistência ao rolamento), com isso a força "possível" se converte em "real", chamada diretamente de força de tração. Porém esta redução da força de tração depende de duas circunstâncias: tipo de solo (textura e teor de água) e tipo de rodado (carga aplicada e área de contato pneu/solo). Esta limitação tem uma conseqüência, a patinagem, que faz com que o trator se mova a uma velocidade menor do que a correspondida pelas voltas oriundas do motor (LINARES, 2001).

Jesuíno (2007) ao avaliar o desempenho de um trator agrícola em função do desgaste das garras dos pneus e das condições superficiais do solo observou que, as condições superficiais do solo interferiram diretamente na relação entre o rodado e o solo. Sendo que nas condições específicas estudadas (pista de solo firme, solo mobilizado e solo com cobertura vegetal) o melhor desempenho do trator aconteceu na pista de solo firme e a condição superficial de solo mobilizado foi responsável pelo pior desempenho do trator.

Segundo Lanças (1996), as condições superficiais do solo firme apresentaram melhores resultados de eficiência trativa comparando-se com solo preparado (solto).

As pistas com superfície firme e com cobertura vegetal apresentaram resultados de desempenho operacional e energético semelhantes (MONTEIRO, 2008). O mesmo autor ao avaliar o desempenho operacional e energético de um trator agrícola, observou que os maiores valores de patinagem e consumo horário de combustível se deram nos tratamentos com solo mobilizado, mostrando que esta condição superficial do solo foi responsável pelo menor desempenho do trator.

$\mathrm{Na}$ avaliação do desempenho operacional de um trator agrícola, em área coberta com diferentes tipos de cobertura vegetal, Gabriel Filho et al. (2004) concluíram que a maior quantidade de matéria seca na superfície do solo tende a aumentar a patinagem e, com isso, diminuir a eficiência de tração, devido ao maior teor de água em solos com grande quantidade de matéria seca na superfície.

Valores de maior patinagem dos rodados sob maior quantidade de matéria seca também foram observados por Duarte Júnior et al. (2008) avaliando o desempenho de um trator agrícola sob superfícies com diferentes quantidades de matéria seca. 
Segundo Mialhe (1991), quando se passa da condição de pista de concreto para terreno agrícola, é justamente na interface rodado-solo onde as perdas de potência se tornam mais críticas.

Ao avaliar o consumo de combustível e a capacidade de campo operacional na semeadura de aveia, em três manejos do solo (plantio direto, plantio convencional e escarificação), Mazetto et al. (2004) concluíram que o consumo horário de combustível e a patinagem do trator foram menores onde a operação de semeadura foi realizada em sistema de plantio direto, o solo escarificado apresentou valores intermediários entres os sistemas de plantio direto e convencional. A semeadura realizada sob o plantio convencional resultou em maiores valores de patinagem e consumo de combustível do trator devido a maior exigência de força de tração.

\subsection{Patinagem dos rodados}

O movimento de uma roda pode ser considerado como a variação de três situações distintas: movida, autopropelida ou motriz. Na primeira situação, não há torque no eixo da roda, apenas a ação de uma força externa. Na condição de autopropelida, o torque é suficiente apenas para movimentar a roda sem que haja a tração. Quando a roda desenvolve tração, ela passa a ser considerada motriz, onde ocorre aumento da patinagem, que será positivo quando houver torque na roda e ela desenvolver tração. A capacidade de tração na roda motriz aumenta conforme aumenta o patinagem até um valor máximo (WISMER e LUTH, 1973).

A patinagem é a denominação que se dá ao deslizamento entre a superfície da banda de rodagem e o solo, sendo ela um fator determinante para que ocorra a tração. Durante uma operação agrícola, a patinagem pode ser facilmente visualizada pelo movimento giratório das rodas motrizes do trator, com pequeno ou nenhum avanço das mesmas, o que acontece devido à falta de aderência das rodas ao solo (GAMERO e LANÇAS, 1996; CORRÊA et al., 1999b).

Para que ocorra tração é necessário que exista patinagem, entretanto, se esta ultrapassar determinados limites, pode ocorrer perda da aderência e redução da tração dos rodados (LANÇAS e UPADHYAIA, 1997). Os mesmos autores concluíram que, nos tratores 
agrícolas a patinagem dos rodados ocorre devido a diversos fatores, entre eles o esforço de tração necessário para deslocar determinado implemento, tipo de superfície que está em contato com a banda de rodagem dos pneus motrizes, tipo de pneu, a pressão de inflação, carga sobre o rodado e tipo da banda de rodagem.

Segundo Jesuíno (2007), avaliando o desempenho de um trator agrícola em função do desgaste das garras dos pneus e das condições superficiais do solo, os níveis de desgaste dos pneus diagonais, respectivamente de 63,4\% para os dianteiros e 41,2\% para os traseiros, provocaram reduções significativas no desempenho do trator em pista de solo mobilizado, porém em pista de solo firme e pista de solo com cobertura vegetal o conjunto de pneus desgastados ainda pode ser utilizado sem prejuízos significativos de desempenho do trator.

Conforme Norma EP496.2 (ASAE, 1997a), a patinagem de um rodado de tração pode ser definida como a redução de deslocamento em determinada condição de piso comparada com uma condição específica, também chamada condição zero, onde se mede o rolamento do rodado em piso indeformável e em situação sem carga.

A ASAE (1997b) recomenda, para obtenção de máxima eficiência de tração, patinagem de 8-10\% em solos não mobilizados e de 11-13\% em solos mobilizados, mas é importante salientar que os solos não mobilizados não têm palhada na superfície, ou seja, o solo está descoberto.

\subsection{Consumo de combustível}

De acordo com Mialhe (1996), a mensuração da quantidade de combustível consumida, constitui-se um dos mais importantes aspectos da avaliação do rendimento de um motor, ou seja, do seu desempenho como máquina térmica conversora de energia. O consumo de combustível pode ser expresso: em relação ao tempo $\left(\mathrm{L} . \mathrm{h}^{-1} ; \mathrm{kg} . \mathrm{h}^{-1}\right.$, etc), em relação ao trabalho mecânico desenvolvido (consumo específico $=\mathrm{g} \cdot \mathrm{cv}^{-1} \cdot \mathrm{h}^{-1}$; g.kW $\mathrm{kW}^{-1} \mathrm{~h}^{-1}$, etc) e em relação a área trabalhada $\left(\mathrm{L} \mathrm{ha}^{-1}\right)$. O consumo horário geralmente é obtido por leitura direta de instrumentos de mensuração que podem ser expressas em termos ponderais $\left(\mathrm{kg} \cdot \mathrm{h}^{-1}\right)$ ou volumétrico $\left(\mathrm{L} \cdot \mathrm{h}^{-1}\right)$. 
O consumo de combustível pode ser apresentado como unidade de volume por unidade de tempo $\left(\mathrm{L}^{\mathrm{h}} \mathrm{h}^{-1}\right)$, caso em que não se considera a influência da variação da temperatura e, tampouco, a quantidade de potência gerada. Outra forma de apresentar o consumo de combustível é por meio de unidade de massa por unidade de tempo $\left(\mathrm{kg} . \mathrm{h}^{-1}\right)$; nesta forma, apesar de considerar a influência da temperatura, também não contempla a potência gerada. A forma mais técnica de se expressar o consumo é unidade de massa por unidade de potência (g.kWh ${ }^{-1}$ ); esta forma é conhecida como consumo específico e, pelo fato de considerar a massa e a potência, pode ser usada para comparar motores, tratores e equipamentos de tamanho e formas diferentes (LOPES et al., 2003). Estes autores ao avaliarem o consumo de combustível de um trator agrícola em função do tipo de pneu, da lastragem e da velocidade de trabalho concluíram que o uso de pneu tipo radial, condição de lastragem com $75 \%$ de água nos pneus e velocidade de $4,8 \mathrm{~km} \cdot \mathrm{h}^{-1}$ permitiram reduzir o consumo específico sem comprometer o desempenho do trator.

$\mathrm{Na}$ implantação de culturas agrícolas, o consumo de combustível é função de vários fatores tais como: adequação e condição do conjunto trator-implemento, potência do motor, profundidade da operação, tipo e condição de solo, tempo de manobras e do número de operações agrícolas adotadas no processo de produção (CORRÊA et al., 1999b).

\subsection{Barra de tração}

A barra de tração é um dos meios de aproveitamento da potência do trator e destina-se a desenvolver força, a qual é comumente direcionada para tração de máquinas e implementos, que necessitam ser deslocados ao longo da área de trabalho. A partir do ensaio na barra de tração, podem-se obter parâmetros quantitativos relativos à força de tração, velocidade, consumo específico, patinagem, potência disponível na barra de tração, coeficiente de tração e rendimento na barra de tração (MIALHE, 1996; SRIVASTAVA et al., 1996).

O rendimento na barra de tração é freqüentemente usado para comparar ou avaliar tratores. Entretanto, o rendimento na barra de tração é afetado pelas condições de superfície, pela relação de engrenagem e pela relação entre peso e potência do trator. Considerando que potência é uma função de velocidade e força na barra de tração, pode se 
afirmar que o rendimento na barra de tração descreve em parte a habilidade de um trator para tracionar. O rendimento máximo na barra de tração normalmente é o critério de desempenho mais útil para tratores agrícolas. (LILJEDAHL, et al. 1996)

Segundo a American Society of Agricultural Engineers (ASAE, D497.4, 1999), na transmissão de potência do motor para a barra de tração ocorrem perdas que, dependendo das condições de operação do trator, distribuição de peso sobre as rodas motrizes e tipo de acoplamento, podem atingir níveis bastante comprometedores.

Conforme Lanças (2009), baseado no "fator 0,86" (Wendel Bowers), que propõe a obtenção das diversas potências disponíveis em diferentes condições de solo através de sucessivas multiplicações da potência geradora por " 0,86 " para se obter a potência útil e rendimento na barra de tração dos tratores agrícolas de rodas pneumáticas, considerando a patinagem média dos rodados de 10 a $12 \%$, portanto, para os casos mais usuais tem-se as Equações de 1 a 6 :

Pot. $T D P=$ Pot. Motor x 0,86

Pot. Max. BT, concreto $=$ Pot. TDP x 0,86

Pot. Max. BT, solo firme $=$ Pot. Max. BT, concreto x 0,86

Pot. Utilizável, BT, solo firme = Pot. Max. BT, solo firme x 0,86

Pot. Utilizável, BT, solo arado = Pot. Utilizável, BT, solo firme x 0,86

Pot. Utilizável, BT, solo solto $=$ Pot. Utilizável, BT, solo arado $\mathrm{x} 0,86$

O rendimento na barra de tração em diversas condições de superfície para tratores de rodas pneumáticas com duas rodas motrizes $(4 \times 2)$ e com tração dianteira auxiliar (4x2-TDA), baseado no fator " 0,86 ” de Wendel Bowers está descrito na Tabela 1 , onde os valores para tratores 4x2-TDA são resultantes do acréscimo de $7 \%$ dos valores de tratores $4 \times 2$. A potência na barra de tração pode ser calculada pela Equação 7 .

$\mathrm{N}_{\mathrm{b}}=\mathrm{N}_{\mathrm{m}} \times \eta_{\mathrm{b}}$ 
Onde:

$\mathrm{N}_{\mathrm{b}}=$ potência útil na barra de tração (cv ou $\mathrm{kW}$ )

$\mathrm{N}_{\mathrm{m}}=$ potência útil do motor $(\mathrm{cv}$ ou $\mathrm{kW})$

$\eta_{\mathrm{b}}=$ rendimento na barra de tração

Tabela 1 - Rendimento na barra de tração para tratores de rodas pneumáticas e diversas condições de solo baseado no fator " 0,86 " de Wendel Bowers.

\begin{tabular}{ccc}
\hline Condições de solo & $\boldsymbol{\eta}_{\mathbf{b}}(\boldsymbol{\%})-$ Tratores 4X2 & $\boldsymbol{\eta}_{\mathbf{b}}(\boldsymbol{\%})$ - Tratores 4X2-TDA \\
\hline Concreto & 74 & 79,2 \\
Solo firme - máxima & 64 & 68,5 \\
Solo firme - utilizável & 55 & 58,8 \\
Solo arado & 47 & 50,3 \\
Solo gradeado & 40 & 42,8 \\
\hline
\end{tabular}

A American Society of Agricultural Engineers (ASAE, 1999) apresentou um diagrama de estimativa de perda de potência nos diferentes setores do trator e em diversos tipos de tratores $(4 \times 2,4 \times 2$ TDA, $4 \times 4$ e de esteiras) e diferentes condições de superfície (Figura 3). A perda de potência disponível na barra de tração em relação à potência líquida no motor de tratores $4 \times 2$ pode variar de 22 a $51 \%$ para piso de concreto e solos soltos, respectivamente, enquanto a perda de potência dos tratores $4 \times 2$ TDA pode variar de 22 a $42 \%$ para piso de concreto e solos soltos, respectivamente.

Considerando as perdas causadas pelas transmissões e condições de superfície trativa (Figura 3) a partir da potência na TDP do trator obtida pela Equação 8, podese determinar a potência na barra de tração utilizando a Equação 9, onde multiplica-se a potência na TDP pelos fatores descritos na Figura 3 conforme a norma ASAE D497.4 (1999).

Potência na TDP = Potência Nominal x 0,83

Potência na Barra de Tração $(N b)=$ Potência na TDP x Fator (Tabela 2) 


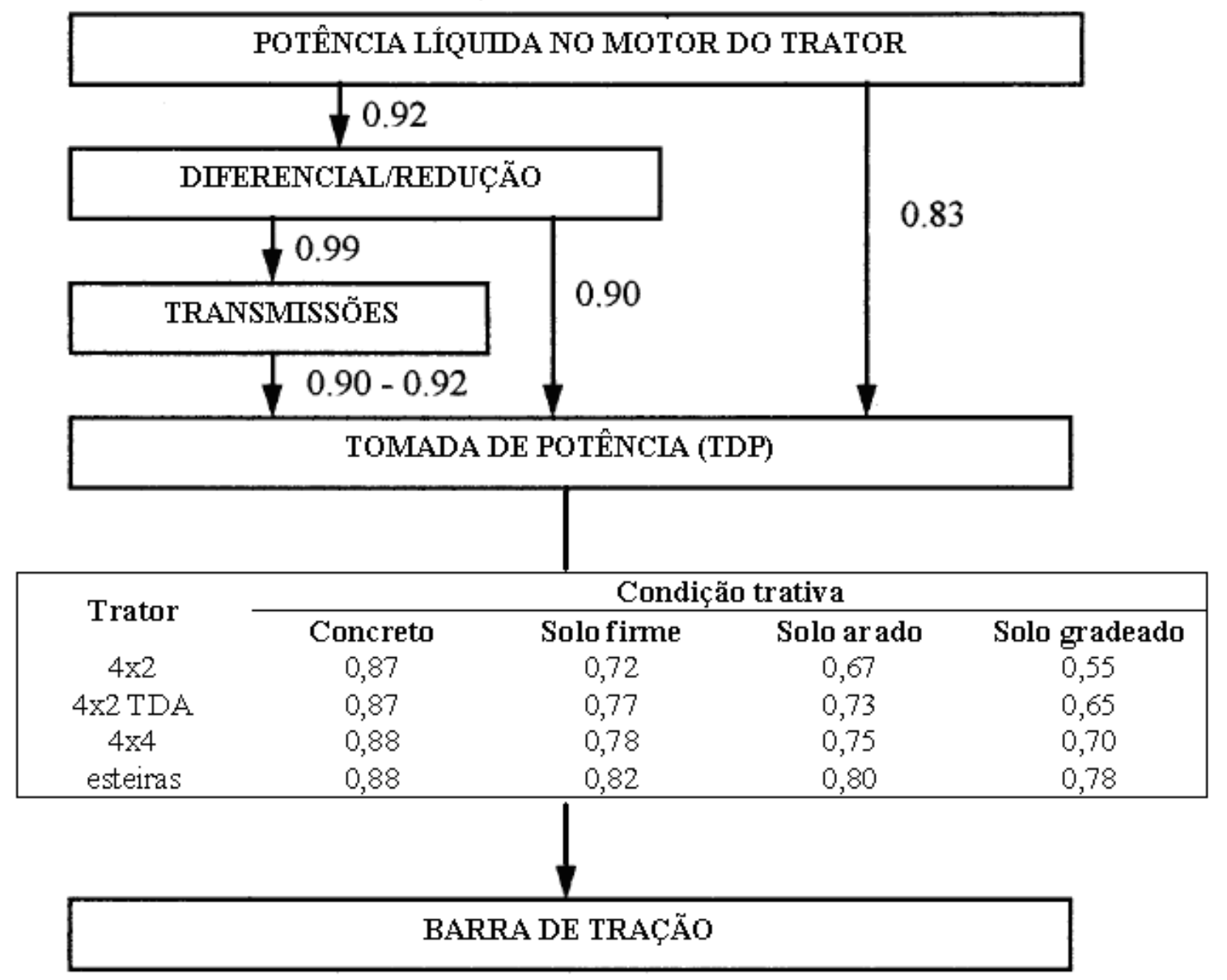

Figura 3 - Diagrama de estimativa de perda de potência nos diferentes setores do trator e em diversos tipos de tratores e condições de piso, adaptado: ASAE D497.4 (1999).

Os valores de rendimento na barra de tração baseados na Norma ASAE

D497.4 (1999) utilizados nesse trabalho estão descritos na Tabela 2.

Tabela 2 - Rendimento na Barra de Tração (\%) de diversos tipos de tratores em diversas condições de superfície baseado na Norma ASAE D497.4 (1999).

\begin{tabular}{ccccc}
\hline \multirow{2}{*}{ Trator } & \multicolumn{4}{c}{ Condição trativa } \\
\cline { 2 - 5 } & Concreto & Solo firme & Solo arado & Solo gradeado \\
\hline $4 \times 2$ & 72,2 & 59,8 & 55,6 & 45,6 \\
$4 \times 2$ TDA & 72,2 & 63,9 & 60,6 & 53,9 \\
$4 \times 4$ & 73 & 64,7 & 62,2 & 58,1 \\
esteiras & 73 & 68,1 & 66,4 & 64,7 \\
\hline
\end{tabular}




\section{MATERIAL E MÉTODOS}

O material utilizado e os métodos adotados para realizar os ensaios estão apresentados separadamente, a seguir:

\subsection{Material}

\subsubsection{Localização da área experimental}

O experimento foi desenvolvido na Fazenda Experimental Lageado, pertencente à FCA/UNESP.

As coordenadas geográficas da área experimental (ponto central), onde estão as pistas são: $22^{\circ} 51^{\prime} \mathrm{S}, 48^{\circ} 25^{\prime} \mathrm{W}$ e altitude de $770 \mathrm{~m}$.

O solo da área experimental foi classificado por Carvalho et. al. (1983) como Terra Rocha Estruturada, sendo adaptado à classificação da Embrapa (1999), como Nitossolo vermelho distroférrico com relevo plano e textura argilosa.

\subsubsection{Pistas de ensaios}

Os ensaios foram realizados nas pistas de ensaios do NEMPA do Departamento de Engenharia Rural, em pista de concreto com 200 metros de comprimento e 4 metros de largura, totalizando $800 \mathrm{~m}^{2}$ de área e em pistas de campo que apresentam 400 
metros de comprimento e 20 metros de largura totalizando $8000 \mathrm{~m}^{2}$ de área cada. Estas pistas apresentam declividade de $1 \%$ no sentido do comprimento e niveladas na largura.

\subsubsection{Pista de concreto}

Foi construída segundo a Norma OECD-Code 2 (2008), apresenta grande uniformidade, sendo utilizada para comparar ensaios de tratores sob a mesma superfície nos centros de ensaios de tratores (Figura 4).

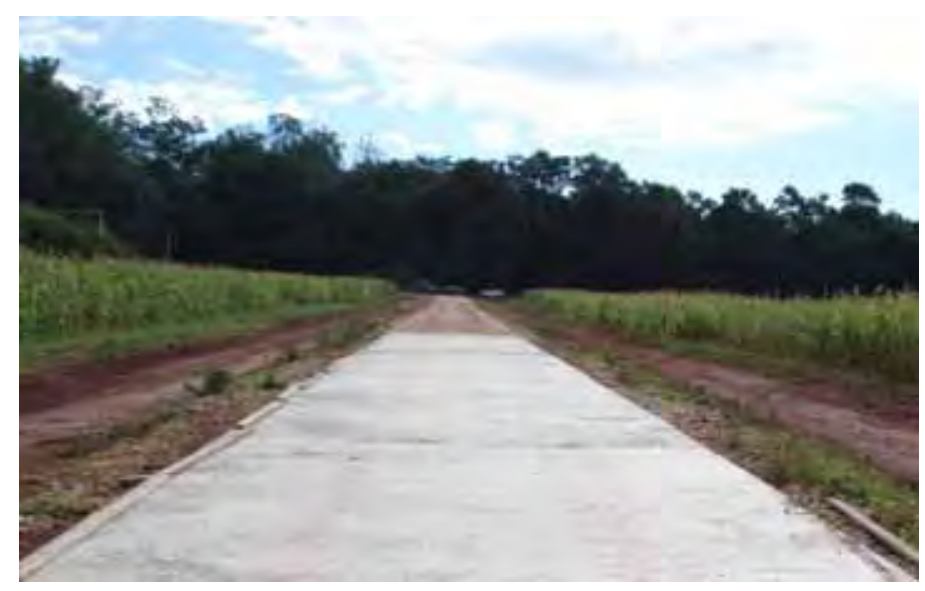

Figura 4 - Pista de concreto.

\subsubsection{Pista de solo firme}

Para adequação desta pista às condições pré-estabelecidas foram realizadas dessecações da vegetação presente na área e depois utilizada uma moto niveladora para uniformizar a superfície e retirar os restos da vegetação, posteriormente utilizou-se um rolo compactador para o acabamento superficial das camadas compactadas (Figura 5). 


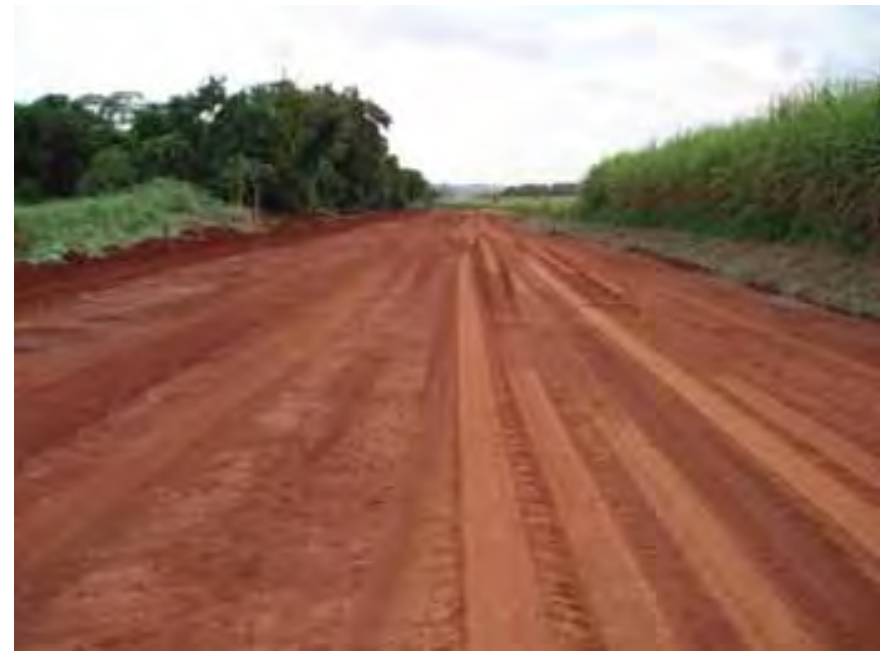

Figura 5 - Pista de solo firme.

\subsubsection{Pista de solo mobilizado}

A mobilização do solo desta área foi realizada conforme o preparo utilizado em sistemas de cultivo convencionais, com uma aração e duas gradagens. Para possibilitar a mobilização do solo nesta área, foi efetuada uma dessecação da vegetação existente e utilizado um escarificador com rolo destorroador para romper a camada compactada (Figura 6).

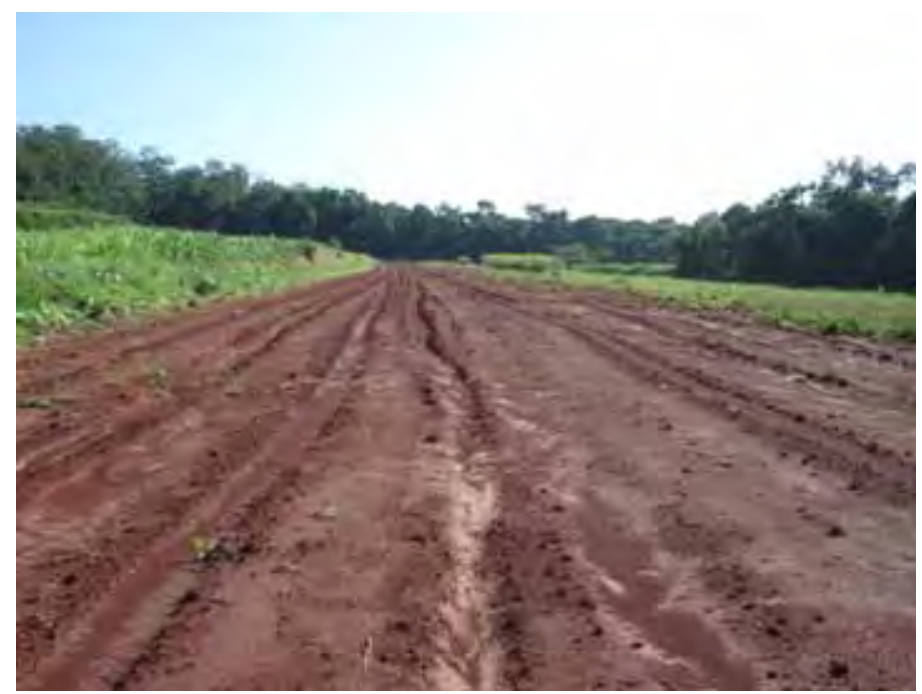

Figura 6 - Pista de solo mobilizado. 


\subsubsection{Pistas de solo com cobertura vegetal}

As coberturas vegetais utilizadas nas pistas de ensaios, dependendo do caso, foram: culturas de Braquiária (Brachiaria decumbens), restos da cultura do milho (Zea mays) e de cana-de-açúcar (Saccharum officinarum) (Figura 7). Utilizou-se diferentes tipos de cobertura vegetal para se obter um valor geral de rendimento sob a mesma, pois o tipo de cobertura pode causar mudanças no rendimento energético do trator, segundo Gabriel Filho et al., (2004)
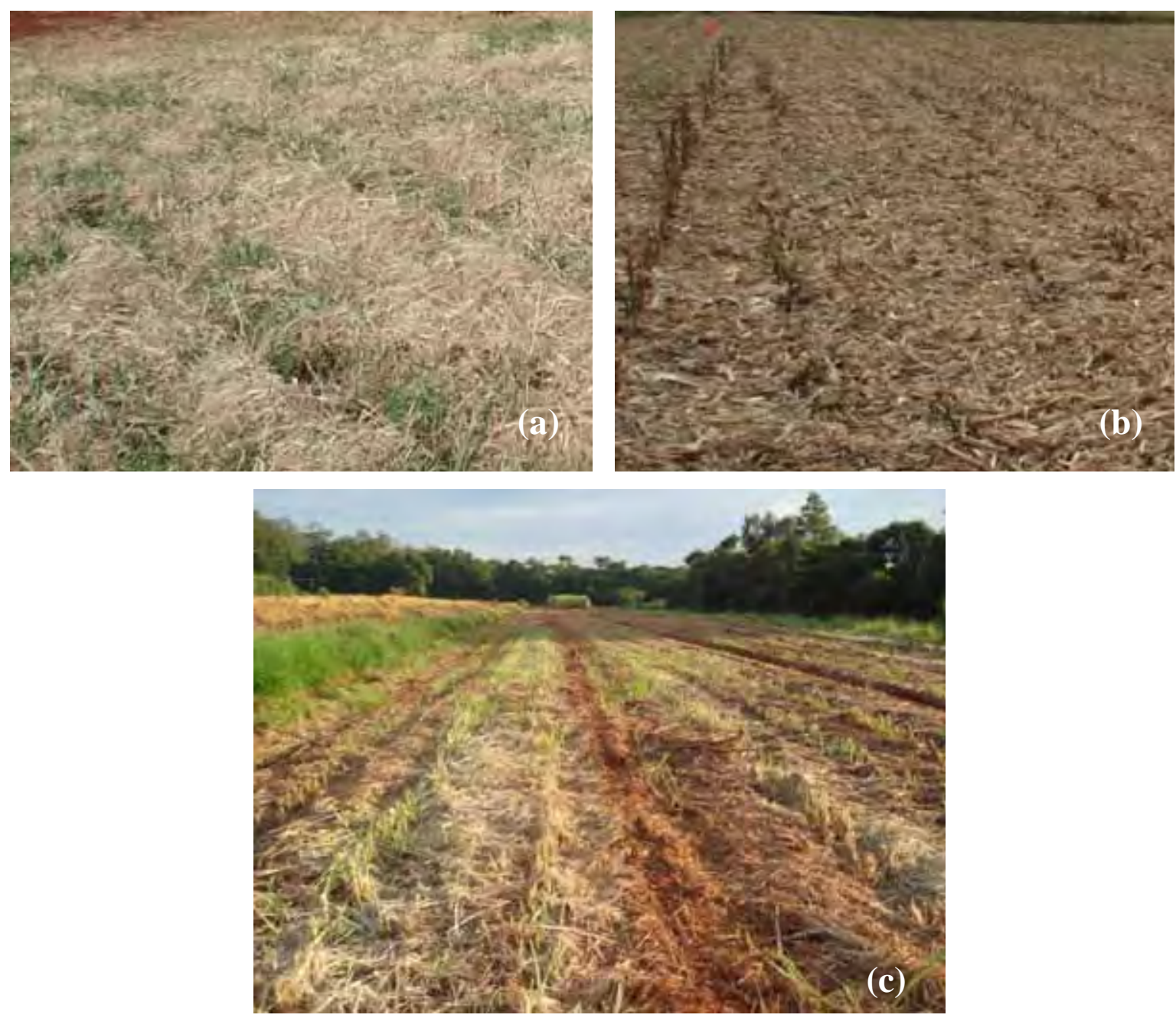

Figura 7 - Pistas de solo com cobertura vegetal: braquiária (a), restos da cultura do milho (b) e restos da cultura de cana-de-açúcar (c). 


\subsubsection{Carro dinamométrico ou de frenagem - UMEB}

O experimento foi realizado utilizando-se um equipamento descrito por Gabriel Filho et al. (2008) e Monteiro et al. (2007) que simula forças na barra de tração do trator, UMEB - Unidade Móvel de Ensaio na Barra de Tração (Figura 8), pertencente ao Núcleo de Ensaios de Máquinas e Pneus Agroflorestais (NEMPA), do Departamento de Engenharia Rural da Faculdade de Ciências Agronômicas - Universidade Estadual Paulista (FCA/UNESP), campus de Botucatu, Estado de São Paulo.

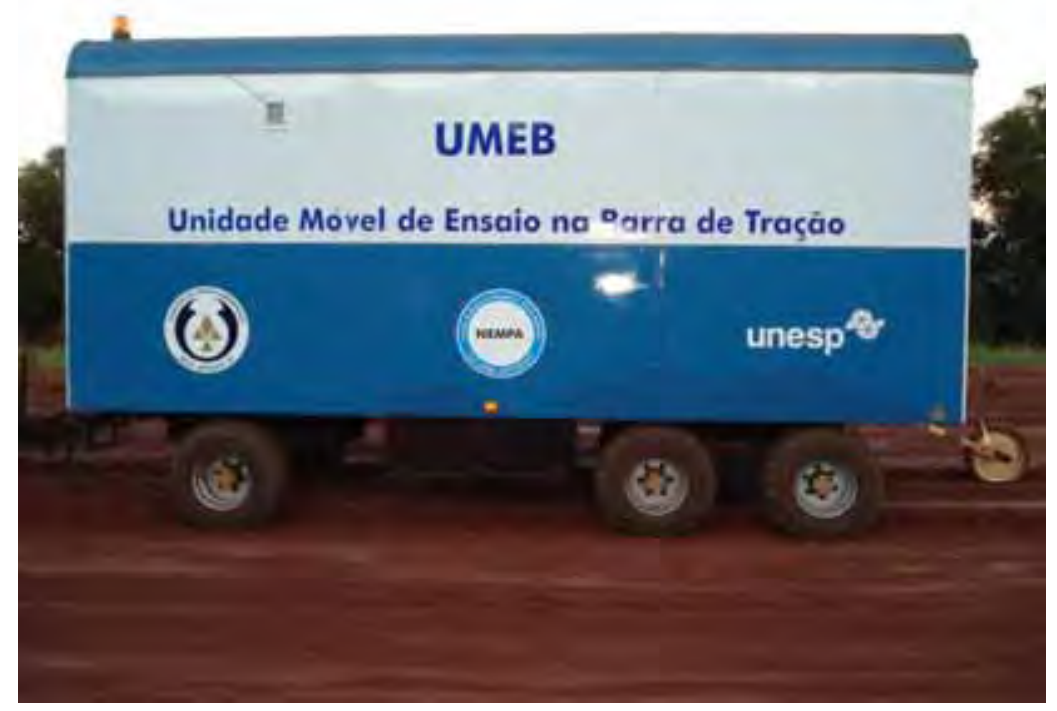

Figura 8 - Unidade Móvel de Ensaio na Barra de Tração (UMEB).

\subsubsection{Tratores e conjuntos de pneus}

Os tratores agrícolas, relações entre o peso e a potência do motor, velocidades teóricas, pistas de ensaios, conjuntos de pneus, pressões utilizadas nos ensaios e respectivas siglas utilizadas para denominação dos ensaios estão descritos nos itens a seguir. A rotação nominal do motor utilizada nos tratores foi a de maior potência (rated speed) conforme catálogo dos fabricantes. 


\subsubsection{Trator (A)}

Trator com $62 \mathrm{~kW}(85 \mathrm{cv})$ de potência no motor e equipado com os conjuntos de pneus e pressões de inflação descritos na Tabela 3. Os dados referentes a relação entre peso e potência do trator e velocidade teórica adotados nos ensaios estão descritos na Tabela 4 de acordo com a superfície do solo.

Tabela 3 - Conjuntos e pressões de inflação dos pneus utilizados no trator (A).

\begin{tabular}{ccccc}
\hline & Pneus & & \multicolumn{2}{c}{ Pressão de Inflação - kPa (psi) } \\
Conjunto & Dianteiros & Traseiros & Dianteiros & Traseiros \\
\hline A1 & $12.4-24$ R1 & $18.4-30 \mathrm{R} 1$ & $110,4(16)$ & $110,4(16)$ \\
A2 & $14.9-24$ R2 & $23.1-26$ R2 & $96,6(14)$ & $124,2(18)$ \\
\hline
\end{tabular}

Tabela 4 - Denominação das parcelas de acordo com o pneu utilizado, relação entre peso e potência, velocidade teórica adotada e superfície trativa.

\begin{tabular}{|c|c|c|c|}
\hline $\begin{array}{l}\text { Trator e } \\
\text { Conjunto }\end{array}$ & $\begin{array}{c}\text { Relação peso/potência } \\
\text { N.kW }{ }^{-1}\left(\mathrm{kgf.cv}^{-1}\right)\end{array}$ & $\begin{array}{c}\text { Velocidade teórica } \\
\left(\mathbf{k m} \cdot \mathrm{h}^{-\mathbf{1}}\right)\end{array}$ & Denominação \\
\hline \multicolumn{4}{|c|}{ Pista de Solo Firme } \\
\hline \multirow{9}{*}{ A1 } & \multirow{3}{*}{$668(50)$} & 5,4 & A1R50,0V5,4 \\
\hline & & 7,8 & A1R50,0V7,8 \\
\hline & & 10,6 & A1R50,0V10,6 \\
\hline & \multirow{3}{*}{$708(53)$} & 5,4 & A1R53,0V5,4 \\
\hline & & 7,8 & A1R53,0V7,8 \\
\hline & & 10,6 & A1R53,0V10,6 \\
\hline & \multirow{6}{*}{$762(57)$} & 5,4 & A1R57,0V5,4 \\
\hline & & 7,8 & A1R57,0V7,8 \\
\hline & & 10,6 & A1R57,0V10,6 \\
\hline \multirow{3}{*}{$\mathrm{A} 2$} & & 5,4 & A2R57,0V5,4 \\
\hline & & 7,8 & A2R57,0V7,8 \\
\hline & & 10,6 & A2R57,0V10,6 \\
\hline \multicolumn{4}{|c|}{ Pista de Solo com Cobertura Vegetal } \\
\hline \multirow{3}{*}{ A1 } & $668(50)$ & \multirow{4}{*}{10,6} & A1R50,0V10,6 \\
\hline & \multirow{3}{*}{$708(53)$} & & A1R53,0V10,6a \\
\hline & & & A1R53,0V10,6b \\
\hline A2 & & & A2R53,0V10,6 \\
\hline
\end{tabular}

Continua... 
Continuação da Tabela 4.

\begin{tabular}{|c|c|c|c|}
\hline \multicolumn{4}{|c|}{ Pista de Solo Mobilizado } \\
\hline \multirow{5}{*}{ A1 } & $668(50)$ & 5,4 & A1R50,0V5,4 \\
\hline & \multirow{2}{*}{$708(53)$} & 5,4 & A1R53,0V5,4 \\
\hline & & 7,8 & A1R53,0V7,8 \\
\hline & \multirow{4}{*}{$762(57)$} & 5,4 & A1R57,0V5,4 \\
\hline & & 7,8 & A1R57,0V7,8 \\
\hline \multirow{2}{*}{ A2 } & & 5,4 & A2R57,0V5,4 \\
\hline & & 7,8 & A2R57,0V7,8 \\
\hline
\end{tabular}

\subsubsection{Trator $(B)$}

Trator com $62 \mathrm{~kW}(85 \mathrm{cv})$ de potência no motor e equipado com o conjunto de pneus e pressões de inflação descritos na Tabela 5. Os dados referentes a relação entre peso e potência do trator e velocidade teórica adotados nos ensaios estão descritos na Tabela 6 de acordo com a superfície trativa.

Tabela 5 - Conjunto e pressões de inflação dos pneus utilizado no trator (B).

\begin{tabular}{ccccc}
\hline & Pneus & & \multicolumn{2}{c}{ Pressão de Inflação - kPa (psi) } \\
Conjunto & Dianteiros & Traseiros & Dianteiros & Traseiros \\
\hline B1 & $12.4-24$ & $18.4-30$ & $82,8(12)$ & $151,8(22)$ \\
\hline
\end{tabular}

Tabela 6 - Denominação das parcelas de acordo com o pneu utilizado, relação entre peso e potência, velocidade teórica adotada e superfície trativa.

\begin{tabular}{|c|c|c|c|}
\hline $\begin{array}{l}\text { Trator e } \\
\text { Conjunto }\end{array}$ & $\begin{array}{c}\text { Relação peso/potência } \\
\text { N.kW }{ }^{-1}\left(\mathrm{kgf.cv}^{-1}\right)\end{array}$ & $\begin{array}{c}\text { Velocidade teórica } \\
\left(\mathbf{k m} \cdot \mathrm{h}^{-1}\right)\end{array}$ & Denominação \\
\hline \multicolumn{4}{|c|}{\begin{tabular}{|l} 
Pista de Solo Firme \\
\end{tabular}} \\
\hline \multirow{3}{*}{ B1 } & \multirow{3}{*}{$762(57)$} & 7,0 & B1R57,0V7,0 \\
\hline & & 8,6 & B1R57,0V8,6 \\
\hline & & 10,7 & B1R57,0V10,7 \\
\hline \multicolumn{4}{|c|}{ Pista de Solo com Cobertura Vegetal } \\
\hline B1 & $762(57)$ & 10,7 & B1R57,0V10,7 \\
\hline \multicolumn{4}{|c|}{ Pista de Solo Mobilizado } \\
\hline \multirow{2}{*}{ B1 } & \multirow{2}{*}{$762(57)$} & 7,0 & B1R57,0V7,0 \\
\hline & & 8,6 & B1R57,0V8,6 \\
\hline
\end{tabular}




\subsubsection{Trator $(C)$}

Trator com $77 \mathrm{~kW}(105 \mathrm{cv})$ de potência no motor e equipado com o conjunto de pneus e pressões de inflação descritos na Tabela 7. Os dados referentes a relação entre peso e potência do trator e velocidade teórica adotados nos ensaios estão descritos na Tabela 8 de acordo com a superfície trativa.

Tabela 7 - Conjunto e pressão de inflação dos pneus utilizado no trator (C).

\begin{tabular}{ccccc}
\hline & Pneus & & \multicolumn{2}{c}{ Pressão de Inflação - kPa (psi) } \\
Conjunto & Dianteiros & Traseiros & Dianteiros & Traseiros \\
\hline $\mathrm{C} 1$ & $14.9-26$ & $23.1-30$ & $110,4(16)$ & $110,4(16)$ \\
\hline
\end{tabular}

Tabela 8 - Denominação das parcelas de acordo com o pneu utilizado, relação entre peso e potência, velocidade teórica adotada e superfície trativa.

\begin{tabular}{|c|c|c|c|}
\hline $\begin{array}{l}\text { Trator e } \\
\text { Conjunto }\end{array}$ & $\begin{array}{c}\text { Relação peso/potência } \\
\left.\text { N.kW }{ }^{-1} \text { (kgf.cv }^{-1}\right)\end{array}$ & $\begin{array}{c}\text { Velocidade teórica } \\
\left(\mathbf{k m} \cdot \mathrm{h}^{-1}\right)\end{array}$ & Denominação \\
\hline \multicolumn{4}{|c|}{ Pista de Concreto } \\
\hline \multirow{10}{*}{$\mathrm{C} 1$} & \multirow{5}{*}{$762(57)$} & 5,0 & C1R57,0V5,0 \\
\hline & & 6,5 & C1R57,0V6,5 \\
\hline & & 7,8 & C1R57,0V7,8 \\
\hline & & 8,3 & C1R57,0V8,3 \\
\hline & & 10,4 & C1R57,0V10,4 \\
\hline & \multirow{5}{*}{$668(50)$} & 5,0 & C1R50,0V5,0 \\
\hline & & 6,5 & C1R50,0V6,5 \\
\hline & & 7,8 & C1R50,0V7,8 \\
\hline & & 8,3 & C1R50,0V8,3 \\
\hline & & 10,4 & C1R50,0V10,4 \\
\hline \multicolumn{4}{|c|}{ Pista de Solo Firme } \\
\hline \multirow{5}{*}{$\mathrm{C} 1$} & \multirow{5}{*}{$762(57)$} & 5,0 & C1R57,0V5,0 \\
\hline & & 6,5 & C1R57,0V6,5 \\
\hline & & 7,8 & C1R57,0V7,8 \\
\hline & & 8,3 & C1R57,0V8,3 \\
\hline & & 10,4 & C1R57,0V10,4 \\
\hline
\end{tabular}




\subsubsection{Trator (D)}

Trator com $77 \mathrm{~kW}(105 \mathrm{cv})$ de potência no motor e equipado com o conjunto de pneus e pressões de inflação descritos na Tabela 9. Os dados referentes a relação entre peso e potência do trator e velocidade teórica adotados nos ensaios estão descritos na Tabela 10 de acordo com a superfície trativa.

Tabela 9 - Conjunto e pressão de inflação dos pneus utilizado no trator (D).

\begin{tabular}{ccccc}
\hline & Pneus & & \multicolumn{2}{c}{ Pressão de Inflação - kPa (psi) } \\
Conjunto & Dianteiros & Traseiros & Dianteiros & Traseiros \\
\hline D1 & $14.9-26$ & $23.1-30$ & $110,4(16)$ & $110,4(16)$ \\
\hline
\end{tabular}

Tabela 10 - Denominação das parcelas de acordo com o pneu utilizado, relação entre peso e potência, velocidade teórica adotada e superfície trativa.

\begin{tabular}{|c|c|c|c|}
\hline $\begin{array}{c}\text { Trator e } \\
\text { Conjunto }\end{array}$ & $\begin{array}{c}\text { Relação peso/potência } \\
\left.\text { N.kW }{ }^{-1} \text { (kgf.cv }^{-1}\right)\end{array}$ & $\begin{array}{c}\text { Velocidade teórica } \\
\left(\mathbf{k m} \cdot \mathrm{h}^{-1}\right)\end{array}$ & Denominação \\
\hline \multicolumn{4}{|c|}{$\begin{array}{l}\text { Pista de Concreto } \\
\end{array}$} \\
\hline \multirow{8}{*}{ D1 } & \multirow{4}{*}{$762(57)$} & 5,0 & D1R57,0V5,0 \\
\hline & & 6,5 & D1R57,0V6,5 \\
\hline & & 8,3 & D1R57,0V8,3 \\
\hline & & 10,4 & D1R57,0V10,4 \\
\hline & \multirow{4}{*}{$668(50)$} & 5,0 & D1R50,0V5,0 \\
\hline & & 6,5 & D1R50,0V6,5 \\
\hline & & 8,3 & D1R50,0V8,3 \\
\hline & & 10,4 & D1R50,0V10,4 \\
\hline \multicolumn{4}{|c|}{ Pista de Solo Firme } \\
\hline \multirow{4}{*}{ D1 } & \multirow{4}{*}{$762(57)$} & 5,0 & D1R57,0V5,0 \\
\hline & & 6,5 & D1R57,0V6,5 \\
\hline & & 8,3 & D1R57,0V8,3 \\
\hline & & 10,4 & D1R57,0V10,4 \\
\hline
\end{tabular}

\subsubsection{Trator $(\mathbf{E})$}

Trator com $88 \mathrm{~kW}(120 \mathrm{cv})$ de potência no motor e equipado com o conjunto de pneus e pressões de inflação descritos na Tabela 11. Os dados referentes a relação 
entre peso e potência do trator e velocidade teórica adotados nos ensaios estão descritos na Tabela 12, realizado somente na superfície trativa de solo firme.

Tabela 11 - Conjunto e pressões de inflação dos pneus utilizado no trator (E).

\begin{tabular}{ccccc}
\hline & Pneus & & \multicolumn{2}{c}{ Pressão de Inflação - kPa (psi) } \\
Conjunto & Dianteiros & Traseiros & Dianteiros & Traseiros \\
\hline E1 & $14.9-26$ & $23.1-30$ & $69(10)$ & $69(10)$ \\
E2 & $14.9-26$ & $23.1-30$ & $96,6(14)$ & $96,6(14)$ \\
E3 & $14.9-26$ & $23.1-30$ & $124,2(18)$ & $124,2(18)$ \\
E4 & $14.9-26$ & $23.1-30$ & $165,6(24)$ & $165,6(24)$ \\
\hline
\end{tabular}

Tabela 12 - Denominação das parcelas de acordo com o pneu utilizado, relação entre peso e potência, velocidade teórica adotada em superfície trativa de solo firme.

\begin{tabular}{|c|c|c|c|}
\hline $\begin{array}{l}\text { Trator e } \\
\text { Conjunto }\end{array}$ & $\begin{array}{c}\text { Relação peso/potência } \\
\text { N.kW'1 }\left(\mathrm{kgf.cv}^{-1}\right)\end{array}$ & $\begin{array}{l}\text { Velocidade teórica } \\
\left(\mathbf{k m} \cdot \mathrm{h}^{-1}\right)\end{array}$ & Denominação \\
\hline \multicolumn{4}{|c|}{ Pista de Solo Firme } \\
\hline E1 & $780(58,4)$ & \multirow{7}{*}{7,0} & E1R58,4V7,0 \\
\hline \multirow{4}{*}{$\mathrm{E} 2$} & $668(50)$ & & E2R50,0V7,0 \\
\hline & $703(52,5)$ & & E2R52,5V7,0 \\
\hline & $750(56,2)$ & & E2R56,2V7,0 \\
\hline & \multirow{3}{*}{$780(58,4)$} & & E2R58,4V7,0 \\
\hline E3 & & & E3R58,4V7,0 \\
\hline E4 & & & E4R58,4V7,0 \\
\hline
\end{tabular}

\subsubsection{Trator $(\mathbf{F})$}

Trator com $118 \mathrm{~kW}(160 \mathrm{cv})$ de potência no motor e equipado com os conjuntos de pneus e pressões de inflação descritos na Tabela 13. Os dados referentes a relação entre peso e potência do trator e velocidade teórica adotados nos ensaios estão descritos nas Tabelas 14, 15 e 16, de acordo com a superfície do solo. 
Tabela 13 - Conjuntos e pressões de inflação dos pneus utilizados no trator (F).

\begin{tabular}{ccccc}
\hline & Pneus & & \multicolumn{2}{c}{ Pressão de Inflação - kPa (psi) } \\
Conjunto & Dianteiros & Traseiros & Dianteiros & Traseiros \\
\hline F1 & $18.4-26$ & $24.5-32$ & $110,4(16)$ & $110,4(16)$ \\
F2 & $16.9-30$ & $24.5-32$ & $110,4(16)$ & $138(20)$ \\
F3 & $20.4-30$ & $20.8-38$ & $138(20)$ & $124,2(18)$ \\
F4 & $18.4-26$ & $24.5-32$ & $124,2(18)$ & $124,2(18)$ \\
\hline
\end{tabular}

Tabela 14 - Denominação das parcelas de acordo com o pneu utilizado, relação entre peso e potência e velocidade teórica adotada em pista de solo firme.

\begin{tabular}{|c|c|c|c|}
\hline $\begin{array}{l}\text { Trator e } \\
\text { Conjunto }\end{array}$ & $\begin{array}{c}\text { Relação peso/potência } \\
\text { N.kW }{ }^{-1}\left(\mathrm{kgf.cv}^{-1}\right)\end{array}$ & $\begin{array}{c}\text { Velocidade teórica } \\
\left(\mathbf{k m} \cdot \mathrm{h}^{-1}\right)\end{array}$ & Denominação \\
\hline \multicolumn{4}{|c|}{ Pista de Solo Firme } \\
\hline \multirow{6}{*}{$\mathrm{F} 1$} & \multirow{3}{*}{$703(52,5)$} & 5,0 & F1R52,5V5,0 \\
\hline & & 5,8 & F1R52,5V5,8 \\
\hline & & 6,7 & F1R52,5V6,7 \\
\hline & \multirow{3}{*}{$735(55)$} & 5,0 & F1R55,0V5,0 \\
\hline & & 5,8 & F1R55,0V5,8 \\
\hline & & 6,7 & F1R55,0V6,7 \\
\hline \multirow{9}{*}{$\mathrm{F} 2$} & \multirow{3}{*}{$703(52,5)$} & 5,0 & F2R52,5V5,0 \\
\hline & & 5,8 & F2R52,5V5,8 \\
\hline & & 6,7 & F2R52,5V6,7 \\
\hline & \multirow{3}{*}{$735(55)$} & 5,0 & F2R55,0V5,0 \\
\hline & & 5,8 & F2R55,0V5,8 \\
\hline & & 6,7 & F2R55,0V6,7 \\
\hline & \multirow{3}{*}{$768(57,5)$} & 5,0 & F2R57,5V5,0 \\
\hline & & 5,8 & F2R57,5V5,8 \\
\hline & & 6,7 & F2R57,5V6,7 \\
\hline \multirow{3}{*}{ F3 } & \multirow{3}{*}{$762(57)$} & 5,0 & F3R57,0V5,0 \\
\hline & & 5,8 & F3R57,0V5,8 \\
\hline & & 6,7 & F3R57,0V6,7 \\
\hline \multirow{3}{*}{$\mathrm{F} 4$} & \multirow{3}{*}{$768(57,5)$} & 5,0 & F4R57,5V5,0 \\
\hline & & 5,8 & F4R57,5V5,8 \\
\hline & & 6,7 & F4R57,5V6,7 \\
\hline
\end{tabular}


Tabela 15 - Denominação das parcelas de acordo com o pneu utilizado, relação entre peso e potência e velocidade teórica adotada em pista de solo com cobertura vegetal.

\begin{tabular}{|c|c|c|c|}
\hline $\begin{array}{l}\text { Trator e } \\
\text { Conjunto }\end{array}$ & $\begin{array}{c}\text { Relação peso/potência } \\
\left.\text { N.kW }{ }^{-1} \text { (kgf.cv }^{-1}\right)\end{array}$ & $\begin{array}{c}\text { Velocidade teórica } \\
\left(\mathbf{k m} \cdot \mathrm{h}^{-1}\right)\end{array}$ & Denominação \\
\hline \multicolumn{4}{|c|}{ Pista de Solo com Cobertura Vegetal } \\
\hline \multirow{3}{*}{$\mathrm{F} 1$} & \multirow{3}{*}{$735(55)$} & 5,0 & F1R55,0V5,0 \\
\hline & & 5,8 & F1R55,0V5,8 \\
\hline & & 6,7 & F1R55,0V6,7 \\
\hline \multirow{9}{*}{$\mathrm{F} 2$} & \multirow{3}{*}{$703(52,5)$} & 5,0 & F2R52,5V5,0 \\
\hline & & 5,8 & F2R52,5V5,8 \\
\hline & & 6,7 & F2R52,5V6,7 \\
\hline & \multirow{3}{*}{$735(55)$} & 5,0 & F2R55,0V5,0 \\
\hline & & 5,8 & F2R55,0V5,8 \\
\hline & & 6,7 & F2R55,0V6,7 \\
\hline & \multirow{3}{*}{$768(57,5)$} & 5,0 & F2R57,5V5,0 \\
\hline & & 5,8 & F2R57,5V5,8 \\
\hline & & 6,7 & F2R57,5V6,7 \\
\hline \multirow{3}{*}{ F3 } & \multirow{3}{*}{$762(57)$} & 5,0 & F3R57,0V5,0 \\
\hline & & 5,8 & F3R57,0V5,8 \\
\hline & & 6,7 & F3R57,0V6,7 \\
\hline \multirow{3}{*}{$\mathrm{F} 4$} & \multirow{3}{*}{$768(57,5)$} & 5,0 & F4R57,5V5,0 \\
\hline & & 5,8 & F4R57,5V5,8 \\
\hline & & 6,7 & F4R57,5V6,7 \\
\hline
\end{tabular}

Tabela 16 - Denominação das parcelas de acordo com o pneu utilizado, relação entre peso e potência e velocidade teórica adotada em pista de solo mobilizado.

\begin{tabular}{|c|c|c|c|}
\hline $\begin{array}{l}\text { Trator e } \\
\text { Conjunto }\end{array}$ & $\begin{array}{c}\text { Relação peso/potência } \\
\text { N.kW }{ }^{-1}\left(\mathrm{kgf.cv}^{-1}\right)\end{array}$ & $\begin{array}{c}\text { Velocidade teórica } \\
\left(\mathbf{k m} \cdot \mathrm{h}^{-1}\right)\end{array}$ & Denominação \\
\hline \multicolumn{4}{|c|}{ Pista de Solo Mobilizado } \\
\hline \multirow{6}{*}{$\mathrm{F} 1$} & \multirow{3}{*}{$703(52,5)$} & 5,0 & F1R52,5V5,0 \\
\hline & & 5,8 & F1R52,5V5,8 \\
\hline & & 6,7 & F1R52,5V6,7 \\
\hline & \multirow{3}{*}{$735(55)$} & 5,0 & F1R55,0V5,0 \\
\hline & & 5,8 & F1R55,0V5,8 \\
\hline & & 6,7 & F1R55,0V6,7 \\
\hline \multirow{2}{*}{$\mathrm{F} 2$} & \multirow{2}{*}{$703(52,5)$} & 5,0 & F2R52,5V5,0 \\
\hline & & 5,8 & F2R52,5V5,8 \\
\hline
\end{tabular}

Continua... 
Continuação da Tabela 16.

\begin{tabular}{|c|c|c|c|}
\hline \multirow{7}{*}{$\mathrm{F} 2$} & $703(52,5)$ & 6,7 & F2R52,5V6,7 \\
\hline & \multirow{3}{*}{$735(55)$} & 5,0 & F2R55,0V5,0 \\
\hline & & 5,8 & F2R55,0V5,8 \\
\hline & & 6,7 & F2R55,0V6,7 \\
\hline & \multirow{3}{*}{$768(57,5)$} & 5,0 & F2R57,5V5,0 \\
\hline & & 5,8 & F2R57,5V5,8 \\
\hline & & 6,7 & F2R57,5V6,7 \\
\hline \multirow{3}{*}{ F3 } & \multirow{3}{*}{$762(57)$} & 5,0 & F3R57,0V5,0 \\
\hline & & 5,8 & F3R57,0V5,8 \\
\hline & & 6,7 & F3R57,0V6,7 \\
\hline \multirow{3}{*}{$\mathrm{F} 4$} & \multirow{3}{*}{$768(57,5)$} & 5,0 & F4R57,5V5,0 \\
\hline & & 5,8 & F4R57,5V5,8 \\
\hline & & 6,7 & F4R57,5V6,7 \\
\hline
\end{tabular}

\subsubsection{Trator $(G)$}

Trator com 118 kW (160 cv) de potência no motor, referente ao trator (F) equipado com rodados duplos traseiros, os conjuntos de pneus e pressões de inflação utilizados estão descritos na Tabela 17. Os dados referentes a relação entre peso e potência do trator e velocidade teórica adotados nos ensaios estão descritos na Tabela 18 de acordo com a superfície do solo.

Tabela 17 - Conjuntos e pressões de inflação dos pneus utilizados no trator (G).

Pneus

\begin{tabular}{ccccc}
\hline & Pneus & & \multicolumn{2}{c}{ Pressão de Inflação - kPa (psi) } \\
Conjunto & Dianteiros & Traseiros & Dianteiros & Traseiros \\
\hline G1 & $18.4-26$ & $20.8-38$ & $151,8(22)$ & 96,6 e 110,4 (14 e 16) \\
G2 & $16.9-30$ & $20.8-38$ & $138(20)$ & 127,6 e $110,4(18,5$ e 16) \\
\hline
\end{tabular}

Pressão de Inflação - kPa (psi) 
Tabela 18 - Denominação das parcelas de acordo com o pneu utilizado, relação entre peso e potência, velocidade teórica adotada e superfície trativa.

\begin{tabular}{|c|c|c|c|}
\hline $\begin{array}{l}\text { Trator e } \\
\text { Conjunto }\end{array}$ & $\begin{array}{c}\text { Relação peso/potência } \\
\text { N.kW'1 }\left(\mathrm{kgf.cv}^{-1}\right)\end{array}$ & $\begin{array}{c}\text { Velocidade teórica } \\
\left(\mathbf{k m} \cdot \mathrm{h}^{-1}\right)\end{array}$ & Denominação \\
\hline \multicolumn{4}{|c|}{ Pista de Solo Firme } \\
\hline \multirow{3}{*}{ G1 } & \multirow{6}{*}{$762(57)$} & 5,0 & G1R57,0V5,0 \\
\hline & & 5,8 & G1R57,0V5,8 \\
\hline & & 6,7 & G1R57,0V6,7 \\
\hline \multirow{3}{*}{$\mathrm{G} 2$} & & 5,0 & G2R57,0V5,0 \\
\hline & & 5,8 & G2R57,0V5,8 \\
\hline & & 6,7 & G2R57,0V6,7 \\
\hline \multicolumn{4}{|c|}{ Pista de Solo com Cobertura Vegetal } \\
\hline \multirow{3}{*}{ G1 } & \multirow{6}{*}{$762(57)$} & 5,0 & G1R57,0V5,0 \\
\hline & & 5,8 & G1R57,0V5,8 \\
\hline & & 6,7 & G1R57,0V6,7 \\
\hline \multirow{3}{*}{$\mathrm{G} 2$} & & 5,0 & G2R57,0V5,0 \\
\hline & & 5,8 & G2R57,0V5,8 \\
\hline & & 6,7 & G2R57,0V6,7 \\
\hline \multicolumn{4}{|c|}{ Pista de Solo Mobilizado } \\
\hline \multirow{3}{*}{ G1 } & \multirow{6}{*}{$762(57)$} & 5,0 & G1R57,0V5,0 \\
\hline & & 5,8 & G1R57,0V5,8 \\
\hline & & 6,7 & G1R57,0V6,7 \\
\hline \multirow{3}{*}{$\mathrm{G} 2$} & & 5,0 & G2R57,0V5,0 \\
\hline & & 5,8 & G2R57,0V5,8 \\
\hline & & 6,7 & G2R57,0V6,7 \\
\hline
\end{tabular}

\subsubsection{Trator $(\mathbf{H})$}

Trator com $118 \mathrm{~kW}(160 \mathrm{cv})$ de potência no motor e equipado com o conjunto de pneus e pressão de inflação descritos na Tabela 19. Os dados referentes a relação entre peso e potência do trator e velocidade teórica adotados nos ensaios estão descritos na Tabela 20, realizado somente na superfície trativa de solo firme. 
Tabela 19 - Conjunto e pressão de inflação dos pneus utilizado no trator $(\mathrm{H})$.

\begin{tabular}{ccccc}
\hline & Pneus & & \multicolumn{2}{c}{ Pressão de Inflação - kPa (psi) } \\
Conjunto & Dianteiros & Traseiros & Dianteiros & Traseiros \\
\hline H1 & $18.4-26$ R1 & $24.5-32$ R1 & $124,2(18)$ & $124,2(18)$ \\
\hline
\end{tabular}

Tabela 20 - Denominação das parcelas de acordo com o pneu utilizado, relação entre peso e potência, velocidade teórica adotada em superfície de solo firme.

\begin{tabular}{|c|c|c|c|}
\hline $\begin{array}{c}\text { Trator e } \\
\text { Conjunto }\end{array}$ & $\begin{array}{c}\text { Relação peso/potência } \\
\left.\text { N.kW'1 } \text { (kgf.cv }^{-1}\right)\end{array}$ & $\begin{array}{c}\text { Velocidade teórica } \\
\left(\mathbf{k m} \cdot \mathrm{h}^{-1}\right)\end{array}$ & Denominação \\
\hline \multicolumn{4}{|c|}{ Pista de Solo Firme } \\
\hline \multirow{7}{*}{$\mathrm{H} 1$} & \multirow{7}{*}{$735(55)$} & 4,4 & H1R55,0V4,4 \\
\hline & & 5,0 & H1R55,0V5,0 \\
\hline & & 8,2 & H1R55,0V8,2 \\
\hline & & 9,6 & H1R55,0V9,6 \\
\hline & & 11,5 & H1R55,0V11,5 \\
\hline & & 13,2 & H1R55,0V13,2 \\
\hline & & 15,6 & H1R55,0V15,6 \\
\hline
\end{tabular}

\subsubsection{Trator $(I)$}

Trator com $132 \mathrm{~kW}(180 \mathrm{cv})$ de potência no motor e equipado com os conjuntos de pneus e pressões de inflação descritos na Tabela 21. Os dados referentes a relação entre peso e potência do trator e velocidade teórica adotados nos ensaios estão descritos na Tabela 22 de acordo com a superfície trativa.

Tabela 21 - Conjuntos e pressões de inflação dos pneus utilizados no trator (I).

\begin{tabular}{ccccc}
\hline & Pneus & & \multicolumn{2}{c}{ Pressão de Inflação - kPa (psi) } \\
Conjunto & Dianteiros & Traseiros & Dianteiros & Traseiros \\
\hline I1 & $600 / 65 R 28$ & $710 / 70 R 38$ & $82,8(12)$ & $69(10)$ \\
I2 & $18.4-26$ & $30.5 \mathrm{~L}-32$ & $110,4(16)$ & $110,4(16)$ \\
I3 & $600 / 65 \mathrm{R} 28$ & $710 / 70 \mathrm{R} 38$ & $82,8(12)$ & $82,8(12)$ \\
\hline
\end{tabular}


Tabela 22 - Denominação das parcelas de acordo com o pneu utilizado, relação entre peso e potência, velocidade teórica adotada e superfície trativa.

\begin{tabular}{|c|c|c|c|}
\hline $\begin{array}{l}\text { Trator e } \\
\text { Conjunto }\end{array}$ & $\begin{array}{c}\text { Relação peso/potência } \\
\text { N.kW'1 }\left(\mathrm{kgf.cv}^{-1}\right)\end{array}$ & $\begin{array}{c}\text { Velocidade teórica } \\
\left(\mathbf{k m} \cdot \mathrm{h}^{-1}\right)\end{array}$ & Denominação \\
\hline \multicolumn{4}{|c|}{ Pista de Solo Firme } \\
\hline \multirow{7}{*}{ I1 } & \multirow{7}{*}{$768(57,5)$} & 4,5 & I1R57,5V4,5 \\
\hline & & 5,0 & I1R57,5V5,0 \\
\hline & & 6,0 & I1R57,5V6,0 \\
\hline & & 7,5 & I1R57,5V7,5 \\
\hline & & 8,0 & I1R57,5V8,0 \\
\hline & & 9,0 & I1R57,5V9,0 \\
\hline & & 10,0 & I1R57,5V10,0 \\
\hline \multirow{6}{*}{$\mathrm{I} 2$} & \multirow{3}{*}{$605(45,3)$} & 6,0 & I2R45,3V6,0 \\
\hline & & 7,0 & $\mathrm{I} 2 \mathrm{R} 45,3 \mathrm{~V} 7,0$ \\
\hline & & 9,0 & I2R45,3V9,0 \\
\hline & \multirow{3}{*}{$730(54,6)$} & 6,0 & I2R54,6V6,0 \\
\hline & & 7,0 & I2R54,6V7,0 \\
\hline & & 9,0 & I2R54,6V9,0 \\
\hline \multirow{6}{*}{$\mathrm{I} 3$} & \multirow{3}{*}{$605(45,3)$} & 6,0 & I3R45,3V6,0 \\
\hline & & 7,0 & I3R45,3V7,0 \\
\hline & & 9,0 & I3R45,3V9,0 \\
\hline & \multirow{3}{*}{$730(54,6)$} & 6,0 & I3R54,6V6,0 \\
\hline & & 7,0 & I3R54,6V7,0 \\
\hline & & 9,0 & I3R54,6V9,0 \\
\hline \multicolumn{4}{|c|}{ Pista de Solo Mobilizado } \\
\hline \multirow{2}{*}{$\mathrm{I} 2$} & \multirow{4}{*}{$730(54,6)$} & \multirow{4}{*}{7,0} & I2R54,6V7,0a \\
\hline & & & I2R54,6V7,0b \\
\hline \multirow{2}{*}{$\mathrm{I} 3$} & & & I3R54,6V7,0a \\
\hline & & & I3R54,6V7,0b \\
\hline
\end{tabular}

\subsubsection{Trator $(\mathbf{J})$}

Trator com $132 \mathrm{~kW}(180 \mathrm{cv})$ de potência no motor e equipado com os conjuntos de pneus e pressões de inflação descritos na Tabela 23. Os dados referentes a relação entre peso e potência do trator e velocidade teórica adotados nos ensaios estão descritos nas Tabelas 24, 25 e 26 de acordo com a superfície trativa. 
Tabela 23 - Conjuntos e pressões de inflação dos pneus utilizados no trator (J).

\begin{tabular}{ccccc}
\hline & Pneus & & \multicolumn{2}{c}{ Pressão de Inflação - kPa (psi) } \\
Conjunto & Dianteiros & Traseiros & Dianteiros & Traseiros \\
\hline J1 & $18.4-26$ & $24.5 \mathrm{~L}-32$ & $117,3(17)$ & $117,3(17)$ \\
J2 & $18.4-26$ & $24.5 \mathrm{~L}-32$ & $151,8(22)$ & $151,8(22)$ \\
J3 & $18.4-26$ & $24.5 \mathrm{~L}-32$ & $186,3(27)$ & $186,3(27)$ \\
J4 & $18.4-26$ & $24.5 \mathrm{~L}-32$ & $220,8(32)$ & $220,8(32)$ \\
J5 & $540 / 65 \mathrm{R} 28$ & $650 / 65 \mathrm{R} 38$ & $82,8(12)$ & $82,8(12)$ \\
J6 & 540/65R28 & $650 / 65 \mathrm{R} 38$ & $117,3(17)$ & $117,3(17)$ \\
J7 & 540/65R28 & $650 / 65 \mathrm{R} 38$ & $151,8(22)$ & $151,8(22)$ \\
J8 & 540/65R28 & 650/65R38 & $186,3(27)$ & $186,3(27)$ \\
\hline
\end{tabular}

Tabela 24 - Denominação das parcelas de acordo com o pneu utilizado, relação entre peso e potência, velocidade teórica adotada em superfície de concreto.

\begin{tabular}{|c|c|c|c|}
\hline $\begin{array}{l}\text { Trator e } \\
\text { Conjunto }\end{array}$ & $\begin{array}{c}\text { Relação peso/potência } \\
\left.\text { N.kW }{ }^{-1} \text { (kgf.cv }^{-1}\right)\end{array}$ & $\begin{array}{l}\text { Velocidade teórica } \\
\qquad\left(\mathbf{k m} \cdot \mathrm{h}^{-1}\right)\end{array}$ & Denominação \\
\hline \multicolumn{4}{|c|}{ Pista de Concreto } \\
\hline \multirow{3}{*}{$\mathrm{J} 1$} & \multirow{21}{*}{$735(55)$} & 4,8 & J1R55,0V4,8 \\
\hline & & 7,8 & J1R55,0V7,8 \\
\hline & & 9,4 & J1R55,0V9,4 \\
\hline \multirow{4}{*}{$\mathrm{J} 2$} & & 4,8 & J2R55,0V4,8 \\
\hline & & 6,5 & J2R55,0V6,5 \\
\hline & & 7,8 & J2R55,0V7,8 \\
\hline & & 9,4 & J2R55,0V9,4 \\
\hline \multirow{4}{*}{$\mathrm{J} 3$} & & 4,8 & J3R55,0V4,8 \\
\hline & & 6,5 & J3R55,0V6,5 \\
\hline & & 7,8 & J3R55,0V7,8 \\
\hline & & 9,4 & J3R55,0V9,4 \\
\hline \multirow{4}{*}{$\mathrm{J} 4$} & & 4,8 & J4R55,0V4,8 \\
\hline & & 6,5 & J4R55,0V6,5 \\
\hline & & 7,8 & $\mathrm{~J} 4 \mathrm{R} 55,0 \mathrm{~V} 7,8$ \\
\hline & & 9,4 & J4R55,0V9,4 \\
\hline \multirow{4}{*}{$\mathrm{J} 5$} & & 4,8 & J5R55,0V4,8 \\
\hline & & 6,5 & J5R55,0V6,5 \\
\hline & & 7,8 & J5R55,0V7,8 \\
\hline & & 9,4 & J5R55,0V9,4 \\
\hline \multirow{2}{*}{ J6 } & & 4,8 & J6R55,0V4,8 \\
\hline & & 6,5 & J6R55,0V6,5 \\
\hline
\end{tabular}

Continua... 
Continuação da Tabela 24.

\begin{tabular}{|c|c|c|c|}
\hline \multirow{2}{*}{ J6 } & \multirow{10}{*}{$735(55)$} & 7,8 & J6R55,0V7,8 \\
\hline & & 9,4 & J6R55,0V9,4 \\
\hline \multirow{4}{*}{ J7 } & & 4,8 & J7R55,0V4,8 \\
\hline & & 6,5 & J7R55,0V6,5 \\
\hline & & 7,8 & J7R55,0V7,8 \\
\hline & & 9,4 & J7R55,0V9,4 \\
\hline \multirow{4}{*}{ J8 } & & 4,8 & J8R55,0V4,8 \\
\hline & & 6,5 & J8R55,0V6,5 \\
\hline & & 7,8 & J8R55,0V7,8 \\
\hline & & 9,4 & J8R55,0V9,4 \\
\hline
\end{tabular}

Tabela 25 - Denominação das parcelas de acordo com o pneu utilizado, relação entre peso e potência, velocidade teórica adotada em superfície trativa de solo firme.

\begin{tabular}{|c|c|c|c|}
\hline $\begin{array}{l}\text { Trator e } \\
\text { Conjunto }\end{array}$ & $\begin{array}{c}\text { Relação peso/potência } \\
\text { N.kW'-1 }\left(\mathrm{kgf.cv}^{-1}\right)\end{array}$ & $\begin{array}{c}\text { Velocidade teórica } \\
\left(\mathbf{k m} \cdot \mathrm{h}^{-1}\right)\end{array}$ & Denominação \\
\hline \multicolumn{4}{|c|}{ Pista de Solo Firme } \\
\hline \multirow{4}{*}{$\mathrm{J} 1$} & \multirow{20}{*}{$735(55)$} & 4,8 & J1R55,0V4,8 \\
\hline & & 6,5 & J1R55,0V6,5 \\
\hline & & 7,8 & J1R55,0V7,8 \\
\hline & & 9,4 & J1R55,0V9,4 \\
\hline \multirow{4}{*}{$\mathrm{J} 2$} & & 4,8 & J2R55,0V4,8 \\
\hline & & 6,5 & J2R55,0V6,5 \\
\hline & & 7,8 & J2R55,0V7,8 \\
\hline & & 9,4 & J2R55,0V9,4 \\
\hline \multirow{4}{*}{$\mathrm{J} 3$} & & 4,8 & J3R55,0V4,8 \\
\hline & & 6,5 & J3R55,0V6,5 \\
\hline & & 7,8 & J3R55,0V7,8 \\
\hline & & 9,4 & J3R55,0V9,4 \\
\hline \multirow{4}{*}{$\mathrm{J} 4$} & & 4,8 & J4R55,0V4,8 \\
\hline & & 6,5 & J4R55,0V6,5 \\
\hline & & 7,8 & J4R55,0V7,8 \\
\hline & & 9,4 & J4R55,0V9,4 \\
\hline \multirow{4}{*}{$\mathrm{J} 5$} & & 4,8 & J5R55,0V4,8 \\
\hline & & 6,5 & J5R55,0V6,5 \\
\hline & & 7,8 & J5R55,0V7,8 \\
\hline & & 9,4 & J5R55,0V9,4 \\
\hline
\end{tabular}

Continua... 
Continuação da Tabela 25.

\begin{tabular}{|c|c|c|c|}
\hline \multirow{4}{*}{ J6 } & \multirow{12}{*}{735 (55) } & 4,8 & J6R55,0V4,8 \\
\hline & & 6,5 & J6R55,0V6,5 \\
\hline & & 7,8 & J6R55,0V7,8 \\
\hline & & 9,4 & J6R55,0V9,4 \\
\hline \multirow{4}{*}{$\mathrm{J} 7$} & & 4,8 & J7R55,0V4,8 \\
\hline & & 6,5 & J7R55,0V6,5 \\
\hline & & 7,8 & J7R55,0V7,8 \\
\hline & & 9,4 & J7R55,0V9,4 \\
\hline \multirow{4}{*}{$\mathrm{J} 8$} & & 4,8 & J8R55,0V4,8 \\
\hline & & 6,5 & J8R55,0V6,5 \\
\hline & & 7,8 & J8R55,0V7,8 \\
\hline & & 9,4 & J8R55,0V9,4 \\
\hline
\end{tabular}

Tabela 26 - Denominação das parcelas de acordo com o pneu utilizado, relação entre peso e potência, velocidade teórica adotada em superfície de solo com cobertura vegetal.

\begin{tabular}{|c|c|c|c|}
\hline $\begin{array}{l}\text { Trator e } \\
\text { Conjunto }\end{array}$ & $\begin{array}{c}\text { Relação peso/potência } \\
\left.\text { N.kW }{ }^{-1} \text { (kgf.cv }^{-1}\right)\end{array}$ & $\begin{array}{c}\text { Velocidade teórica } \\
\left(\mathbf{k m} \cdot \mathrm{h}^{-\mathbf{1}}\right)\end{array}$ & Denominação \\
\hline \multicolumn{4}{|c|}{ Pista de Solo com Cobertura Vegetal } \\
\hline \multirow{4}{*}{$\mathrm{J} 1$} & \multirow{16}{*}{$735(55)$} & 4,8 & $\mathrm{~J} 1 \mathrm{R} 55,0 \mathrm{~V} 4,8$ \\
\hline & & 6,5 & J1R55,0V6,5 \\
\hline & & 7,8 & J1R55,0V7,8 \\
\hline & & 9,4 & J1R55,0V9,4 \\
\hline \multirow{4}{*}{$\mathrm{J} 2$} & & 4,8 & $\mathrm{~J} 2 \mathrm{R} 55,0 \mathrm{~V} 4,8$ \\
\hline & & 6,5 & J2R55,0V6,5 \\
\hline & & 7,8 & $\mathrm{~J} 2 \mathrm{R} 55,0 \mathrm{~V} 7,8$ \\
\hline & & 9,4 & J2R55,0V9,4 \\
\hline \multirow{4}{*}{ J5 } & & 4,8 & J5R55,0V4,8 \\
\hline & & 6,5 & J5R55,0V6,5 \\
\hline & & 7,8 & $\mathrm{~J} 5 \mathrm{R} 55,0 \mathrm{~V} 7,8$ \\
\hline & & 9,4 & J5R55,0V9,4 \\
\hline \multirow{4}{*}{$\mathrm{J} 7$} & & 4,8 & J7R55,0V4,8 \\
\hline & & 6,5 & J7R55,0V6,5 \\
\hline & & 7,8 & J7R55,0V7,8 \\
\hline & & 9,4 & J7R55,0V9,4 \\
\hline
\end{tabular}




\subsubsection{Trator $(\mathrm{K})$}

Trator com $132 \mathrm{~kW}(180 \mathrm{cv})$ de potência no motor e equipado com os conjuntos de pneus e pressões de inflação descritos na Tabela 27. Os dados referentes a relação entre peso e potência do trator e velocidade teórica adotados nos ensaios estão descritos na Tabela 28 de acordo com a superfície trativa.

Tabela 27 - Conjuntos e pressões de inflação dos pneus utilizados no trator (K).

\begin{tabular}{ccccc}
\hline & Pneus & & \multicolumn{2}{c}{ Pressão de Inflação - kPa (psi) } \\
Conjunto & Dianteiros & Traseiros & Dianteiros & Traseiros \\
\hline K1 & $18.4-26$ & $25.4-32$ & $110,4(16)$ & $110,4(16)$ \\
K2 & $18.4 \mathrm{R} 26$ & $650 / 75 \mathrm{R} 32$ & $124,2(18)$ & $103,5(15)$ \\
K3 & $660 / 65 \mathrm{R} 30.5$ & $710 / 65 \mathrm{R} 38$ & $110,4(16)$ & $110,4(16)$ \\
K4 & $600 / 55-30.5$ & $650 / 60-38$ & $110,4(16)$ & $110,4(16)$ \\
K5 & $18.4-26$ & $24.5-32$ & $110,4(16)$ & $110,4(16)$ \\
\hline
\end{tabular}

Tabela 28 - Denominação das parcelas de acordo com o pneu utilizado, relação entre peso e potência, velocidade teórica adotada e superfície trativa.

\begin{tabular}{|c|c|c|c|}
\hline $\begin{array}{c}\text { Trator e } \\
\text { Conjunto }\end{array}$ & $\begin{array}{c}\text { Relação peso/potência } \\
\text { N.kW } \\
\left.\text { (kgf.cv }{ }^{-1}\right)\end{array}$ & $\begin{array}{c}\text { Velocidade teórica } \\
\left(\mathbf{k m} \cdot \mathrm{h}^{-1}\right)\end{array}$ & Denominação \\
\hline \multicolumn{4}{|c|}{ Pista de Solo Firme } \\
\hline \multirow{4}{*}{ K1 } & \multirow{8}{*}{$772(57,8)$} & 5,0 & K1R57,8V5,0a \\
\hline & & 5,0 & K1R57,8V5,0b \\
\hline & & 7,0 & K1R57,8V7,0a \\
\hline & & 7,0 & K1R57,8V7,0b \\
\hline \multirow{4}{*}{$\mathrm{K} 2$} & & 5,0 & K2R57,8V5,0a \\
\hline & & 5,0 & K2R57,8V5,0b \\
\hline & & 7,0 & K2R57,8V7,0a \\
\hline & & 7,0 & K2R57,8V7,0b \\
\hline \multirow{4}{*}{ K3 } & \multirow{4}{*}{$742(55,5)$} & 5,0 & K3R55,5V5,0a \\
\hline & & 5,0 & K3R55,5V5,0b \\
\hline & & 7,0 & K3R55,5V7,0a \\
\hline & & 7,0 & K3R55,5V7,0b \\
\hline \multirow{3}{*}{ K4 } & \multirow{3}{*}{$762(57)$} & 5,0 & K4R57,0V5,0a \\
\hline & & 5,0 & K4R57,0V5,0b \\
\hline & & 7,0 & K4R57,0V7,0a \\
\hline
\end{tabular}

Continua... 
Continuação da Tabela 28.

\begin{tabular}{|c|c|c|c|}
\hline K4 & $762(57)$ & 7,0 & K4R57,0V7,0b \\
\hline \multirow{4}{*}{ K5 } & \multirow{4}{*}{$772(57,8)$} & 4,0 & K5R57,8V4,0 \\
\hline & & 6,0 & K5R57,8V6,0 \\
\hline & & 7,0 & K5R57,8V7,0 \\
\hline & & 8,0 & K5R57,8V8,0 \\
\hline & \multicolumn{3}{|c|}{ Pista de Solo com Cobertura Vegetal } \\
\hline \multirow{2}{*}{$\mathrm{K} 1$} & \multirow{3}{*}{$772(57,8)$} & 5,0 & K1R57,8V5,0 \\
\hline & & 7,0 & K1R57,8V7,0 \\
\hline $\mathrm{K} 2$ & & 5,0 & K2R57,8V5,0 \\
\hline $\mathrm{K} 2$ & $772(57,8)$ & 7,0 & K2R57,8V7,0 \\
\hline \multirow{2}{*}{ K3 } & \multirow{2}{*}{$742(55,5)$} & 5,0 & K3R55,5V5,0 \\
\hline & & 7,0 & K3R55,5V7,0 \\
\hline \multirow{2}{*}{ K4 } & \multirow{2}{*}{$762(57)$} & 5,0 & K4R57,0V5,0 \\
\hline & & 7,0 & K4R57,0V7,0 \\
\hline \multicolumn{4}{|c|}{ Pista de Solo Mobilizado } \\
\hline \multirow{4}{*}{$\mathrm{K} 1$} & \multirow{8}{*}{$772(57,8)$} & 5,0 & K1R57,8V5,0a \\
\hline & & 5,0 & K1R57,8V5,0b \\
\hline & & 7,0 & K1R57,8V7,0a \\
\hline & & 7,0 & K1R57,8V7,0b \\
\hline \multirow{4}{*}{$\mathrm{K} 2$} & & 5,0 & K2R57,8V5,0a \\
\hline & & 5,0 & K2R57,8V5,0b \\
\hline & & 7,0 & K2R57,8V7,0a \\
\hline & & 7,0 & K2R57,8V7,0b \\
\hline \multirow{4}{*}{$\mathrm{K} 3$} & \multirow{4}{*}{$742(55,5)$} & 5,0 & K3R55,5V5,0a \\
\hline & & 5,0 & K3R55,5V5,0b \\
\hline & & 7,0 & K3R55,5V7,0a \\
\hline & & 7,0 & K3R55,5V7,0b \\
\hline \multirow{4}{*}{$\mathrm{K} 4$} & \multirow{4}{*}{$762(57)$} & 5,0 & K4R57,0V5,0a \\
\hline & & 5,0 & K4R57,0V5,0b \\
\hline & & 7,0 & K4R57,0V7,0a \\
\hline & & 7,0 & K4R57,0V7,0b \\
\hline
\end{tabular}

\subsubsection{Trator $(\mathbf{L})$}

Trator com $158 \mathrm{~kW}(215 \mathrm{cv})$ de potência no motor e equipado com os conjuntos de pneus e pressões de inflação descritos na Tabela 29. Os dados referentes a 
relação entre peso e potência do trator e velocidade teórica adotados nos ensaios estão descritos na Tabela 30 de acordo com a superfície trativa.

Tabela 29 - Conjuntos e pressões de inflação dos pneus utilizados no trator (L).

\begin{tabular}{ccccc}
\hline & Pneus & & \multicolumn{2}{c}{ Pressão de Inflação - kPa (psi) } \\
Conjunto & Dianteiros & Traseiros & Dianteiros & Traseiros \\
\hline L1 & $660 / 60-30.5$ & $850 / 50-38$ & $110,4(16)$ & $110,4(16)$ \\
L2 & $660 / 60-30.5$ & $850 / 50-38$ & $124,2(18)$ & $138(20)$ \\
L3 & $18.4-26$ & $30.5 \mathrm{~L}-32$ & $124,2(18)$ & $165,6(24)$ \\
L4 & $660 / 60-30.5$ & $710 / 65-38$ & $124,2(18)$ & $138(20)$ \\
\hline
\end{tabular}

Tabela 30 - Denominação das parcelas de acordo com o pneu utilizado, relação entre peso e potência, velocidade teórica adotada e superfície trativa.

\begin{tabular}{|c|c|c|c|}
\hline $\begin{array}{l}\text { Trator e } \\
\text { Conjunto }\end{array}$ & $\begin{array}{c}\text { Relação peso/potência } \\
\left.\text { N.kW'1 } \text { (kgf.cv }^{-1}\right)\end{array}$ & $\begin{array}{c}\text { Velocidade teórica } \\
\left(\mathbf{k m} \cdot \mathrm{h}^{-\mathbf{1}}\right)\end{array}$ & Denominação \\
\hline \multicolumn{4}{|c|}{$\begin{array}{l}\text { Pista de Solo Firme } \\
\end{array}$} \\
\hline \multirow{4}{*}{ L1 } & \multirow{10}{*}{$713(53,4)$} & 6,5 & L1R53,4V6,5a \\
\hline & & 6,5 & L1R53,4V6,5b \\
\hline & & 7,4 & L1R53,4V7,4a \\
\hline & & 7,4 & L1R53,4V7,4b \\
\hline \multirow{6}{*}{ L2 } & & 4,9 & L2R53,4V4,9a \\
\hline & & 4,9 & L2R53,4V4,9b \\
\hline & & 6,5 & L2R53,4V6,5a \\
\hline & & 6,5 & L2R53,4V6,5b \\
\hline & & 7,4 & L2R53,4V7,4 \\
\hline & & 8,7 & L2R53,4V8,7 \\
\hline \multirow{4}{*}{ L3 } & \multirow{4}{*}{$764(57,2)$} & 6,5 & L3R53,4V6,5a \\
\hline & & 6,5 & L3R53,4V6,5b \\
\hline & & 7,4 & L3R53,4V7,4a \\
\hline & & 7,4 & L3R53,4V7,4b \\
\hline \multirow{4}{*}{ L4 } & \multirow{4}{*}{$726(54,3)$} & 6,5 & L4R53,4V6,5a \\
\hline & & 6,5 & L4R53,4V6,5b \\
\hline & & 7,4 & L4R53,4V7,4a \\
\hline & & 7,4 & L4R53,4V7,4b \\
\hline \multicolumn{4}{|c|}{ Pista de Solo com Cobertura Vegetal } \\
\hline \multirow{2}{*}{ L1 } & \multirow{2}{*}{$713(53,4)$} & 6,5 & L1R53,4V6,5 \\
\hline & & 7,4 & L1R53,4V7,4 \\
\hline
\end{tabular}

Continua... 
Continuação da Tabela 30.

\begin{tabular}{|c|c|c|c|}
\hline \multirow{2}{*}{ L2 } & \multirow{2}{*}{$713(53,4)$} & 4,9 & L2R53,4V4,9 \\
\hline & & 6,5 & L2R53,4V6,5 \\
\hline \multirow{2}{*}{ L3 } & \multirow{2}{*}{$764(57,2)$} & 6,5 & L3R57,2V6,5 \\
\hline & & 7,4 & L3R57,2V7,4 \\
\hline \multirow{2}{*}{ L4 } & \multirow{2}{*}{$726(54,3)$} & 6,5 & L4R54,3V6,5 \\
\hline & & 7,4 & L4R54,3V7,4 \\
\hline \multicolumn{4}{|c|}{ Pista de Solo Mobilizado } \\
\hline \multirow{2}{*}{ L1 } & \multirow{4}{*}{$713(53,4)$} & 6,5 & L1R53,4V6,5 \\
\hline & & 7,4 & L1R53,4V7,4 \\
\hline \multirow{2}{*}{ L2 } & & 4,9 & L2R53,4V4,9 \\
\hline & & 6,5 & L2R53,4V6,5 \\
\hline \multirow{2}{*}{ L3 } & \multirow{2}{*}{$764(57,2)$} & 6,5 & L3R57,2V6,5 \\
\hline & & 7,4 & L3R57,2V7,4 \\
\hline \multirow{2}{*}{$\mathrm{L} 4$} & \multirow{2}{*}{$726(54,3)$} & 6,5 & L4R54,3V6,5 \\
\hline & & 7,4 & L4R54,3V7,4 \\
\hline
\end{tabular}

\subsubsection{Sistema de aquisição de dados}

Para aquisição e acompanhamento dos sinais obtidos pelos sensores instalados nos rodados pneumáticos dos tratores, na roda odométrica da UMEB, no sistema de alimentação de combustível e na barra de tração utilizou-se dois tipos de sistemas de aquisição de dados. Nos primeiros ensaios realizados pela UMEB utilizou-se um painel com instrumentos eletrônicos indicadores e um indicador de força instantânea tipo "MICRO-P" (Figura 9a), conforme descrito por Jesuíno (2007). Esse sistema foi utilizado nos ensaios dos tratores: (A), (B), (F), (G), (K) e (L).

Nos demais ensaios realizados se utilizou um controlador lógico programável (CLP) para coleta dos dados, permitindo a leitura e o armazenamento dos sinais enviados pelos sensores (Figura 9b). Utilizou-se esse sistema nos ensaios dos tratores: (C), (D), (E), (H), (I) e (J). 

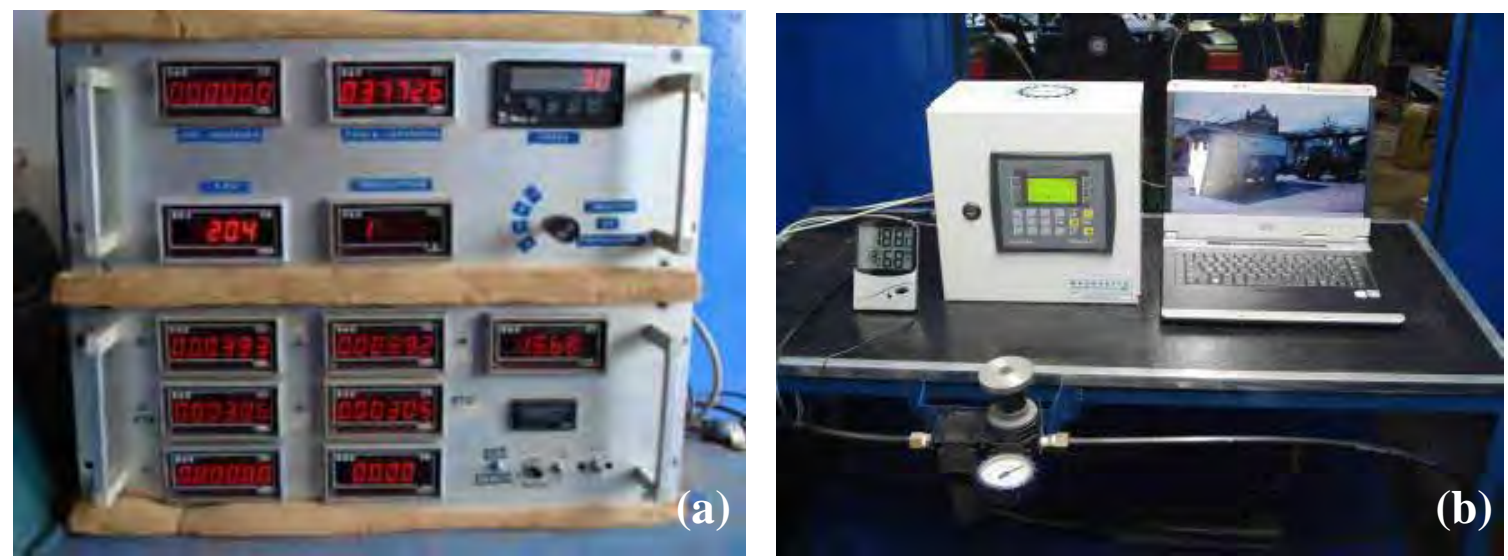

Figura 9 - Painel com indicadores eletrônicos (a) e bancada de instrumentação com o CLP e um microcomputador portátil (b).

\subsubsection{Força na barra de tração do trator}

Os valores da força na barra de tração foram obtidos através de uma célula de carga marca SODMEX, modelo N400, com sensibilidade de 2,16 mV/V e escala nominal de $100 \mathrm{kN}$ (Figura 10). Essa célula foi instalada no cabeçalho da UMEB.

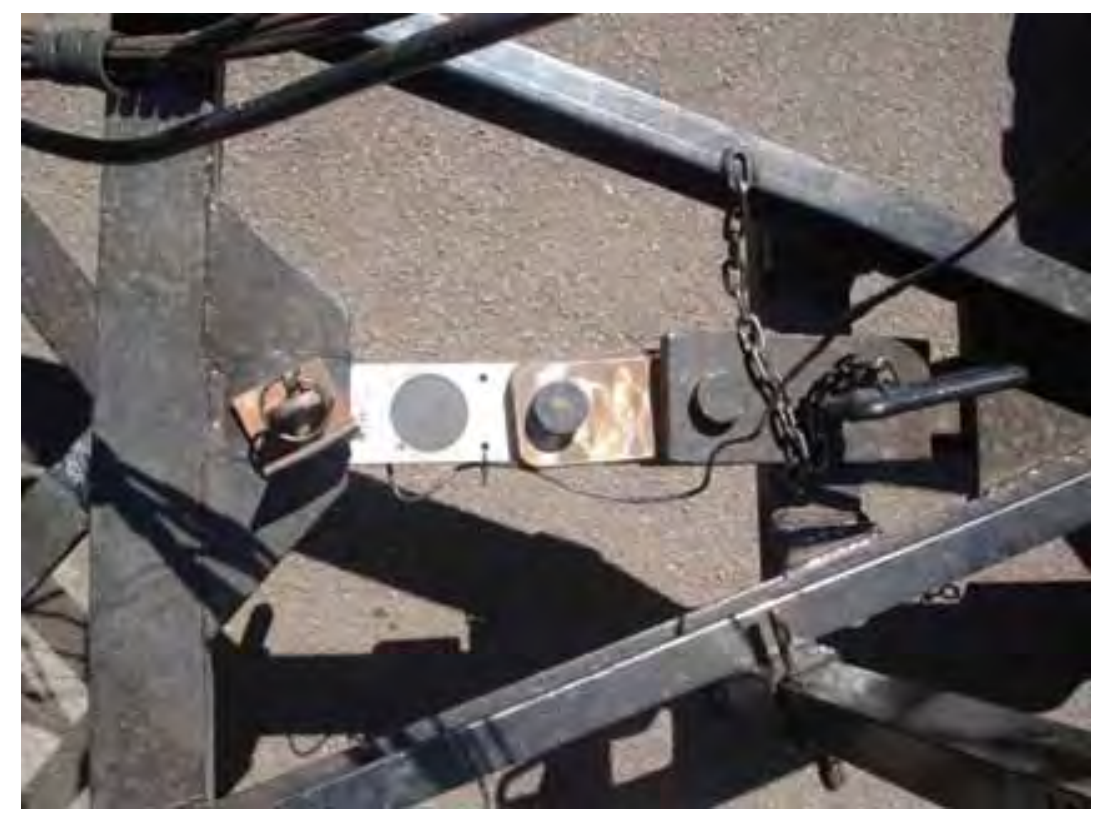

Figura 10 - Célula de carga marca SODMEX, modelo N400. 


\subsubsection{Patinagem dos rodados do trator}

A determinação da patinagem das quatro rodas do trator foi obtida utilizando-se geradores de pulsos, modelo GIDP-60-U-12V, com uma frequiência de 60 pulsos por volta, conforme Figura 11.

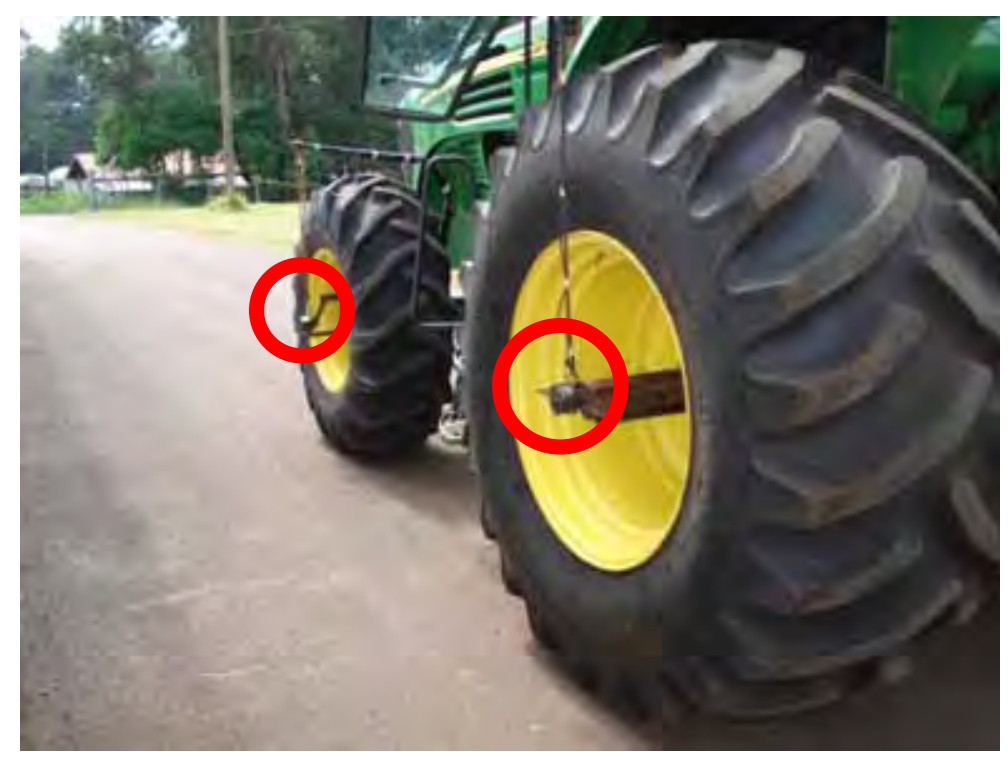

Figura 11 - Geradores de pulsos instalados no trator para determinar a patinagem nos rodados.

\subsubsection{Consumo de combustível do trator}

Para medição do consumo horário e específico de combustível foram utilizados dois fluxômetros volumétricos M-III, da FLOWMATE fabricado pela OVAL Corporation do Japão e distribuído no Brasil pela K\&K do Brasil, modelo LSN41L8-M2, vazão de $1 \mathrm{~mL} /$ pulso, conforme Figura 12, um instalado entre os filtros e a bomba injetora do motor do trator e o outro no retorno do combustível ao tanque. O consumo real foi calculado pela diferença entre os valores dos pulsos gerados pelos fluxômetros. 


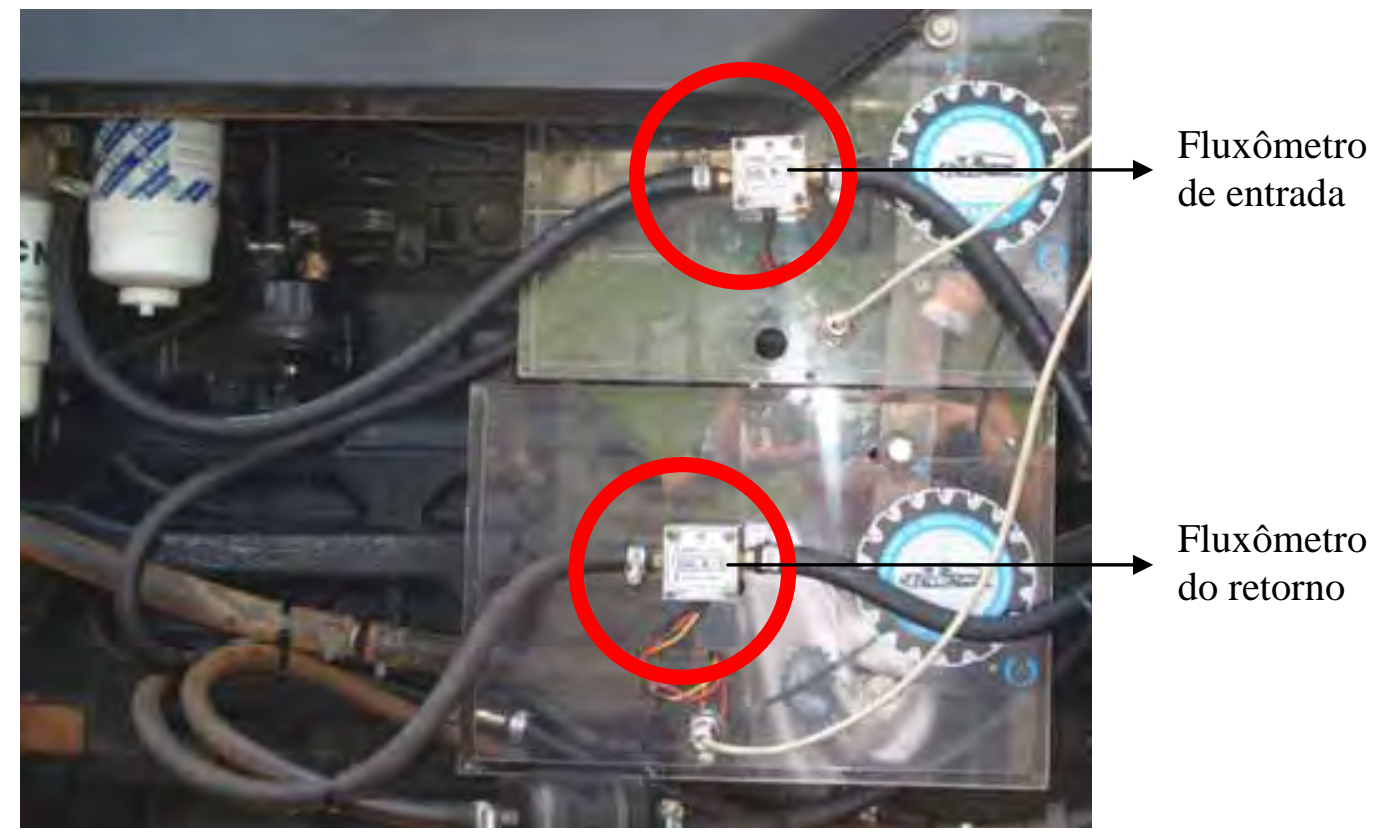

Figura 12 - Fluxômetros volumétricos.

\subsection{Métodos}

\subsubsection{Condução do experimento}

Os dados de rendimento máximo na barra de tração dos tratores obtidos nos ensaios foram arranjados em grupos, sendo utilizada a estatística descritiva obtendo-se a média do rendimento máximo dinâmico na barra de tração e desvio padrão para cada condição de superfície. Os tratamentos foram distintos conforme as condições de superfície de tração utilizadas nos ensaios:

- Pista de concreto

- Pista de solo firme

- Pista de solo mobilizado

- Pista de solo com cobertura vegetal

Todos os ensaios foram realizados após a aplicação e estabilização da carga de tração, tracionando a UMEB, para cada condição descrita no item 5.1.4, os tratores 
ensaiados foram submetidos a uma força constante na barra de tração, num percurso de 30 metros, demarcado através da roda odométrica da UMEB.

O valor da carga inicial aplicada na barra de tração dos tratores dependeu da potência e tipo de superfície trativa. Cada avaliação subseqüente apresentou um aumento de carga na barra de tração de, aproximadamente, $500 \mathrm{kgf}$, sendo realizadas no mínimo quatro avaliações por condição (500, 1000, 1500, 2000 kgf), obtendo-se a força máxima desenvolvida pelos tratores em cada condição, até que o motor apresentasse uma diminuição na rotação de trabalho (abaixo de $2000 \mathrm{rpm}$ ) ou que a patinagem das rodas fosse excessiva (acima de 30\%).

\subsubsection{Descrição das parcelas}

Cada parcela foi definida como sendo o rendimento máximo na barra de tração de cada condição de ensaio realizada e obtida através de curvas de melhor ajuste (polinomial de $2^{\circ}$ grau), onde para cada condição se obteve os valores de rendimento máximo na barra de tração nas curvas avaliadas, com os respectivos dados de patinagem e consumo específico de combustível, conforme exemplo em Apêndice 1.

\subsubsection{Força na barra de tração do trator}

A força na barra de tração do trator foi obtida através dos sinais emitidos pela célula de carga, instalada no cabeçalho da UMEB, com os valores obtidos da força de tração média determinados pela Equação 10.

$$
F_{m}=\frac{\sum_{i=1}^{n} F i}{t_{p}}
$$

onde:

$F_{i}=$ força de tração instantânea $\left(\mathrm{kN} . \mathrm{s}^{-1}\right)$

$F_{m}=$ força de tração média $(\mathrm{kN})$

$t_{p}=$ tempo de percurso na parcela $(\mathrm{s})$ 


\subsubsection{Velocidade de deslocamento do conjunto}

A velocidade média de deslocamento foi determinada cronometrando-se o tempo necessário para percorrer cada parcela de 30 metros de comprimento. A distância percorrida foi monitorada, no sistema de aquisição utilizado, pelos pulsos gerados pela roda odométrica e calculada de acordo com a Equação 11.

$V m=\frac{s}{t} \times 3,6$

onde:

$V m=$ velocidade média $\left(\mathrm{km} \cdot \mathrm{h}^{-1}\right)$

$s=$ espaço percorrido (metros)

$t=$ tempo decorrido (segundos)

$3,6=$ fator de conversão

\subsubsection{Patinagem dos rodados do trator}

Com os sinais recebidos dos geradores de pulsos instalados nos rodados, dianteiro e traseiro e utilizando a Equação 12, foi possível determinar a patinagem dos rodados do trator. O número de pulsos sem carga foi obtido pelo trator sem carga aplicada na barra de tração e o número de pulsos com carga foi obtido pelo trator tracionando a UMEB em cada condição. Os valores de patinagem dos rodados obtidos neste trabalho foram determinados por curvas de melhor ajuste em função do ponto de maior rendimento na barra de tração de cada parcela, conforme Apêndice 1 .

$P a t=\frac{N_{1}-N_{0}}{N_{1}}$

onde:

$P a t=$ patinagem das rodas motrizes $(\%)$

$N_{0}=$ número de pulsos sem carga

$N_{l}=$ número de pulsos com carga 


\subsubsection{Potência disponível na barra de tração do trator}

A potência disponível na barra de tração foi calculada em função da força de tração e da velocidade de deslocamento, conforme a Equação 13:

$N b=\frac{F m \times V}{3,6}$

onde:

$N b=$ potência na barra de tração $(\mathrm{kW})$

$F m=$ força de tração média $(\mathrm{kN})$

$V=$ velocidade de deslocamento $\left(\mathrm{km} \cdot \mathrm{h}^{-1}\right)$

\subsubsection{Rendimento na barra de tração do trator}

O cálculo do rendimento na barra de tração foi realizado utilizando a Equação 14. Os valores de rendimento máximo na barra de tração foram determinados por curvas de melhor ajuste para cada parcela, conforme Apêndice 1.

$\eta b=\frac{N b}{N m} \times 100$

onde:

$\eta \mathrm{b}=$ rendimento médio na barra de tração (\%)

$\mathrm{Nb}=$ potência média na barra de tração $(\mathrm{kW})$

$\mathrm{Nm}=$ potência no motor $(\mathrm{kW})$, (conforme informação do fabricante)

\subsubsection{Consumo horário de combustível}

Os pulsos gerados pelo fluxômetro volumétrico foram convertidos em volume, considerando a vazão de $1 \mathrm{~mL} /$ pulso. O cálculo do consumo horário foi feito de acordo com a Equação 15: 
$C H=\frac{n p \times 3,6}{t}$

onde:

CH = consumo horário (L.h-1)

$n p=$ número de pulso do medidor de combustível

$t=$ tempo de percurso da parcela $(\mathrm{s})$

\subsubsection{Consumo específico de combustível}

O consumo específico de combustível foi calculado em todas as parcelas (equação 16) e obtido o valor de consumo referente ao valor da patinagem de maior rendimento na barra de tração na curva de melhor ajuste, conforme Apêndice 1.

Cesp $=\frac{C h \times d}{N b} \times 1000$

onde:

Cesp = consumo específico $\left(\mathrm{kg} \cdot \mathrm{kW}^{-1} \cdot \mathrm{h}^{-1}\right)$

$C h=$ consumo horário $\left(\mathrm{L} . \mathrm{h}^{-1}\right)$

$\mathrm{d}=$ densidade do combustível $\left(0,825 \mathrm{~g} . \mathrm{L}^{-1}\right)$

$\mathrm{Nb}=$ Potência na barra de tração $(\mathrm{kW})$ 


\section{RESULTADOS E DISCUSSÃO}

Os resultados estão apresentados da seguinte forma:

- Resultados obtidos por tipo e modelo de trator.

- Resultados obtidos nas diferentes superfícies trativas.

\subsection{Resultados obtidos por tipo e modelo de trator}

Nas Tabelas 31 a 42, a seguir, estão apresentados os valores máximos de rendimento na barra de tração e respectivos valores de patinagem dos rodados e consumo específico de combustível dos tratores $4 \times 2$ TDA utilizados nessa pesquisa em todas as condições ensaiadas, obtidos pelo ponto de máximo rendimento da curva ajustada.

Tabela 31 - Valores de rendimento máximo na barra de tração, patinagem dos rodados e consumo específico de combustível para as condições do ensaio do trator (A).

\begin{tabular}{|c|c|c|c|}
\hline Denominação & $\begin{array}{c}\text { Rendimento na barra } \\
(\%)\end{array}$ & $\begin{array}{c}\text { Patinagem } \\
(\%)\end{array}$ & $\begin{array}{c}\text { Consumo específico } \\
\left(\mathbf{k g} \cdot \mathrm{kW}^{-1} \cdot \mathrm{h}^{-1}\right)\end{array}$ \\
\hline \multicolumn{4}{|c|}{ Pista de Solo Firme } \\
\hline A1R50,0V5,4 & 35,0 & 15,5 & 0,435 \\
\hline A1R50,0V7,8 & 47,8 & 19,6 & 0,360 \\
\hline A1R50,0V10,6 & 67,0 & 10,5 & 0,300 \\
\hline A1R53,0V5,4 & 36,0 & 16,6 & 0,405 \\
\hline A1R53,0V7,8 & 53,0 & 21,5 & 0,350 \\
\hline
\end{tabular}

Continua... 
Continuação da Tabela 31.

\begin{tabular}{cccc}
\hline A1R53,0V10,6 & 63,0 & 8,8 & 0,330 \\
A1R57,0V5,4 & 34,7 & 17,3 & 0,385 \\
A1R57,0V7,8 & 57,0 & 19,0 & 0,270 \\
A1R57,0V10,6 & 66,0 & 6,8 & 0,280 \\
A2R57,0V5,4 & 37,6 & 19,3 & 0,363 \\
A2R57,0V7,8 & 51,3 & 18,7 & 0,341 \\
A2R57,0V10,6 & 60,0 & 15,0 & 0,310 \\
Média & $\mathbf{5 0 , 7}$ & $\mathbf{1 5 , 7}$ & $\mathbf{0 , 3 4 4}$ \\
Desvio Padrão & $\mathbf{1 2 , 4}$ & $\mathbf{4 , 7}$ & $\mathbf{0 , 0 5 0}$ \\
\hline & Pista de Solo com Cobertura Vegetal & \\
\hline A1R50,0V10,6 & 62,7 & 10,9 & 0,272 \\
A1R53,0V10,6a & 57,5 & 7,1 & 0,306 \\
A1R53,0V10,6b & 59,1 & 6,0 & 0,289 \\
A2R53,0V10,6 & 53,0 & 11,3 & 0,318 \\
Média & $\mathbf{5 8 , 1}$ & $\mathbf{8 , 8}$ & $\mathbf{0 , 2 9 6}$ \\
Desvio Padrão & $\mathbf{4 , 0}$ & $\mathbf{2 , 7}$ & $\mathbf{0 , 0 2 0}$ \\
\hline & $\mathbf{P i s t a}$ de Solo Mobilizado & 0,440 \\
\hline A1R50,0V5,4 & 26,7 & 13,9 & 0,480 \\
A1R53,0V5,4 & 26,8 & 18,7 & 0,457 \\
A1R53,0V7,8 & 38,8 & 18,7 & 0,473 \\
A1R57,0V5,4 & 25,4 & 13,9 & 0,420 \\
A1R57,0V7,8 & 38,9 & 10,3 & 0,455 \\
A2R57,0V5,4 & 30,0 & 22,0 & 0,447 \\
A2R57,0V7,8 & 39,2 & $\mathbf{0 , 4 5 3}$ \\
Média & $\mathbf{3 2 , 3}$ & $\mathbf{0 , 0 2 0}$ \\
Desvio Padrão & $\mathbf{6 , 4}$ & $\mathbf{1 6 , 9}$ &
\end{tabular}

Tabela 32 - Valores de rendimento máximo na barra de tração, patinagem dos rodados e consumo específico de combustível para as condições do ensaio do trator (B).

\begin{tabular}{|c|c|c|c|}
\hline Denominação & $\begin{array}{c}\text { Rendimento na barra } \\
(\%)\end{array}$ & $\begin{array}{c}\text { Patinagem } \\
(\%)\end{array}$ & $\begin{array}{c}\text { Consumo específico } \\
\left(\mathrm{kg} \cdot \mathrm{kW}^{-1} \cdot \mathbf{h}^{-1}\right)\end{array}$ \\
\hline \multicolumn{4}{|c|}{ Pista de Solo Firme } \\
\hline B1R57,0V7,0 & 56,0 & 14,2 & 0,315 \\
\hline B1R57,0V8,6 & 62,0 & 8,5 & 0,345 \\
\hline B1R57,0V10,7 & 72,0 & 7,5 & 0,322 \\
\hline Média & 63,3 & 10,1 & 0,327 \\
\hline Desvio Padrão & 8,1 & 3,6 & 0,016 \\
\hline
\end{tabular}

Continua... 
Continuação da Tabela 32 .

\begin{tabular}{cccc}
\hline \multicolumn{4}{c}{ Pista de Solo com Cobertura Vegetal } \\
\hline B1R57,0V10,7 & 65,0 & 6,8 & 0,327 \\
\hline B1R57,0V7,0 & \multicolumn{1}{c}{ Pista de Solo Mobilizado } & \\
B1R57,0V8,6 & 47,5 & 18,5 & 0,385 \\
Média & 58,0 & 17,5 & 0,408 \\
Desvio Padrão & $\mathbf{5 2 , 8}$ & $\mathbf{1 8 , 0}$ & $\mathbf{0 , 3 9 7}$ \\
\hline
\end{tabular}

Tabela 33 - Valores de rendimento máximo na barra de tração, patinagem dos rodados e consumo específico de combustível para as condições do ensaio do trator (C).

\begin{tabular}{|c|c|c|c|}
\hline Denominação & $\begin{array}{c}\text { Rendimento na barra } \\
\qquad(\%)\end{array}$ & $\begin{array}{c}\text { Patinagem } \\
(\%)\end{array}$ & $\begin{array}{c}\text { Consumo específico } \\
\left(\mathbf{k g} \cdot \mathbf{k W}^{-1} \cdot \mathbf{h}^{-1}\right)\end{array}$ \\
\hline \multicolumn{4}{|c|}{ Pista de Concreto } \\
\hline C1R57,0V5,0 & 62,0 & 14,0 & 0,400 \\
\hline C1R57,0V6,5 & 74,0 & 9,8 & 0,328 \\
\hline C1R57,0V7,8 & 72,5 & 7,5 & 0,325 \\
\hline C1R57,0V8,3 & 74,3 & 7,2 & 0,32 \\
\hline C1R57,0V10,4 & 76,0 & 4,8 & 0,335 \\
\hline C1R50,0V5,0 & 44,0 & 13,5 & 0,385 \\
\hline C1R50,0V6,5 & 59,7 & 13,1 & 0,373 \\
\hline C1R50,0V7,8 & 69,0 & 10,9 & 0,362 \\
\hline C1R50,0V8,3 & 71,0 & 11,5 & 0,350 \\
\hline C1R50,0V10,4 & 73,0 & 7,8 & 0,361 \\
\hline Média & 67,6 & 10,0 & 0,354 \\
\hline Desvio Padrão & 9,9 & 3,1 & $\mathbf{0 , 0 2 7}$ \\
\hline \multicolumn{4}{|c|}{ Pista de Solo Firme } \\
\hline C1R57,0V5,0 & 48,0 & 19,0 & 0,420 \\
\hline C1R57,0V6,5 & 64,5 & 12,2 & 0,280 \\
\hline C1R57,0V7,8 & 66,5 & 11,5 & 0,365 \\
\hline C1R57,0V8,3 & 75,0 & 11,1 & 0,270 \\
\hline C1R57,0V10,4 & 67,5 & 6,0 & 0,338 \\
\hline Média & 64,3 & 12,0 & $\mathbf{0 , 3 3 5}$ \\
\hline Desvio Padrão & 9,9 & 4,6 & 0,062 \\
\hline
\end{tabular}


Tabela 34 - Valores de rendimento máximo na barra de tração, patinagem dos rodados e consumo específico de combustível para as condições do ensaio do trator (D).

\begin{tabular}{cccc}
\hline Denominação & $\begin{array}{c}\text { Rendimento na barra } \\
(\mathbf{\%})\end{array}$ & $\begin{array}{c}\text { Patinagem } \\
(\mathbf{\%})\end{array}$ & $\begin{array}{c}\text { Consumo específico } \\
\left(\mathbf{k g . k}^{\mathbf{- 1}} \mathbf{. h}^{\mathbf{- 1}} \mathbf{)}\right.\end{array}$ \\
\hline D1R57,0V5,0 & \multicolumn{2}{c}{ Pista de Concreto } & 0,280 \\
D1R57,0V6,5 & 69,0 & 16,4 & 0,313 \\
D1R57,0V8,3 & 63,4 & 8,0 & 0,337 \\
D1R57,0V10,4 & 67,3 & 5,2 & 0,288 \\
D1R50,0V5,0 & 67,0 & 4,0 & 0,348 \\
D1R50,0V6,5 & 44,0 & 14,0 & 0,320 \\
D1R50,0V8,3 & 53,5 & 14,0 & 0,293 \\
D1R50,0V10,4 & 65,0 & 9,5 & 0,300 \\
\hline Média & 65,5 & 7,0 & $\mathbf{0 , 3 1 0}$ \\
Desvio Padrão & $\mathbf{6 1 , 8}$ & $\mathbf{9 , 8}$ & $\mathbf{0 , 0 2 4}$ \\
\hline D1R57,0V5,0 & $\mathbf{8 , 6}$ & $\mathbf{4 , 5}$ & \\
D1R57,0V6,5 & Pista de Solo Firme & 0,372 \\
D1R57,0V8,3 & 44,0 & 12,7 & 0,360 \\
D1R57,0V10,4 & 51,4 & 15,3 & 0,270 \\
Média & 66,0 & 7,0 & 0,293 \\
Desvio Padrão & 62,4 & $\mathbf{0 , 3 2 4}$ \\
\hline
\end{tabular}

Tabela 35 - Valores de rendimento máximo na barra de tração, patinagem dos rodados e consumo específico de combustível para as condições do ensaio do trator (E).

\begin{tabular}{|c|c|c|c|}
\hline Denominação & $\begin{array}{c}\text { Rendimento na barra } \\
(\%)\end{array}$ & $\begin{array}{c}\text { Patinagem } \\
(\%)\end{array}$ & $\begin{array}{c}\text { Consumo específico } \\
\left(\mathrm{kg} \cdot \mathrm{kW}^{-1} \cdot \mathrm{h}^{-1}\right)\end{array}$ \\
\hline \multicolumn{4}{|c|}{ Pista de Solo Firme } \\
\hline E1R58,4V7,0 & 64,0 & 10,5 & 0,310 \\
\hline E2R50,0V7,0 & 55,0 & 14,0 & 0,360 \\
\hline E2R52,5V7,0 & 59,0 & 12,5 & 0,340 \\
\hline E2R56,2V7,0 & 58,0 & 10,5 & 0,345 \\
\hline E2R58,4V7,0 & 58,0 & 10,0 & 0,330 \\
\hline E3R58,4V7,0 & 58,0 & 11,0 & 0,340 \\
\hline $\mathrm{E} 4 \mathrm{R} 58,4 \mathrm{~V} 7,0$ & 59,0 & 11,5 & 0,340 \\
\hline Média & 58,7 & 11,4 & 0,338 \\
\hline Desvio Padrão & 2,7 & 1,4 & 0,015 \\
\hline
\end{tabular}


Tabela 36 - Valores de rendimento máximo na barra de tração, patinagem dos rodados e consumo específico de combustível para as condições do ensaio do trator (F).

\begin{tabular}{|c|c|c|c|}
\hline Denominação & $\begin{array}{c}\text { Rendimento na barra } \\
(\%)\end{array}$ & $\begin{array}{c}\text { Patinagem } \\
(\%)\end{array}$ & $\begin{array}{c}\text { Consumo específico } \\
\left(\mathrm{kg} \cdot \mathrm{kW}^{-1} \cdot \mathrm{h}^{-1}\right)\end{array}$ \\
\hline \multicolumn{4}{|c|}{ Pista de Solo Firme } \\
\hline F1R52,5V5,0 & 46,0 & 10,8 & 0,377 \\
\hline F1R52,5V5,8 & 49,8 & 15,2 & 0,347 \\
\hline F1R52,5V6,7 & 59,0 & 15,8 & 0,297 \\
\hline F1R55,0V5,0 & 47,0 & 15,6 & 0,341 \\
\hline F1R55,0V5,8 & 59,0 & 13,8 & 0,320 \\
\hline F1R55,0V6,7 & 59,0 & 13,2 & 0,327 \\
\hline F2R52,5V 5,0 & 53,0 & 17,7 & 0,326 \\
\hline F2R52,5V 5,8 & 50,0 & 15,8 & 0,381 \\
\hline F2R52,5V6,7 & 55,0 & 22,2 & 0,373 \\
\hline F2R55,0V5,0 & 41,0 & 15,7 & 0,383 \\
\hline F2R55,0V5,8 & 44,1 & 18,2 & 0,406 \\
\hline F2R55,0V6,7 & 58,2 & 14,2 & 0,350 \\
\hline F2R57,5V5,0 & 44,3 & 16,2 & 0,364 \\
\hline F2R57,5V 5,8 & 51,4 & 16,0 & 0,363 \\
\hline F2R57,5V6,7 & 52,5 & 18,7 & 0,342 \\
\hline F3R57,0V5,0 & 43,0 & 13,6 & 0,383 \\
\hline F3R57,0V 5,8 & 49,0 & 20,0 & 0,380 \\
\hline F3R57,0V6,7 & 56,9 & 14,4 & 0,342 \\
\hline F4R57,5V 5,0 & 45,0 & 15,5 & 0,380 \\
\hline F4R57,5V 5,8 & 48,5 & 8,7 & 0,350 \\
\hline F4R57,5V6,7 & 55,2 & 8,2 & 0,340 \\
\hline Média & 50,8 & 15,2 & 0,356 \\
\hline Desvio Padrão & 5,8 & 3,3 & $\mathbf{0 , 0 2 7}$ \\
\hline \multicolumn{4}{|c|}{ Pista de Solo com Cobertura Vegetal } \\
\hline F1R55,0V5,0 & 37,9 & 10,6 & 0,390 \\
\hline F1R55,0V5,8 & 50,5 & 21,0 & 0,409 \\
\hline F1R55,0V6,7 & 55,0 & 12,8 & 0,425 \\
\hline F2R52,5V5,0 & 44,0 & 16,9 & 0,390 \\
\hline F2R52,5V5,8 & 51,0 & 16,3 & 0,378 \\
\hline F2R52,5V6,7 & 51,8 & 12,4 & 0,380 \\
\hline F2R55,0V5,0 & 42,1 & 21,1 & 0,423 \\
\hline F2R55,0V 5,8 & 49,4 & 16,7 & 0,377 \\
\hline F2R55,0V6,7 & 52,0 & 12,5 & 0,371 \\
\hline
\end{tabular}

Continua... 
Continuação da Tabela 36.

\begin{tabular}{|c|c|c|c|}
\hline & & & \\
\hline $\mathrm{F} 2 \mathrm{R} 57,5 \mathrm{~V} 5,0$ & 44,0 & 20,0 & 0,405 \\
\hline F2R57,5V5,8 & 46,7 & 20,6 & 0,414 \\
\hline F2R57,5V6,7 & 51,1 & 15,2 & 0,377 \\
\hline F3R57,0V5,0 & 42,2 & 17,2 & 0,395 \\
\hline F3R57,0V5,8 & 47,7 & 18,1 & 0,393 \\
\hline F3R57,0V6,7 & 53,0 & 15,7 & 0,354 \\
\hline F4R57,5V 5,0 & 48,0 & 20,8 & 0,440 \\
\hline F4R57,5V5,8 & 49,2 & 19,9 & 0,387 \\
\hline F4R57,5V6,7 & 52,7 & 12,9 & 0,294 \\
\hline Média & 48,2 & 16,7 & $\mathbf{0 , 3 8 9}$ \\
\hline Desvio Padrão & 4,6 & 3,4 & $\mathbf{0 , 0 3 2}$ \\
\hline \multicolumn{4}{|c|}{ Pista de Solo Mobilizado } \\
\hline F1R52,5V5,0 & 39,0 & 19,9 & 0,422 \\
\hline F1R52,5V5,8 & 43,4 & 21,0 & 0,426 \\
\hline F1R52,5V6,7 & 48,0 & 18,7 & 0,400 \\
\hline F1R55,0V5,0 & 38,0 & 14,0 & 0,400 \\
\hline F1R55,0V5,8 & 42,6 & 18,1 & 0,431 \\
\hline F1R55,0V6,7 & 47,0 & 18,5 & 0,430 \\
\hline F2R52,5V5,0 & 35,0 & 18,8 & 0,448 \\
\hline F2R52,5V5,8 & 39,6 & 15,7 & 0,427 \\
\hline F2R52,5V6,7 & 49,0 & 14,9 & 0,408 \\
\hline F2R55,0V5,0 & 38,0 & 20,8 & 0,436 \\
\hline F2R55,0V5,8 & 43,0 & 17,6 & 0,430 \\
\hline F2R55,0V6,7 & 49,0 & 11,5 & 0,400 \\
\hline F2R57,5V5,0 & 40,0 & 19,8 & 0,432 \\
\hline F2R57,5V5,8 & 46,0 & 19,2 & 0,411 \\
\hline F2R57,5V6,7 & 49,0 & 15,3 & 0,394 \\
\hline F3R57,0V5,0 & 38,1 & 18,5 & 0,436 \\
\hline F3R57,0V5,8 & 46,0 & 16,0 & 0,377 \\
\hline F3R57,0V6,7 & 48,6 & 11,2 & 0,410 \\
\hline F4R57,5V5,0 & 41,9 & 19,0 & 0,427 \\
\hline F4R57,5V5,8 & 47,0 & 17,7 & 0,410 \\
\hline F4R57,5V6,7 & 50,1 & 15,6 & 0,396 \\
\hline Média & 43,7 & 17,2 & $\mathbf{0 , 4 1 7}$ \\
\hline Desvio Padrão & 4,6 & 2,8 & $\mathbf{0 , 0 1 8}$ \\
\hline
\end{tabular}


Tabela 37 - Valores de rendimento máximo na barra de tração, patinagem dos rodados e consumo específico de combustível para as condições do ensaio do trator $(\mathrm{G})$.

\begin{tabular}{cccc}
\hline Denominação & $\begin{array}{c}\text { Rendimento na barra } \\
\mathbf{( \% )}\end{array}$ & $\begin{array}{c}\text { Patinagem } \\
\mathbf{( \% )}\end{array}$ & $\begin{array}{c}\text { Consumo específico } \\
\mathbf{( k g . k W}^{\mathbf{1}} \mathbf{. h}^{\mathbf{- 1}} \mathbf{)}\end{array}$ \\
\hline G1R57,0V5,0 & \multicolumn{2}{c}{ Pista de Solo Firme } & \\
G1R57,0V5,8 & 47,9 & 17,1 & 0,374 \\
G1R57,0V6,7 & 52,0 & 9,5 & 0,334 \\
G2R57,0V5,0 & 55,3 & 10,7 & 0,335 \\
G2R57,0V5,8 & 42,5 & 19,6 & 0,418 \\
G2R57,0V6,7 & 53,0 & 13,6 & 0,341 \\
Média & 58,3 & 10,3 & 0,338 \\
Desvio Padrão & $\mathbf{5 1 , 5}$ & $\mathbf{1 3 , 5}$ & $\mathbf{0 , 3 5 7}$ \\
\hline G1R57,0V5,0 & $\mathbf{5 , 6}$ & $\mathbf{4 , 1}$ & $\mathbf{0 , 0 3 4}$ \\
G1R57,0V5,8 & Pista de Solo com Cobertura Vegetal & 0,385 \\
G1R57,0V6,7 & 41,0 & 11,5 & 0,374 \\
G2R57,0V5,0 & 48,6 & 17,9 & 0,362 \\
G2R57,0V5,8 & 54,0 & 10,8 & 0,360 \\
G2R57,0V6,7 & 44,2 & 15,1 & 0,374 \\
Média & 50,0 & 17,9 & 0,351 \\
Desvio Padrão & 53,2 & 12,4 & $\mathbf{0 , 3 6 8}$ \\
\hline G1R57,0V5,0 & $\mathbf{4 8 , 5}$ & $\mathbf{1 4 , 3}$ & $\mathbf{0 , 0 1 2}$ \\
\hline G1R57,0V5,8 & $\mathbf{5 , 1}$ & $\mathbf{3 , 2}$ & 0,460 \\
G1R57,0V6,7 & Pista de Solo Mobilizado & 0,447 \\
G2R57,0V5,0 & 33,0 & 13,6 & 0,407 \\
G2R57,0V5,8 & 41,5 & 18,8 & 0,464 \\
G2R57,0V6,7 & 47,0 & 10,8 & 0,419 \\
Média & 35,1 & 18,8 & 0,395 \\
Desvio Padrão & 41,3 & $\mathbf{0 , 4 3 2}$ \\
\hline & 51,0 & $\mathbf{1 4 , 9}$ & $\mathbf{0 , 0 2 9}$ \\
\hline
\end{tabular}


Tabela 38 - Valores de rendimento máximo na barra de tração, patinagem dos rodados e consumo específico de combustível para as condições do ensaio do trator $(\mathrm{H})$.

\begin{tabular}{cccc}
\hline Denominação & $\begin{array}{c}\text { Rendimento na barra } \\
(\mathbf{\%})\end{array}$ & $\begin{array}{c}\text { Patinagem } \\
(\boldsymbol{\%})\end{array}$ & $\begin{array}{c}\text { Consumo específico } \\
\left(\mathbf{k g . k}^{\mathbf{- 1}} \mathbf{. h}^{\mathbf{- 1}} \mathbf{)}\right.\end{array}$ \\
\hline H1R55,0V4,4 & \multicolumn{2}{c}{ Pista de Solo Firme } & \\
H1R55,0V5,0 & 40,0 & 11,8 & 0,450 \\
H1R55,0V8,2 & 47,0 & 12,2 & 0,400 \\
H1R55,0V9,6 & 64,5 & 11,4 & 0,310 \\
H1R55,0V11,5 & 69,7 & 7,8 & 0,302 \\
H1R55,0V13,2 & 74,9 & 42,0 & 0,279 \\
H1R55,0V15,6 & 71,0 & 7,3 & 0,304 \\
Média & 74,4 & 5,2 & 0,287 \\
Desvio Padrão & $\mathbf{6 3 , 1}$ & $\mathbf{1 4 , 0}$ & $\mathbf{0 , 3 3 3}$ \\
\hline
\end{tabular}

Tabela 39 - Valores de rendimento máximo na barra de tração, patinagem dos rodados e consumo específico de combustível para as condições do ensaio do trator (I).

\begin{tabular}{|c|c|c|c|}
\hline Denominação & $\begin{array}{c}\text { Rendimento na barra } \\
(\%)\end{array}$ & $\begin{array}{c}\text { Patinagem } \\
(\%)\end{array}$ & $\begin{array}{c}\text { Consumo específico } \\
\left(\mathbf{k g} \cdot \mathrm{kW}^{-1} \cdot \mathrm{h}^{-1}\right)\end{array}$ \\
\hline \multicolumn{4}{|c|}{ Pista de Solo Firme } \\
\hline I1R57,5V4,5 & 39,0 & 10,5 & 0,350 \\
\hline I1R57,5V5,0 & 50,0 & 17,0 & 0,340 \\
\hline I1R57,5V6,0 & 62,0 & 14,0 & 0,335 \\
\hline I1R57,5V7,5 & 70,0 & 10,5 & 0,315 \\
\hline I1R57,5V8,0 & 65,0 & 6,0 & 0,310 \\
\hline I1R57,5V9,0 & 75,2 & 9,0 & 0,279 \\
\hline I1 R57,5V10,0 & 77,6 & 6,0 & 0,277 \\
\hline $\mathrm{I} 2 \mathrm{R} 45,3 \mathrm{~V} 6,0$ & 43,0 & 13,5 & 0,305 \\
\hline $\mathrm{I} 2 \mathrm{R} 45,3 \mathrm{~V} 7,0$ & 48,0 & 11,5 & 0,245 \\
\hline $\mathrm{I} 2 \mathrm{R} 45,3 \mathrm{~V} 9,0$ & 61,0 & 12,0 & 0,280 \\
\hline I2R54,6V6,0 & 54,0 & 11,5 & 0,390 \\
\hline I2R54,6V7,0 & 55,3 & 15,1 & 0,300 \\
\hline I2R54,6V9,0 & 70,0 & 10,5 & 0,255 \\
\hline I3R45,3V6,0 & 49,0 & 11,0 & 0,360 \\
\hline $\mathrm{I} 3 \mathrm{R} 45,3 \mathrm{~V} 7,0$ & 55,0 & 8,9 & 0,355 \\
\hline I3R45,3V9,0 & 70,5 & 9,0 & 0,335 \\
\hline I3R54,6V6,0 & 55,4 & 8,5 & 0,378 \\
\hline I3R54,6V7,0 & 66,1 & 8,5 & 0,317 \\
\hline
\end{tabular}

Continua... 
Continuação da Tabela 39.

\begin{tabular}{cccc}
\hline I3R $54,6 V 9,0$ & 76,0 & 7,0 & 0,300 \\
Média & $\mathbf{6 0 , 1}$ & $\mathbf{1 0 , 5}$ & $\mathbf{0 , 3 1 7}$ \\
Desvio Padrão & $\mathbf{1 1 , 5}$ & $\mathbf{3 , 0}$ & $\mathbf{0 , 0 4 0}$ \\
\hline & \multicolumn{1}{c}{ Pista de Solo Mobilizado } & \\
\hline I2R54,6V7,0a & 38,0 & 15,5 & 0,450 \\
I2R 54,6V7,0b & 37,0 & 16,2 & 0,415 \\
I3R54,6V7,0a & 42,8 & 19,7 & 0,360 \\
I3R54,6V7,0b & 41,3 & 16,6 & 0,396 \\
Média & $\mathbf{3 9 , 8}$ & $\mathbf{1 7 , 0}$ & $\mathbf{0 , 4 0 5}$ \\
Desvio Padrão & $\mathbf{2 , 7}$ & $\mathbf{1 , 9}$ & $\mathbf{0 , 0 3 8}$ \\
\hline
\end{tabular}

Tabela 40 - Valores de rendimento máximo na barra de tração, patinagem dos rodados e consumo específico de combustível para as condições do ensaio do trator (J).

\begin{tabular}{|c|c|c|c|}
\hline Denominação & $\begin{array}{c}\text { Rendimento na barra } \\
(\%)\end{array}$ & $\begin{array}{c}\text { Patinagem } \\
(\%)\end{array}$ & $\begin{array}{c}\text { Consumo específico } \\
\left(\mathrm{kg} \cdot \mathrm{kW}^{-1} \cdot \mathrm{h}^{-1}\right)\end{array}$ \\
\hline \multicolumn{4}{|c|}{ Pista de Concreto } \\
\hline J1R55,0V4,8 & 48,1 & 7,6 & 0,400 \\
\hline J1R55,0V7,8 & 64,0 & 6,0 & 0,365 \\
\hline J1R55,0V9,4 & 64,3 & 4,4 & 0,364 \\
\hline $\mathrm{J} 2 \mathrm{R} 55,0 \mathrm{~V} 4,8$ & 40,8 & 6,4 & 0,390 \\
\hline J2R55,0V6,5 & 64,7 & 8,0 & 0,354 \\
\hline $\mathrm{J} 2 \mathrm{R} 55,0 \mathrm{~V} 7,8$ & 69,6 & 6,5 & 0,312 \\
\hline J2R55,0V9,4 & 69,0 & 4,1 & 0,318 \\
\hline J3R55,0V4,8 & 52,6 & 9,0 & 0,366 \\
\hline J3R55,0V6,5 & 68,0 & 9,1 & 0,328 \\
\hline J3R55,0V7,8 & 68,0 & 7,0 & 0,318 \\
\hline J3R55,0V9,4 & 65,8 & 5,1 & 0,326 \\
\hline $\mathrm{J} 4 \mathrm{R} 55,0 \mathrm{~V} 4,8$ & 51,7 & 10,9 & 0,380 \\
\hline J4R55,0V6,5 & 65,0 & 10,0 & 0,349 \\
\hline $\mathrm{J} 4 \mathrm{R} 55,0 \mathrm{~V} 7,8$ & 69,3 & 6,8 & 0,334 \\
\hline J4R55,0V9,4 & 66,6 & 5,8 & 0,354 \\
\hline J5R55,0V4,8 & 55,1 & 5,9 & 0,299 \\
\hline J5R55,0V6,5 & 62,3 & 6,0 & 0,263 \\
\hline J5R55,0V7,8 & 62,9 & 3,8 & 0,291 \\
\hline J5R55,0V9,4 & 60,5 & 3,6 & 0,296 \\
\hline J6R55,0V4,8 & 59,5 & 6,3 & 0,219 \\
\hline J6R55,0V6,5 & 69,7 & 5,4 & 0,192 \\
\hline J6R55,0V7,8 & 69,7 & 4,1 & 0,210 \\
\hline
\end{tabular}

Continua... 
Continuação da Tabela 40.

\begin{tabular}{|c|c|c|c|}
\hline J6R55,0V9,4 & 67,0 & 2,7 & 0,221 \\
\hline J7R55,0V4,8 & 56,9 & 7,6 & 0,258 \\
\hline J7R55,0V6,5 & 67,5 & 6,1 & 0,240 \\
\hline J7R55,0V7,8 & 66,0 & 4,6 & 0,237 \\
\hline J7R55,0V9,4 & 64,0 & 2,6 & 0,255 \\
\hline J8R55,0V4,8 & 54,2 & 9,8 & 0,279 \\
\hline J8R55,0V6,5 & 61,5 & 6,4 & 0,252 \\
\hline J8R55,0V7,8 & 63,6 & 5,7 & 0,233 \\
\hline J8R55,0V9,4 & 61,0 & 4,7 & 0,256 \\
\hline Média & 62,2 & 6,2 & 0,299 \\
\hline Desvio Padrão & 7,0 & 2,1 & 0,059 \\
\hline \multicolumn{4}{|c|}{ Pista de Solo Firme } \\
\hline J1R55,0V4,8 & 37,0 & 14,1 & 0,441 \\
\hline J1R55,0V6,5 & 52,0 & 14,9 & 0,409 \\
\hline $\mathrm{J} 1 \mathrm{R} 55,0 \mathrm{~V} 7,8$ & 66,0 & 10,3 & 0,362 \\
\hline J1R55,0V9,4 & 61,4 & 5,4 & 0,387 \\
\hline $\mathrm{J} 2 \mathrm{R} 55,0 \mathrm{~V} 4,8$ & 45,0 & 17,2 & 0,423 \\
\hline J2R55,0V6,5 & 62,0 & 13,4 & 0,391 \\
\hline J2R55,0V7,8 & 65,0 & 7,7 & 0,370 \\
\hline J2R55,0V9,4 & 63,0 & 4,9 & 0,370 \\
\hline J3R55,0V4,8 & 45,0 & 12,1 & 0,390 \\
\hline J3R55,0V6,5 & 59,0 & 13,2 & 0,393 \\
\hline J3R55,0V7,8 & 64,5 & 11,0 & 0,355 \\
\hline J3R55,0V9,4 & 56,9 & 6,7 & 0,385 \\
\hline J4R55,0V4,8 & 47,0 & 15,4 & 0,398 \\
\hline J4R55,0V6,5 & 61,0 & 12,4 & 0,379 \\
\hline $\mathrm{J} 4 \mathrm{R} 55,0 \mathrm{~V} 7,8$ & 64,8 & 9,5 & 0,356 \\
\hline J4R55,0V9,4 & 63,1 & 6,2 & 0,357 \\
\hline J5R55,0V4,8 & 49,0 & 15,0 & 0,380 \\
\hline J5R55,0V6,5 & 59,0 & 8,8 & 0,300 \\
\hline J5R55,0V7,8 & 58,8 & 7,1 & 0,293 \\
\hline J5R55,0V9,4 & 57,9 & 5,0 & 0,311 \\
\hline J6R55,0V4,8 & 48,0 & 14,1 & 0,340 \\
\hline J6R55,0V6,5 & 59,0 & 13,8 & 0,300 \\
\hline J6R55,0V7,8 & 61,0 & 6,0 & 0,280 \\
\hline J6R55,0V9,4 & 58,5 & 4,8 & 0,290 \\
\hline J7R55,0V4,8 & 45,0 & 10,8 & 0,390 \\
\hline J7R55,0V6,5 & 59,5 & 9,2 & 0,352 \\
\hline
\end{tabular}

Continua... 
Continuação da Tabela 40.

\begin{tabular}{rccc}
\hline J7R55,0V7,8 & 67,0 & 6,8 & 0,238 \\
J7R55,0V9,4 & 63,5 & 5,0 & 0,223 \\
J8R55,0V4,8 & 47,0 & 13,1 & 0,390 \\
J8R55,0V6,5 & 64,5 & 12,0 & 0,290 \\
J8R55,0V7,8 & 63,0 & 6,7 & 0,295 \\
J8R55,0V9,4 & 64,0 & 5,0 & 0,260 \\
Média & $\mathbf{5 7 , 4}$ & $\mathbf{9 , 9}$ & $\mathbf{0 , 3 4 7}$ \\
Desvio Padrão & $\mathbf{7 , 9}$ & $\mathbf{3 , 8}$ & $\mathbf{0 , 0 5 5}$ \\
\hline Pista de Solo com Cobertura Vegetal & \\
\hline J1R55,0V4,8 & 26,4 & 15,6 & 0,577 \\
J1R55,0V6,5 & 36,4 & 12,3 & 0,490 \\
J1R55,0V9,4 & 43,5 & 13,8 & 0,498 \\
J2R55,0V4,8 & 48,5 & 15,3 & 0,460 \\
J2R55,0V6,5 & 31,1 & 13,5 & 0,576 \\
J2R55,0V7,8 & 37,5 & 15,5 & 0,565 \\
J2R55,0V9,4 & 46,0 & 15,7 & 0,490 \\
J5R55,0V4,8 & 52,1 & 13,5 & 0,495 \\
J5R55,0V6,5 & 38,5 & 14,4 & 0,460 \\
J5R55,0V7,8 & 56,0 & 17,0 & 0,370 \\
J5R55,0V9,4 & 58,0 & 15,2 & 0,369 \\
J7R55,0V4,8 & 57,3 & 7,4 & 0,368 \\
J7R55,0V6,5 & 41,0 & 18,0 & 0,430 \\
J7R55,0V7,8 & 50,1 & 14,0 & 0,414 \\
J7R55,0V9,4 & 57,0 & 11,1 & 0,385 \\
Média & 61,0 & 6,8 & 0,340 \\
Desvio Padrão & $\mathbf{4 6 , 3}$ & $\mathbf{0 , 4 5 5}$ \\
\hline & $\mathbf{1 0 , 4}$ & $\mathbf{3 , 1}$ & $\mathbf{0 , 0 7 8}$ \\
\hline
\end{tabular}

Tabela 41 - Valores de rendimento máximo na barra de tração, patinagem dos rodados e consumo específico de combustível para as condições do ensaio do trator (K).

\begin{tabular}{|c|c|c|c|}
\hline Denominação & $\begin{array}{c}\text { Rendimento na barra } \\
(\%)\end{array}$ & $\begin{array}{c}\text { Patinagem } \\
(\%)\end{array}$ & $\begin{array}{c}\text { Consumo específico } \\
\left(\mathrm{kg} \cdot \mathrm{kW}^{-1} \cdot \mathrm{h}^{-1}\right)\end{array}$ \\
\hline \multicolumn{4}{|c|}{ Pista de Solo Firme } \\
\hline K1R57,8V5,0a & 52,5 & 12,3 & 0,343 \\
\hline K1R57,8V5,0b & 44,4 & 18,0 & 0,384 \\
\hline $\mathrm{K} 1 \mathrm{R} 57,8 \mathrm{~V} 7,0 \mathrm{a}$ & 65,0 & 8,5 & 0,420 \\
\hline $\mathrm{K} 1 \mathrm{R} 57,8 \mathrm{~V} 7,0 \mathrm{~b}$ & 57,9 & 7,4 & 0,304 \\
\hline
\end{tabular}

Continua... 
Continuação da Tabela 41.

\begin{tabular}{|c|c|c|c|}
\hline K2R57,8V5,0a & 50,4 & 15,8 & 0,391 \\
\hline K2R57,8V5,0b & 48,2 & 11,1 & 0,384 \\
\hline $\mathrm{K} 2 \mathrm{R} 57,8 \mathrm{~V} 7,0 \mathrm{a}$ & 65,9 & 4,9 & 0,297 \\
\hline $\mathrm{K} 2 \mathrm{R} 57,8 \mathrm{~V} 7,0 \mathrm{~b}$ & 63,0 & 8,3 & 0,331 \\
\hline K3R55,5V5,0a & 53,9 & 6,6 & 0,335 \\
\hline K3R55,5V5,0b & 50,1 & 12,1 & 0,359 \\
\hline $\mathrm{K} 3 \mathrm{R} 55,5 \mathrm{~V} 7,0 \mathrm{a}$ & 77,7 & 3,3 & 0,289 \\
\hline K3R55,5V7,0b & 72,8 & 8,7 & 0,308 \\
\hline K4R57,0V5,0a & 42,5 & 18,6 & 0,402 \\
\hline K4R57,0V5,0b & 42,0 & 8,8 & 0,396 \\
\hline K4R57,0V7,0a & 62,0 & 17,0 & 0,360 \\
\hline K4R57,0V7,0b & 56,0 & 14,6 & 0,364 \\
\hline K5R57,8V4,0 & 39,4 & 18,6 & 0,336 \\
\hline K5R57,8V6,0 & 56,7 & 13,2 & 0,300 \\
\hline $\mathrm{K} 5 \mathrm{R} 57,8 \mathrm{~V} 7,0$ & 58,7 & 13,3 & 0,289 \\
\hline K5R57,8V8,0 & 62,5 & 9,5 & 0,290 \\
\hline Média & 56,1 & 11,5 & 0,344 \\
\hline Desvio Padrão & 10,3 & 4,6 & 0,043 \\
\hline \multicolumn{4}{|c|}{ Pista de Solo com Cobertura Vegetal } \\
\hline K1R57,8V5,0 & 51,5 & 15,6 & 0,365 \\
\hline $\mathrm{K} 1 \mathrm{R} 57,8 \mathrm{~V} 7,0$ & 51,5 & 14,5 & 0,370 \\
\hline K2R57,8V5,0 & 53,1 & 21,9 & 0,397 \\
\hline $\mathrm{K} 2 \mathrm{R} 57,8 \mathrm{~V} 7,0$ & 62,1 & 8,3 & 0,359 \\
\hline K3R55,5V5,0 & 53,5 & 18,7 & 0,389 \\
\hline $\mathrm{K} 3 \mathrm{R} 55,5 \mathrm{~V} 7,0$ & 59,6 & 13,2 & 0,364 \\
\hline K4R57,0V5,0 & 44,1 & 21,4 & 0,440 \\
\hline K4R57,0V7,0 & 55,0 & 13,5 & 0,391 \\
\hline Média & 53,8 & 15,9 & 0,384 \\
\hline Desvio Padrão & 5,5 & 4,6 & $\mathbf{0 , 0 2 7}$ \\
\hline \multicolumn{4}{|c|}{ Pista de Solo Mobilizado } \\
\hline K1R57,8V5,0a & 42,3 & 15,5 & 0,422 \\
\hline K1R57,8V5,0b & 43,0 & 12,8 & 0,420 \\
\hline K1R57,8V7,0a & 44,7 & 7,1 & 0,417 \\
\hline $\mathrm{K} 1 \mathrm{R} 57,8 \mathrm{~V} 7,0 \mathrm{~b}$ & 52,9 & 5,2 & 0,354 \\
\hline K2R57,8V5,0a & 45,3 & 15,4 & 0,431 \\
\hline K2R57,8V5,0b & 47,2 & 16,0 & 0,432 \\
\hline $\mathrm{K} 2 \mathrm{R} 57,8 \mathrm{~V} 7,0 \mathrm{a}$ & 55,2 & 14,8 & 0,407 \\
\hline $\mathrm{K} 2 \mathrm{R} 57,8 \mathrm{~V} 7,0 \mathrm{~b}$ & 52,2 & 12,4 & 0,431 \\
\hline
\end{tabular}

Continua... 
Continuação da Tabela 41.

\begin{tabular}{cccc}
\hline K3R55,5V5,0a & 50,0 & 20,5 & 0,410 \\
K3R55,5V5,0b & 45,4 & 20,7 & 0,438 \\
K3R55,5V7,0a & 58,6 & 16,5 & 0,372 \\
K3R55,5V7,0b & 57,5 & 14,0 & 0,389 \\
K4R57,0V5,0a & 38,4 & 17,4 & 0,459 \\
K4R57,0V5,0b & 38,9 & 11,7 & 0,471 \\
K4R57,0V7,0a & 50,5 & 20,0 & 0,460 \\
K4R57,0V7,0b & 52,0 & 17,5 & 0,428 \\
Média & $\mathbf{4 8 , 4}$ & $\mathbf{1 4 , 8}$ & $\mathbf{0 , 4 2 1}$ \\
Desvio Padrão & $\mathbf{6 , 2}$ & $\mathbf{4 , 4}$ & $\mathbf{0 , 0 3 1}$ \\
\hline
\end{tabular}

Tabela 42 - Valores de rendimento máximo na barra de tração, patinagem dos rodados e consumo específico de combustível para as condições do ensaio do trator (L).

\begin{tabular}{|c|c|c|c|}
\hline Denominação & $\begin{array}{c}\text { Rendimento na barra } \\
(\%)\end{array}$ & $\begin{array}{c}\text { Patinagem } \\
(\%)\end{array}$ & $\begin{array}{c}\text { Consumo específico } \\
\left(\mathrm{kg} \cdot \mathrm{kW}^{-1} \cdot \mathrm{h}^{-1}\right)\end{array}$ \\
\hline \multicolumn{4}{|c|}{ Pista de Solo Firme } \\
\hline L1R53,4V6,5a & 53,7 & 9,0 & 0,314 \\
\hline L1R53,4V6,5b & 51,6 & 12,5 & 0,311 \\
\hline $\mathrm{L} 1 \mathrm{R} 53,4 \mathrm{~V} 7,4 \mathrm{a}$ & 64,5 & 16,8 & 0,303 \\
\hline L1R53,4V7,4b & 62,5 & 8,1 & 0,299 \\
\hline $\mathrm{L} 2 \mathrm{R} 53,4 \mathrm{~V} 4,9 \mathrm{a}$ & 39,5 & 6,6 & 0,335 \\
\hline L2R53,4V4,9b & 38,9 & 12,8 & 0,338 \\
\hline L2R53,4V6,5a & 54,5 & 15,0 & 0,333 \\
\hline L2R53,4V6,5b & 53,4 & 7,4 & 0,302 \\
\hline L2R53,4V7,4 & 62,7 & 7,3 & 0,314 \\
\hline L2R53,4V8,7 & 64,6 & 4,8 & 0,299 \\
\hline L3R53,4V6,5a & 59,5 & 11,6 & 0,324 \\
\hline L3R53,4V6,5b & 54,0 & 10,5 & 0,339 \\
\hline $\mathrm{L} 3 \mathrm{R} 53,4 \mathrm{~V} 7,4 \mathrm{a}$ & 65,0 & 8,9 & 0,321 \\
\hline L3R53,4V7,4b & 64,9 & 8,1 & 0,330 \\
\hline L4R53,4V6,5a & 53,0 & 17,0 & 0,370 \\
\hline L4R53,4V6,5b & 55,5 & 19,7 & 0,357 \\
\hline $\mathrm{L} 4 \mathrm{R} 53,4 \mathrm{~V} 7,4 \mathrm{a}$ & 63,4 & 7,8 & 0,346 \\
\hline L4R53,4V7,4b & 65,3 & 7,8 & 0,332 \\
\hline Média & $\mathbf{5 7 , 0}$ & 10,7 & 0,326 \\
\hline Desvio Padrão & 8,2 & 4,2 & 0,020 \\
\hline
\end{tabular}

Pista de Solo com Cobertura Vegetal

\begin{tabular}{llll}
\hline L1R53,4V6,5 & 54,2 & 11,8 & 0,327 \\
\hline
\end{tabular}

Continua... 
Continuação da Tabela 42.

\begin{tabular}{cccc}
\hline L1R53,4V7,4 & 45,0 & 12,0 & 0,393 \\
L2R53,4V4,9 & 38,3 & 11,4 & 0,358 \\
L2R53,4V6,5 & 50,3 & 15,4 & 0,384 \\
L3R57,2V6,5 & 50,2 & 8,5 & 0,345 \\
L3R57,2V7,4 & 55,4 & 12,9 & 0,371 \\
L4R54,3V6,5 & 50,4 & 21,6 & 0,415 \\
L4R54,3V7,4 & 59,0 & 19,5 & 0,415 \\
Média & $\mathbf{5 0 , 4}$ & $\mathbf{1 4 , 1}$ & $\mathbf{0 , 3 7 6}$ \\
Desvio Padrão & $\mathbf{6 , 4}$ & $\mathbf{4 , 4}$ & $\mathbf{0 , 0 3 2}$ \\
\hline & $\mathbf{P i s t a ~ d e ~ S o l o ~ M o b i l i z a d o ~}$ & 0,353 \\
L1R53,4V6,5 & 45,3 & 10,7 & 0,389 \\
L1R53,4V7,4 & 46,6 & 17,3 & 0,394 \\
L2R53,4V4,9 & 35,6 & 21,0 & 0,375 \\
L2R53,4V6,5 & 50,2 & 16,3 & 0,401 \\
L3R57,2V6,5 & 45,7 & 17,3 & 0,406 \\
L3R57,2V7,4 & 55,1 & 15,1 & 0,370 \\
L4R54,3V6,5 & 53,0 & 17,5 & 0,392 \\
L4R54,3V7,4 & 56,0 & 12,5 & $\mathbf{0 , 3 8 5}$ \\
Média & $\mathbf{4 8 , 4}$ & $\mathbf{1 6 , 0}$ & $\mathbf{0 , 0 1 8}$ \\
Desvio Padrão & $\mathbf{6 , 7}$ & $\mathbf{3 , 2}$ & \\
\hline
\end{tabular}

Na Tabela 43 estão apresentados os valores médios de rendimento máximo na barra de tração, patinagem dos rodados e consumo específico de combustível por trator. Essa grande variabilidade de tratores e condições avaliadas é importante para se obter um valor médio de rendimento na barra e respectivos valores de patinagem e consumo específico de combustível próximo à realidade brasileira.

Nas superfícies trativas avaliadas observa-se que os valores médios de rendimento na barra variaram em função do modelo e potência do trator, além de variar também em função do tipo de pneu, pressão de inflação, velocidade de deslocamento e relação entre peso e potência do motor. Esta grande variação em função da relação entre peso e potência do motor em diferentes marcas de tratores também correspondeu aos resultados encontrados por Lanças, (1996); Lanças et al. (2009); Monteiro et al. (2009b) e Schlosser et al. (2005). 
Tabela 43 - Média dos valores de rendimento máximo na barra de tração, patinagem dos rodados e consumo específico de combustível para os tratores avaliados e respectivas condições de superfície trativa.

\begin{tabular}{|c|c|c|c|}
\hline Trator & $\begin{array}{c}\text { Rendimento na barra } \\
(\%)\end{array}$ & $\begin{array}{c}\text { Patinagem } \\
(\%) \\
\end{array}$ & $\begin{array}{c}\text { Consumo específico } \\
\left(\mathrm{kg}^{\mathrm{k}} \mathrm{kW}^{-1} \cdot \mathrm{h}^{-1}\right)\end{array}$ \\
\hline \multicolumn{4}{|c|}{ Pista de Concreto } \\
\hline (C) & 67,6 & 10,0 & 0,354 \\
\hline (D) & 61,8 & 9,8 & 0,310 \\
\hline$(\mathrm{J})$ & 62,2 & 6,2 & 0,299 \\
\hline \multicolumn{4}{|c|}{ Pista de Solo Firme } \\
\hline (A) & 50,7 & 15,7 & 0,344 \\
\hline (B) & 63,3 & 10,1 & 0,327 \\
\hline (C) & 64,3 & 12,0 & 0,335 \\
\hline (D) & 56,0 & 10,0 & 0,324 \\
\hline (E) & 58,7 & 11,4 & 0,338 \\
\hline$(\mathrm{F})$ & 50,8 & 15,2 & 0,356 \\
\hline (G) & 51,5 & 13,5 & 0,357 \\
\hline (H) & 63,1 & 14,0 & 0,333 \\
\hline (I) & 60,1 & 10,5 & 0,317 \\
\hline$(\mathrm{J})$ & 57,4 & 9,9 & 0,347 \\
\hline$(\mathrm{K})$ & 56,1 & 11,5 & 0,344 \\
\hline$(\mathrm{L})$ & 57,0 & 10,7 & 0,326 \\
\hline \multicolumn{4}{|c|}{ Pista de Solo com Cobertura Vegetal } \\
\hline (A) & 58,1 & 8,8 & 0,296 \\
\hline (B) & 65,0 & 6,8 & 0,327 \\
\hline$(\mathrm{F})$ & 48,2 & 16,7 & 0,389 \\
\hline (G) & 48,5 & 14,3 & 0,368 \\
\hline$(\mathrm{J})$ & 46,3 & 13,7 & 0,455 \\
\hline$(\mathrm{K})$ & 53,8 & 15,9 & 0,384 \\
\hline$(\mathrm{L})$ & 50,4 & 14,1 & 0,376 \\
\hline \multicolumn{4}{|c|}{ Pista de Solo Mobilizado } \\
\hline (A) & 32,3 & 16,9 & 0,423 \\
\hline (B) & 52,8 & 18,0 & 0,397 \\
\hline$(\mathrm{F})$ & 43,7 & 17,2 & 0,417 \\
\hline (G) & 41,5 & 14,9 & 0,432 \\
\hline (I) & 39,8 & 17,0 & 0,405 \\
\hline$(\mathrm{K})$ & 48,4 & 14,8 & 0,421 \\
\hline (L) & 48,4 & 16,0 & 0,385 \\
\hline
\end{tabular}




\subsection{Resultados obtidos nas diferentes superfícies trativas}

$\mathrm{Na}$ Tabela 44 estão apresentados os resultados médios dos ensaios realizados em cada condição de superfície do solo: concreto, solo firme, solo com cobertura vegetal e solo mobilizado.

A pista de concreto apresentou os maiores resultados de rendimento na barra e os menores resultados de patinagem e consumo específico de combustível entre as quatro condições de superfície, sendo esse resultado justificado pela patinagem dos rodados do trator ter sido, na média, 53,1\% menor do que na pista de solo mobilizado, 43,2\% menor que na pista de solo com cobertura vegetal e $26,6 \%$ menor que na pista de solo firme. Analisando os dados de consumo específico de combustível na pista de concreto, este foi $25,4 \%$ menor com relação à pista de solo mobilizado, $19,9 \%$ menor que na pista de solo com cobertura vegetal e 6,5\% menor em relação à pista de solo firme. A média dos dados de rendimento na barra na pista de concreto foi 6,7\% maior quando comparado a pista de solo firme, 13,5\% maior que na pista de solo com cobertura vegetal e 19,2\% maior que na pista de solo mobilizado (Tabela 44).

Os maiores valores de patinagem e consumo horário de combustível se deram nos tratamentos com solo mobilizado, mostrando que esta condição superficial do solo foi responsável pelo menor desempenho do trator. Confirmando os resultados apresentados por Lanças (1996), onde as condições superficiais do solo firme apresentam melhores resultados de eficiência trativa comparando-se com o solo preparado (mobilizado). Isso se deve aos fenômenos da patinagem, que provocam a redução no avanço do trator, e ao recalque ou afundamento do rodado no solo que aumenta a resistência ao rolamento (MIALHE, 1991).

As pistas de solo com superfície firme e com cobertura vegetal não apresentaram resultados de desempenho operacional e energético semelhantes. Este resultado não correspondeu ao encontrado por Monteiro (2008), que encontrou semelhança entre estas duas pistas. Estes resultados em áreas onde existe cobertura vegetal são devidos, há alteração na interação do rodado com o solo que afeta a capacidade do trator em desenvolver a tração, de acordo com Gabriel Filho et al. (2004). 
Tabela 44 - Média dos valores de rendimento máximo na barra de tração, patinagem dos rodados e consumo específico de combustível para as condições de superfície trativa.

\begin{tabular}{|c|c|c|c|}
\hline Superfície & $\begin{array}{c}\text { Rendimento na barra } \\
\qquad(\%)\end{array}$ & $\begin{array}{c}\text { Patinagem } \\
(\%)\end{array}$ & $\begin{array}{c}\text { Consumo específico } \\
\left(\mathrm{kg} \cdot \mathrm{kW}^{-1} \cdot \mathrm{h}^{-1}\right)\end{array}$ \\
\hline Concreto & 63,2 & 7,6 & 0,312 \\
\hline Solo Firme & 56,5 & 11,9 & 0,339 \\
\hline Solo com Cobertura Vegetal & 49,7 & 14,6 & 0,395 \\
\hline Solo Mobilizado & 44,0 & 16,2 & 0,418 \\
\hline
\end{tabular}

Os valores médios de rendimento máximo na barra de tração de tratores com tração dianteira auxiliar (4x2 TDA) obtidos neste trabalho, em pista de concreto foram inferiores aos valores da bibliografia conforme a Figura 13 (Fator 0,86 de Wendel Bowers e norma ASAE D497.4). Em superfície de solo firme o valor médio de rendimento máximo na barra de tração obtido neste trabalho confirmou os valores teóricos da bibliografia citados nesta pesquisa (Figura 14). O valor de rendimento na barra de tração obtido em pista de solo mobilizado foi semelhante ao valor proposto por Wendel Bowers e inferior ao proposto pela norma ASAE D497.4 (Figura 16). O valor médio de rendimento máximo na barra de tração de tratores 4x2 TDA obtido neste trabalho, na condição de superfície de solo com cobertura vegetal, foi de 49,7\% (Figura 15), apresentando um valor intermediário entre as condições de superfície de solo firme e solo mobilizado.

Os valores de rendimento máximo na barra de tração, da bibliografia e práticos obtidos neste trabalho nas respectivas condições de superfície trativa estão apresentados na Tabela 45 .

Tabela 45 - Valores de rendimento máximo na barra de tração de tratores 4x2 TDA, valores da bibliografia e valores dinâmicos obtidos neste trabalho.

\begin{tabular}{cccc}
\hline Superfície & Fator 0,86 & ASABE & Este Trabalho \\
\hline Concreto & $79,2 \%$ & $72,2 \%$ & $63,2 \%$ \\
Solo firme & $58,8 \%$ & $63,9 \%$ & $56,5 \%$ \\
Solo Gradeado & $42,8 \%$ & $53,9 \%$ & $44,0 \%$ \\
Solo com cobertura vegetal & - & - & $49,7 \%$ \\
\hline
\end{tabular}




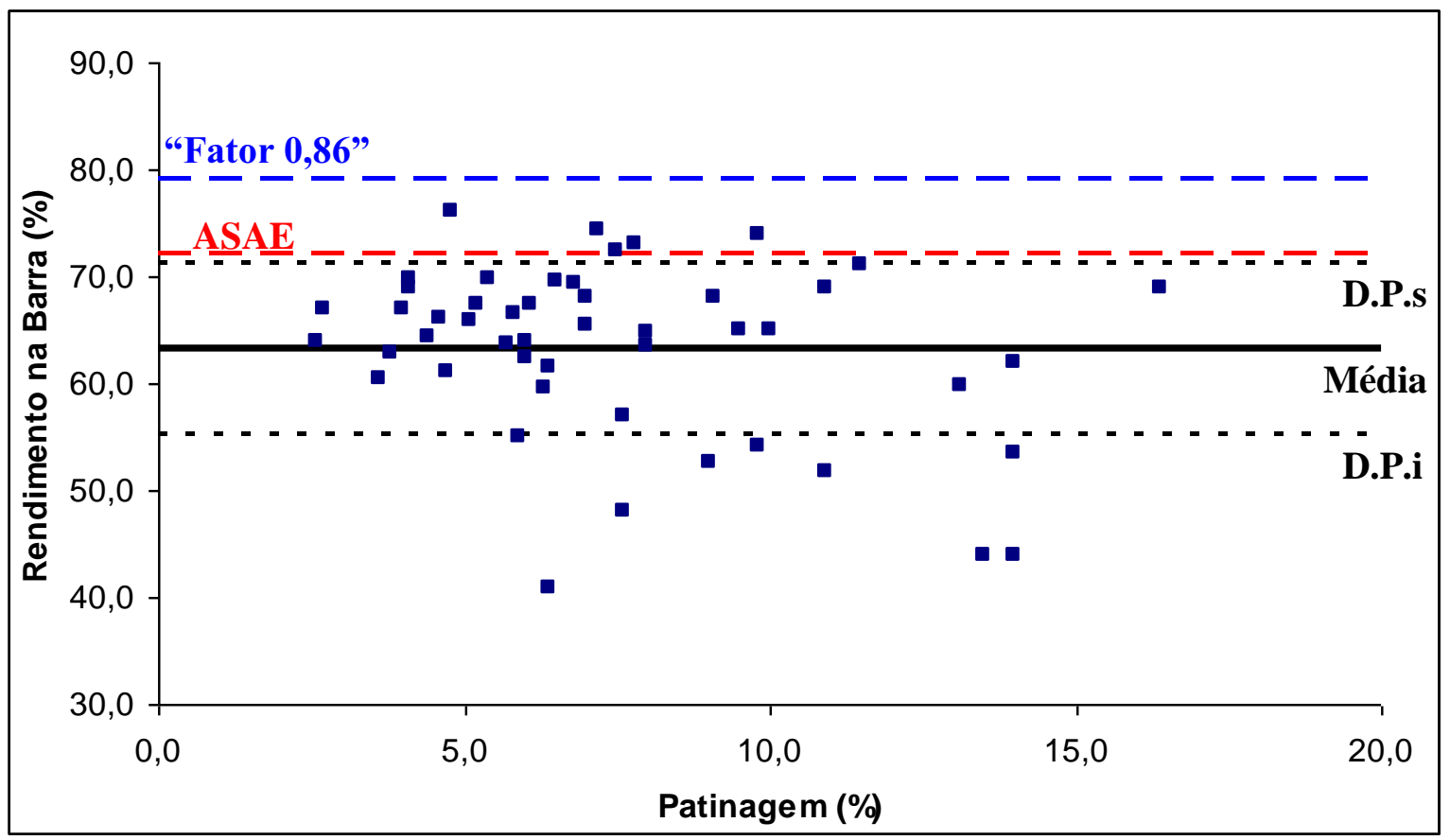

Figura 13 - Resultados obtidos em pista de concreto, valor médio, desvio padrão superior e inferior e valores da bibliografia de rendimento máximo na barra de tração.

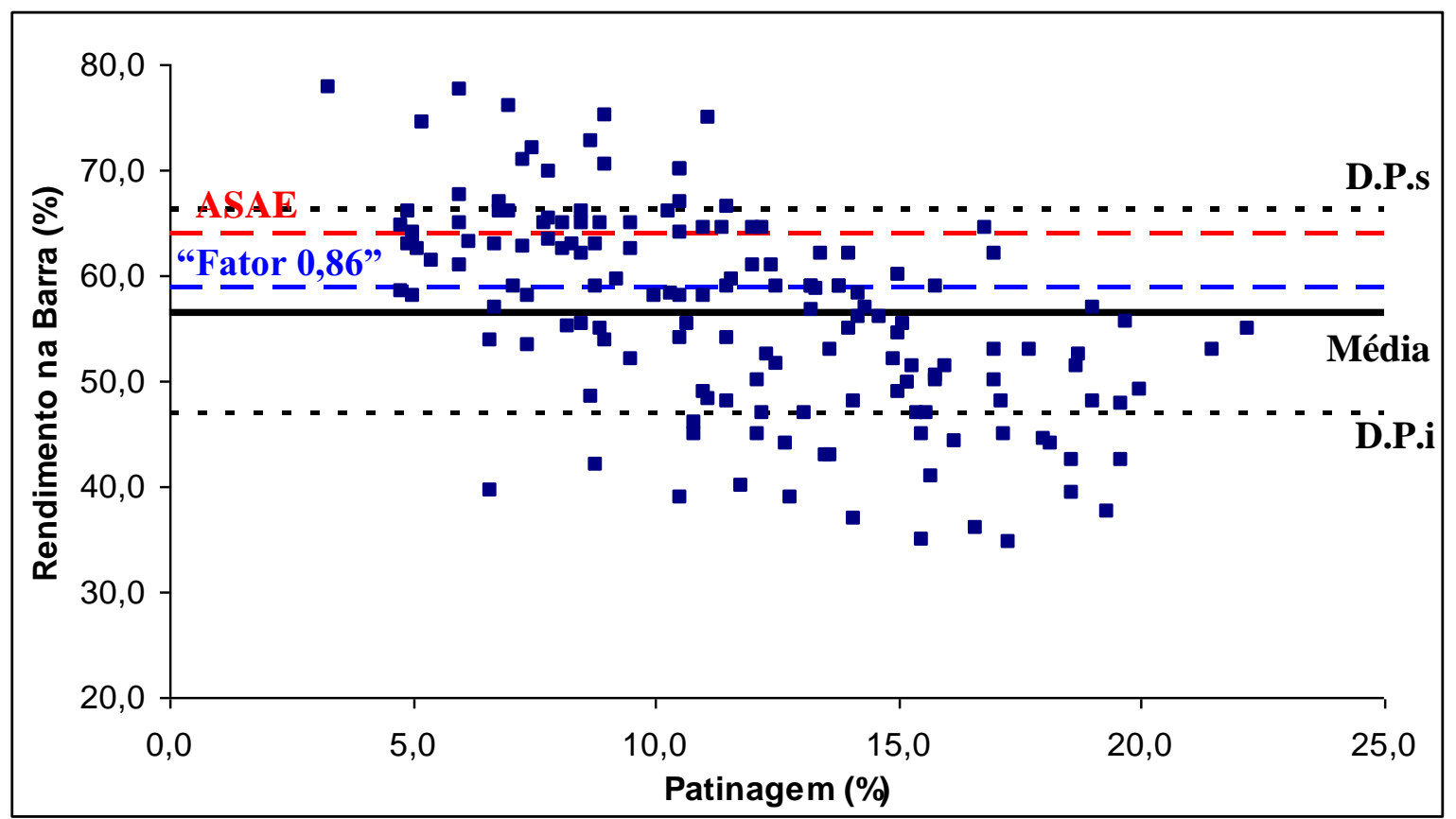

Figura 14 - Resultados obtidos em pista de solo firme, valor médio, desvio padrão superior e inferior e valores da bibliografia de rendimento máximo na barra de tração. 


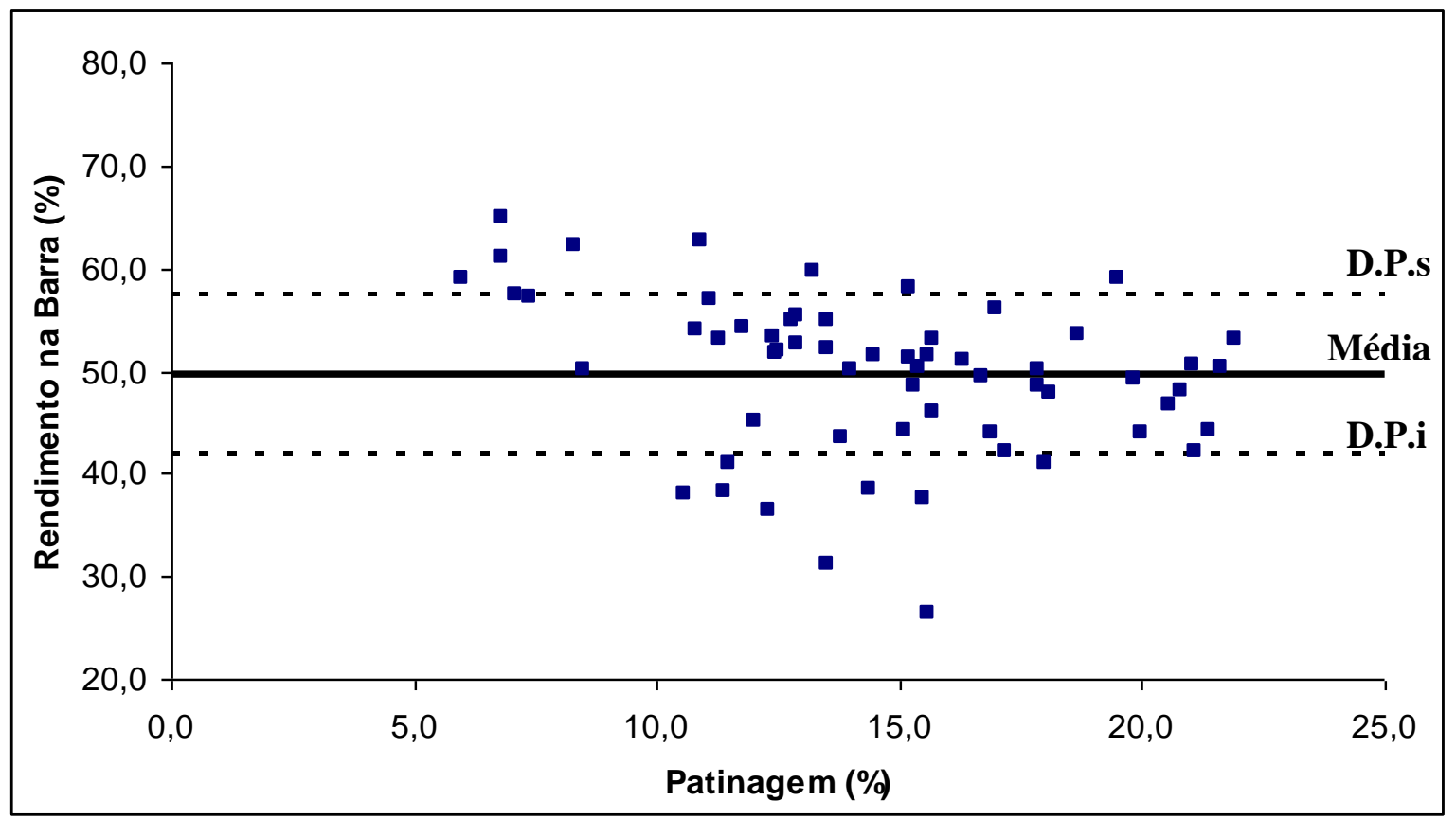

Figura 15 - Resultados obtidos em pista de solo com cobertura vegetal, valor médio, desvio padrão superior e inferior.

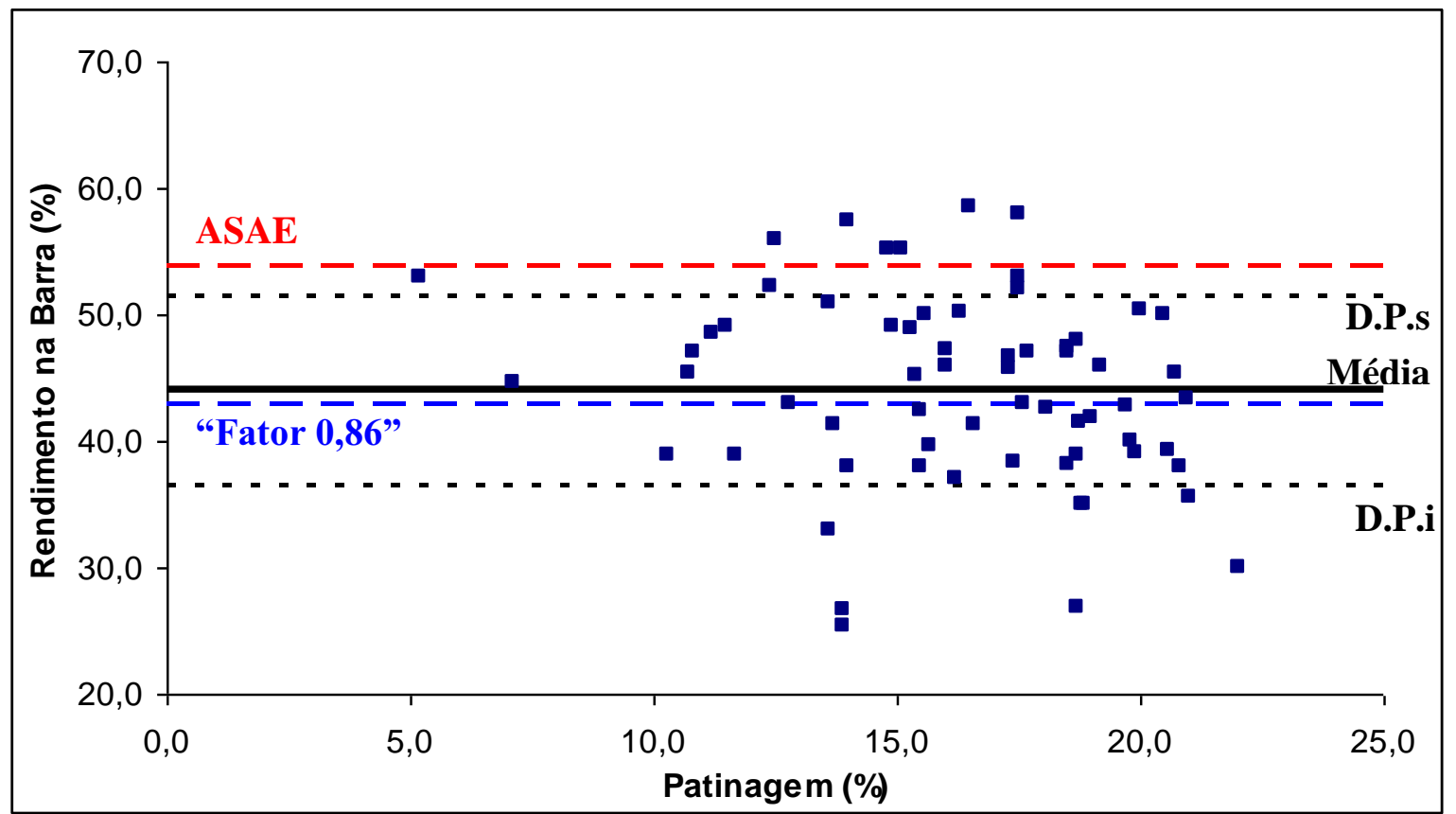

Figura 16 - Resultados obtidos em pista de solo mobilizado, valor médio, desvio padrão superior e inferior e valores da bibliografia de rendimento máximo na barra de tração. 


\section{CONCLUSÕES}

Em pista de concreto o valor médio de rendimento máximo na barra de tração obtido foi inferior aos valores teóricos da bibliografia, "fator 0,86" de Wendel Bowers e norma ASAE D497.4.

Em pista de solo firme o valor dinâmico obtido foi semelhante aos valores da bibliografia consultada neste trabalho

Em pista de solo mobilizado o valor médio de rendimento máximo na barra obtido foi similar ao valor proposto por Wendel Bowers e inferior ao valor proposto pela norma ASAE D497.4.

Em pista de solo com cobertura vegetal o valor médio de rendimento máximo na barra de tração obtido foi $49,7 \%$. 


\section{REFERÊNCIAS BIBLIOGRÁFICAS}

AMERICAN SOCIETY OF AGRICULTURAL ENGINEERS. Agricultural machinery management data ASAE D497.4. In: ASAE standards 1999: standards engineering practices data. St. Joseph: ASAE, 1999. p. 359-366.

AMERICAN SOCIETY OF AGRICULTURAL ENGINEERS. Agricultural machinery management ASAE EP496.2. In: ASAE standards 1997: standards engineering practices data. 44. ed. St. Joseph: ASAE, 1997a. p. 357-362.

AMERICAN SOCIETY OF AGRICULTURAL ENGINEERS. Agricultural tractor test code SAE J708. In: ASAE standards 1997: standards engineering practices data. 44. ed. St. Joseph: ASAE, 1997b. p. 407-411.

ASSOCIAÇÃO BRASILEIRA DE PNEUS E AROS. Livro de normas técnicas. São Paulo, 1994. 108p.

BARBOSA, J. A.; VIEIRA, L. B.; DIAS, G. P.; DIAS JÚNIOR, M. S. Desempenho operacional de um trator agrícola equipado alternadamente com pneus radiais e diagonais. Engenharia Agrícola, v. 25, n. 2, mai/ago. 2005.

CAMPOS, F. H.; GUERRA, S. P. S.; LANÇAS, K. P.; MONTEIRO, L. A.; MONTANHA, G. $\mathrm{K}$. The effect of cinematic advance on the tractor performance with front Wheel traction on. In: International Conference of Agricultural Engineering and XXXVII Congresso Brasileiro de Engenharia Agrícola. Anais... Foz-do-Iguaçu: SBEA, 2008. CD-ROM.

CARVALHO, W.A.; ESPÍNDOLA, C.R.; PACCOLA, A.A. Levantamento de solos da Fazenda Lageado - Estação Experimental "Presidente Médici". Boletim Científico da Faculdade de Ciências Agronômicas da UNESP, Botucatu, n.1, p.1-85, 1983. 
CORDEIRO M.A.L. Desempenho de um trator agrícola em função do pneu, da lastragem e da velocidade de deslocamento. 2000. 153f. Tese (Doutorado em Agronomia/Energia na Agricultura)-Faculdade de Ciências Agronômicas, Universidade Estadual Paulista, Botucatu, 2000 .

CORRÊA, I.M.; MAZIERO, J.V.G.; YANAI, K; LOPES, A. Técnicas de determinação da patinagem das rodas motrizes de tratores agrícolas. Campinas: Instituto Agronômico, 1999a. 15 p. Boletim Técnico no 179.

CORRÊA, I. M. ; YANAI, K ; MAZIERO, J. V. G.; LANÇAS, K. P. Determinação da circunferência de rolamento de pneus agrícolas utilizando dois métodos: manual e eletrônico. Bragantia, Campinas, v. 58, n. 1, p. 179-184, 1999b.

DUARTE JÚNIOR, J. B.; GARCIA, R. F.; COELHO, F. C.; AMIM, R. T. Desempenho de trator-implemento na cana-de-açúcar em sistemas de plantio direto e convencional. Revista Brasileira de Engenharia Agrícola e Ambiental, Campina Grande, v. 12, n. 6, nov./dez. 2008.

EMBRAPA. Centro Nacional de Pesquisa de Solos. Sistema brasileiro de classificação de solos. Rio de Janeiro: Embrapa, 412p. 1999.

FONTANA, C.F.; DALLMEYER, A.U.; POZZERA, J.; WEISS, A. Desempenho comparativo de tratores com e sem tração dianteira auxiliar durante a escarificação do solo. Revista do Centro de Ciências Rurais, Santa Maria, RS, v.16, n. 3, p.237-249, 1986.

GABRIEL FILHO, A.; LANÇAS, K. P.; GUERRA, S. P. S.; PAULA, C. A.; MONTEIRO, L. A. UMEB - Unidade móvel para ensaio na barra de tração. Engenharia Agrícola, v. 28, n. 4, p. $782-789$, out/dez. 2008.

GABRIEL FILHO, A.; SILVA, S. L.; MODOLO, A. J.; SILVEIRA, J. C. M. Desempenho de um trator operando em solo com diferentes tipos de cobertura vegetal. Engenharia Agrícola, v. 24, n. 3, p. 781-789, set/dez. 2004.

GAMERO, C.A.; LANÇAS, K.P. Ensaio e certificação das máquinas de mobilização periódica do solo. In: MIALHE, L.G. Máquinas agrícolas: ensaios e certificação. Piracicaba: Fundação de estudos agrários Luiz de Queiroz, 1996. p. 463-514.

JESUÍNO, P. R. Desempenho de um trator agrícola em função do desgaste das garras dos pneus e das condições superficiais do solo. 2007. 76f. Dissertação (Mestrado em Agronomia/Energia na Agricultura)-Faculdade de Ciências Agronômicas, Universidade Estadual Paulista, Botucatu, 2007.

LANÇAS, K. P.; MONTEIRO, L. A.; GUERRA, S. P. S.; GABRIEL FILHO, A.; MARASCA, I, Efeito da pressão de inflação dos pneus no desempenho operacional de um trator agrícola. In: X Congresso Argentino de Ingeniería Rural y II Del MERCOSUR. Actas... Rosario: UNR Editora, 2009. p. 763-768. CD-ROM. 
LANÇAS, K. P. Elementos básicos para adequação de conjuntos mecanizados. In:

MONTEIRO, L. A.; SILVA, P. R. A. Operação com tratores agrícolas. Botucatu: Edição dos autores, 2009. p. 59-74.

LANÇAS, K. P., UPADHYAYA, S. K. Pneus radiais para tratores. Guia para a seleção correta da pressão de inflação. Energia na Agricultura, FCA/UNESP, Botucatu, 1997. 33p. Boletim Técnico $\mathrm{n}^{\circ} 1$.

LANÇAS, K. P.; Desempenho operacional de pneus radiais em função da pressão de inflação, da lastragem e do deslizamento das rodas de tratores agrícolas. 1996. $171 \mathrm{f}$. Tese (Livre Docência na disciplina de Mecânica Aplicada/Departamento de Engenharia Rural)Faculdade de Ciências Agronômicas, Universidade Estadual Paulista, Botucatu, 1996.

LILJEDAHL, J. B.; TURNQUIST, P. K.; SMITH, D. W.; HOKI, M. Tractors and their power units. 4. ed. St. Joseph: ASAE Textbook, 1996. 463 p.

LINARES, P. Transmisiones (I). Agrotécnica, p. 71-78, enero. 2001.

LINARES, P. Teoria de la tración de tractores agrícolas. Madrid. Madrid : Universidad Politécnica de Madrid, Escuela Técnica Superior de Inginieros Agrónomos, 1996, 157 p.

LOPES, A; LANÇAS, K. P.; FURLANI, C. E. A.; NAGAOKA, A. K.; CASTRO NETO, P.; GROTTA, D. C. C. Consumo de combustível de um trator em função do tipo de pneu, da lastragem e da velocidade de trabalho. Revista Brasileira de Engenharia Agrícola e Ambiental, Campina Grande, v. 7, n. 2, p. - , mai/ago. 2003.

LOPES, A.; LANÇAS, K. P.; SILVA, R. P. Desempenho de um trator em função do tipo de pneu, da lastragem e da velocidade de trabalho. Ciência Rural, Santa Maria, v.35, n.2, p. 366370, 2005.

MÁRQUEZ, L. Solo Tractor '90. Madrid: Laboreo, 198 p.1990.

MASIERO, F. C.; LANÇAS, K. P; MONTEIRO, L. A.; MARASCA, I.; GARCIA, E. A. Desempenho de um trator agrícola em função das variações da pressão de inflação dos pneus e da força na barra de tração. In: X Congresso Argentino de Ingeniería Rural y II Del MERCOSUR. Avances en Ingeniería Rural 2007-2009. Rosario: UNR Editora, 2009. p. 180-188. CD-ROM.

MAZETTO, F. R.; LANÇAS, K. P.; NAGAOKA, A. K.; CASTRO NETO, P.; GUERRA, S. P. S. Avaliação do contato pneu-solo em três modelos de pneus agrícolas. Engenharia Agrícola, Jaboticabal, v.24, n.3, p.750-757, set. 2004.

MIALHE, L. G. Máquinas agrícolas: Ensaios e certificação. Piracicaba: Fundação de estudos agrários Luiz de Queiroz, 1996. 722 p. 
MIALHE, L.G. Gerência de sistema tratorizado vs operação otimizada de tratores. Piracicaba: ESALQ/USP, 1991. 30 p.

MIALHE, L.G. Máquinas Motoras na Agricultura. São Paulo: Editora da Universidade de São Paulo, v. 2, 1980. 366 p.

MIALHE, L. G. Manual de mecanização agrícola. São Paulo: Editora Agronômica Ceres, 1974. $301 \mathrm{p}$.

MONTEIRO, L. A. Desempenho operacional e energético de um trator agrícola em função do tipo de pneu, velocidade de deslocamento, lastragem líquida e condição superficial do solo. 2008. 69 f. Dissertação (Mestrado em Agronomia/Energia na Agricultura)-Faculdade de Ciências Agronômicas, Universidade Estadual Paulista, Botucatu, 2008.

MONTEIRO, L. A.; LANÇAS, K. P.; GABRIEL FILHO, A. Desempenho de um trator agrícola em função do tipo construtivo do pneu e da lastragem líquida em três velocidades de deslocamento na pista com superfície firme. Energia na Agricultura, Botucatu, v. 24, n. 1, p. 68-84, 2009a.

MONTEIRO, L. A.; LANÇAS, K. P.; GABRIEL FILHO, A.; GUERRA, S. P. S.; TOSIN, R. C.; PAULA, C. A. Construção e avaliação da Unidade Móvel para Ensaio na Barra de Tração. In: XXXVI Congresso Brasileiro de Engenharia Agrícola. Anais... Bonito: SBEA, 2007. CDROM.

MONTEIRO, L. A.; LANÇAS, K. P.; MASIERO, F. C. Conjuntos: Adição de lastro e quando colocar. Panorama Rural, Ribeirão Preto, SP, n. 125, p. 50-55, jul. 2009 b.

NAGAOKA, A. K.; LANÇAS, K. P.; CASTRO NETO, P.; LOPES, A.; GUERRA, S. P. S. Projeto, construção e avaliação de um equipamento para ensaio dinâmico de pneu agrícola individual. Engenharia Agrícola, Jaboticabal, 2002.

OECD CODE 2. Standard code for the official testing of agricultural and forestry tractor performance. $2008.88 \mathrm{p}$.

RACKHAM, D. H.; BLIGHT, D. P. Four wheel drive tractors - A review. Journal of Agricultural Engineers, v. 56, p. 185-201, 1985.

SCHLOSSER, J. F.; DALLMEYER, A. U. Desempenho operacional de um trator com tração dianteira auxiliar operando com as rodas dentro e fora de sulco. In: XVII Congresso Brasileiro de Engenharia Agrícola. Anais... Iperó: CENEA/SBEA, 1988. v.2, p.432-437.

SCHLOSSER, J. F.; DEBIASI, H.; WILLES, J. A.; MACHADO, O. D. C. Análise comparativa do peso específico dos tratores agrícolas fabricados no Brasil e seus efeitos sobre a seleção e uso. Ciência Rural, Santa Maria, v. 35, n. 1, p. 92-97, jan/fev. 2005. 
SCHLOSSER, J. F.; LINARES, P.; MÁRQUEZ, L. Influência do avanço cinemático das rodas dianteiras sobre a eficiência em tração de tratores com quatro rodas motrizes não isodiamétricas. Ciência Rural, Santa Maria, v. 34, n. 6, p. 1801-1805, nov/dez. 2004.

SERRANO, J. M. P. R. Pressão de insuflagem dos pneus no desempenho do conjunto tratorgrade de discos. Pesquisa Agropecuária Brasileira, Brasília, v. 43, n. 2, p. 227-233, fev. 2008.

SILVA, S.L., BENEZ, S.H. Construção de um sistema de aquisição de dados para avaliação do desempenho energético de máquinas e implementos agrícolas em ensaios de campo.

Energia na agricultura. Botucatu, v.12, n.3, p.10-18, 1997.

SILVA, S.L., BENEZ, S.H., LEVIEN, R., SIQUEIRA, R. Força de tração obtida com integrador de força e sistema computadorizado, operando um rolo faca. In: XXVI Congresso Brasileiro de Engenharia Agrícola, 1997, Campina grande. anais... Campina Grande: UFPB/SBEA, 1997. CD-ROM.

SILVA, S. L., RICIERI, R. P., PEREIRA, J. O., BENEZ, S.H. Sistemas de aquisição de dados para ensaios de campo: comparação da força de tração média obtida com micrologger 21x e milivoltímetro na operação de escarificação. In: IV CONGRESSO INTERNACIONAL DE INGENIERÍA AGRÍCOLA, Chillán. Anales...Chillán: 2001.

SRIVASTAVA, A.K., GOERING, C.E., ROHRBACH, R.P. Tractor hitching, traction and testing. In: Engineering principles of agricultural machines. 3 ed. St. Joseph: American Society of Agricultural Engieers, p.117-145, 1996.

TRELLEBORG. Agricultural tyres manual. 2002. 20p.

WISMER, R.D.; LUTH, H.J. Off-road traction prediction for wheeled vehicles. Transactions of the ASAE, St. Joseph, v.17, n.1, p.8-14, 1973.

WITTCOTT, H.A.; REUBEN, B. G. Industrial organic chemicals in perspective. New York: John Wiley, 1980. v.2, 502p.

YANAI, K.; CORRÊA, I.M.; MAZIERO, J.V.G.; MENEZES, J.F. de; PECHE, A.T.M. Desempenho comparativo de tratores com e sem tração dianteira auxiliar em pista de concreto. In: XVII Congresso Brasieliro de Engenharia Agrícola. Anais... Iperó: CENEA/SBEA, 1988. v.2, p.438-444.

YANAI, K.; SILVEIRA, G. M.; LANÇAS, K. P.; CORRÊA, I. M.; MAZIERO, J. V. G. Desempenho operacional de trator com e sem o acionamento da tração dianteira auxiliar. Pesquisa Agropecuária Brasileira, Brasília, DF, v. 34, n. 8, p. 1427-1434, ago, 1999.

ZOZ, F. Belt and Tire Tractive Performance. Milwaukee: Society of Automotive Engineers, 1997, 8p. 
ZOZ, F., GRISSO, R.D. Traction and tractor performance. St Joseph: ASAE. 2003. 46p. 
APÊNDICE 
APÊNDICE 1. Exemplo de curva de melhor ajuste utilizada na determinação dos valores de rendimento máximo, patinagem e consumo específico de combustível para cada condição ensaiada.

1.1 Curva de rendimento na barra de tração em função da patinagem.

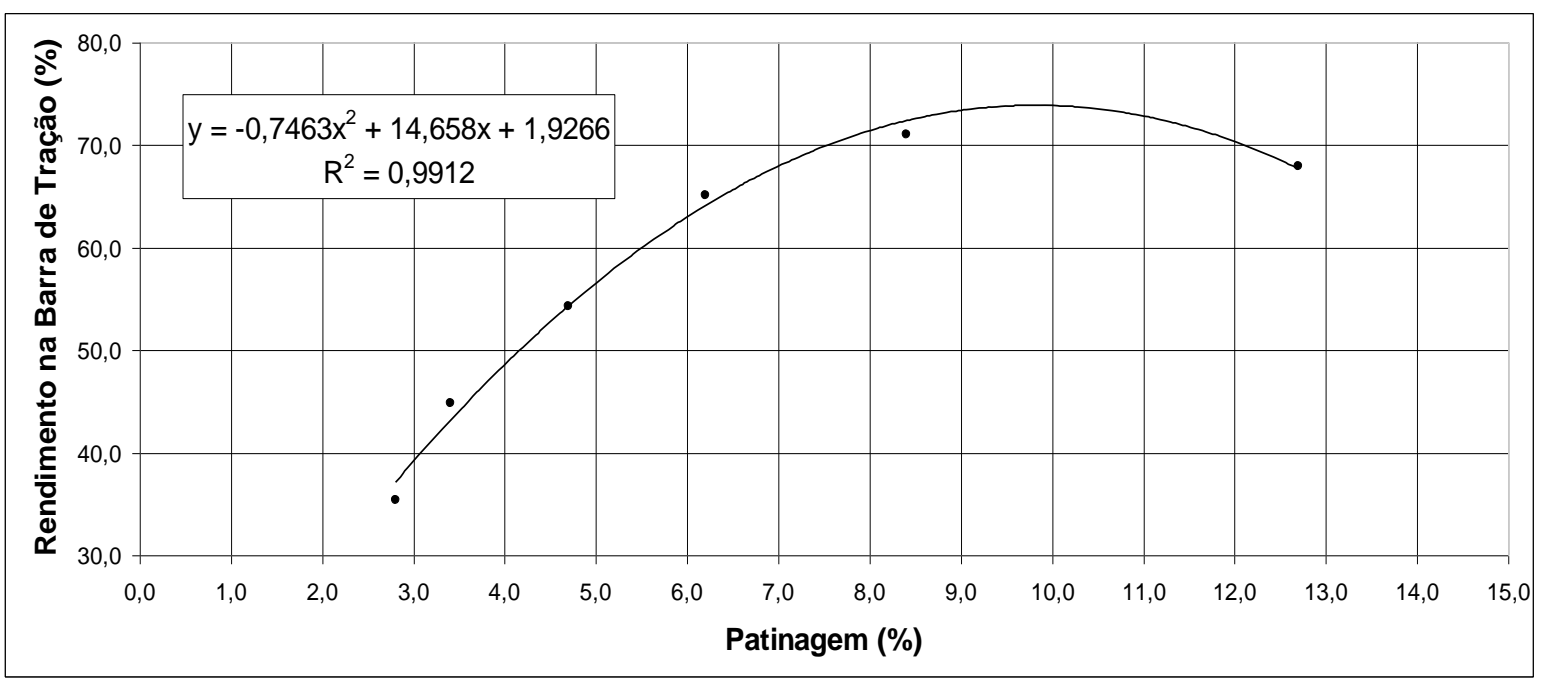

Ponto de ótima patinagem: $9,82 \%$ (derivada da equação igualada a zero)

Ponto de máximo rendimento na barra: $\mathbf{7 3 , 9 \%}$

1.2 Curva de consumo específico de combustível em função da patinagem.

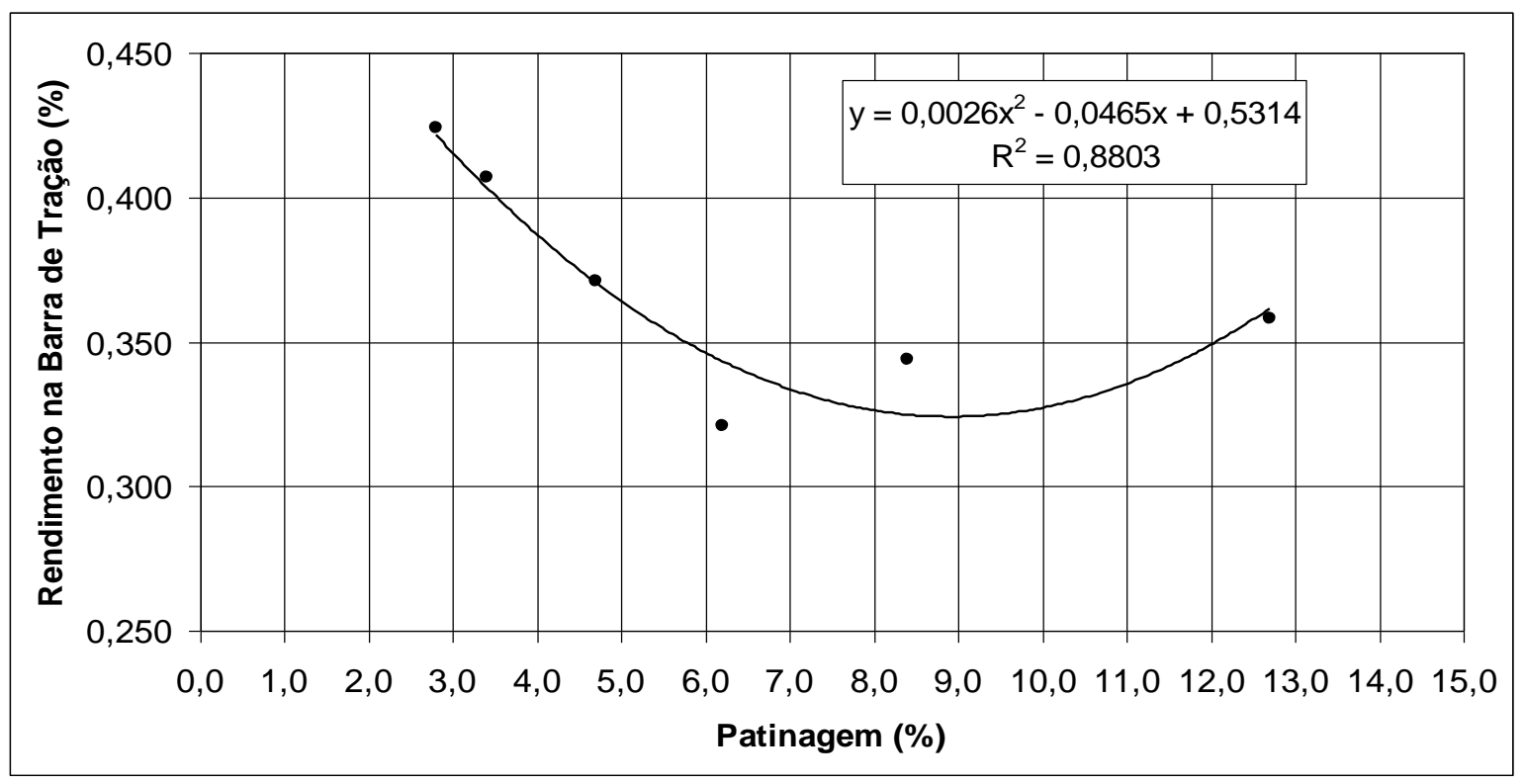

